Florida International University FIU Digital Commons

7-23-1991

\title{
Student ratings of instruction in a community college : effects of student and faculty ethnicity
}

Ana Alejandre Ciereszko

Florida International University

DOI: $10.25148 /$ etd.FI14060834

Follow this and additional works at: https://digitalcommons.fiu.edu/etd

Part of the Community College Leadership Commons

\section{Recommended Citation}

Ciereszko, Ana Alejandre, "Student ratings of instruction in a community college : effects of student and faculty ethnicity" (1991). FIU Electronic Theses and Dissertations. 2364.

https://digitalcommons.fiu.edu/etd/2364 
student Ratings of Instruction in a community college: Effects of student and Faculty Ethnicity

by

Ana Alejandre Ciereszko

Florida International University, 1991

Miami, Florida

Professor Joseph Cook, Major Professor

Purpose

The purpose of this study is to explore the relationship between student and faculty ethnicity and possible effects upon student ratings of faculty performance in an urban community college setting characterized by extensive ethnic diversity.

\section{Problem}

Though many variables on student ratings of instruction have been studied in the past, studies of the effects of student and faculty ethnicities on student ratings at the post secondary level have not been conducted. As increased numbers of minority students embark on post secondary studies, the question arises as to whether these students perceive instructors and their efforts in the classroom differentiy than traditional students.

\section{Methodology}

A survey-type instrument, the student Feedback Questionnaire, was developed at Miami-Dade Community College and administered to students enrolled in randomly selected English composition courses ( $=948$ students, 72 instructors). Factor analysis was conducted on the instrument and the relationship of these factors with student and faculty ethnicity was examined by means of multivariate analysis of variance. Instructors were separated into higher and lower rated groups according to a total score obtained from the instrument. Differences on student ratings for these two groups according to student and instructor ethnicity were examined. 


\section{Findings}

The following factors were obtained:

Factor 1: Focus on the Individual

Factor 2: Competence in Classroom

Factor 3: Approach to Material

Factor 4: Grading Policy

Factor 5: Listening to Students

Factor 6: Clarity in Course objectives

Factor 7: Fairness of Exams

Factor 8: Active Learning

Hispanic faculty were rated less favorably by white non-Hispanic students for Factor 2, Factor 3, and Factor 5. For Factor 5, Hispanic students rated white non-Hispanic faculty lower than black students.

For higher rated instructors there were no significant differences in ratings according to student ethnicity. For lower rated instructors, students of the same ethnicity as their instructor did not give significantly different ratings than other students.

student gender was significant for both higher and lower rated instructors, with males giving significantly worse scores. 
FLORIDA INTERNATIONAL UNIVERSITY

Miami, Florida

Student Ratings of Instruction in a Community college: Effects of student and Faculty Ethnicity

A dissertation submitted in partial satisfaction of the requirements for the degree of Educational Doctorate in community college Teaching

by

Ana Alejandre Ciereszko 
To Professors:

Peter J. Cistone

Joseph B. Cook

Barry Greenberg

This dissertation, having been approved in respect to form and mechanical execution, is referred to you for judgement upon its substantial merit.

Dean I. Ira Goldenberg

College of Education

The dissertation of Ana Alejandre Ciereszko is approved.

Peter J. Cistone

Barry Greenberg

Joseph B. Cook, Major Professor

Date of Examination:

23,1941

Dean Richard L. Campbel1

Division of Graduate studies 
(c) copyright by

Ana Alejandre Ciereszko

1991 


\section{DEDICATION}

This dissertation is dedicated to my husband, stan, and our sons, Lee and Thomas. They willing took extra tasks and responsibilities, and gave up time with "wife" and "mom", so that I could concentrate on taking courses and completing this dissertation.

I would also like to dedicate this dissertation to my parents, Margarita and Armando Alejandre, who instilled in me a love for learning and an understanding of the value of a good education. 


\section{ACKNOWLEDGEMENTS}

Many people were instrumental in the completion of this study. My major professor and graduate program advisor, Joe cook, was always there to discuss any facet of my program or dissertation, giving me encouragement and moral support throughout this process. The other members of my dissertation committee, Peter Cistone and Barry Greenberg, provided me with invaluable assistance and advice throughout the development of the study until its completion. All three prodded me into producing a dissertation that I could be proud of. Paulette Johnson, the statistical Consultant at Florida International University, was willing to help me on very short notice to guide me through the statistical analysis. Her help was invaluable.

My colleagues from the Faculty Advancement Procedures Committee of the Teaching/Learning Project became my friends during the almost two years in which we struggled with the writing of Procedures and the student Feedback Questionnaire. To them I owe my gratitude for allowing the questions on ethnicity to become part of the instrument. They are:

\author{
Sylvia Edge \\ Rene Garcia \\ Ned Glenn \\ Bob Hunter \\ Rocio Lamadriz \\ Ira Medina
}

\author{
Rolando Montoya \\ Audrey Roth \\ Pam Singer \\ Walt Tucker \\ Wick Whalen
}

Many people gave me their time, effort, knowledge, encouragement, and support. Without them, I seriously doubt that this dissertation would have been completed. They are the following:

Jack Abstein

Marcia Belcher

Sally Buxton

Larry Bray

Gladys celis

Janet cochrane

Hal corson

Maria Echemendia

Sherrie Goldstein

Ed Gomez

Kati Gomez-Mons

Dorma Gottlieb

Roberto Hernandez

Sally Jacobson

Mardee Jenrette
Marta Junco-Ivern

Abe Lavender

Irene Lipof

John Losak

Jane MacDonald

Maria Maseda

Margaret Massey

Robert Mccabe

Diane McKinney

Alfredo Menendez

Karen Paiva

Judy Schmelzer

Larry steed

Dick Townsend 


\section{VITA}

August 26, 1948

1969

$1969-1971$

1971-1972

1973

$1973-1974$

$1973-1974$

1975-1976

1976-Present
Born, Havana, Cuba

B.S., Chemistry

University of Miami

Coral Gables, Florida

Peace Corps

st. Vincent, West Indies

Mathematics Teacher

North Miami Beach Sr. High School

Miami, Florida

Teaching Assistant

old Dominion University

Norfolk, Virginia

Graduate student Fellowship

old Dominion University

M.S., Chemistry

old Dominion University

Norfolk, Virginia

Science Teacher

Citrus Grove Junior High School

Miami, Florida

Professor of chemistry

Miami-Dade Community College

Miami, Florida

\section{PUBLICATIONS AND PRESENTATIONS}

Caine, D., Powers, W. J., III, \& Alejandre, A. M. (1968). Photochemical rearrangements of $6 / 5$ fused cross-conjugated cyclohexadieones in dioxane. Tetrahedron Letters, 58.

Ciereszko, A. A. (1987). Mandated testing in Florida: A faculty perspective. In D. F. Halpern (Ed.). New Directions for Higher Education: Student outcomes Assessment: What Institutions stand to Gain, 59, (pp. 69-76). San Francisco: Jossey-Bass.

Ciereszko, A. A. (1987, November). The college Level Academic Skilis Test and Its Impact on the curriculum. Paper presented at the meeting of the Two-Year college chemistry Conference, Jacksonville, FL. 
Ciereszko, A. A. (1988, May). The History of Cuba: From Columbus' Discovery to Its Independence on May $20,1902$. Paper presented at the Independence Day Celebration of the Y.M.C.A. Jose Marti, Miami, FL.

Ciereszko, A. A. \& Pappas, A. J. (1990). Introductory Chemistry Modules. Miami. FL: Miami-Dade Community College.

Williams, R. L., Ciereszko, A., Morandini, F., \& Williams, G. (1977). 1,4(2H,5H)-Dioxoimidazo $[1,5,4-\mathrm{h}, \mathrm{i}]$ indazoline: A new heterocyclic ring system. Heterocycles, $\underline{6}(11), 1767-71$. 
TABLE OF CONTENTS

PAGE

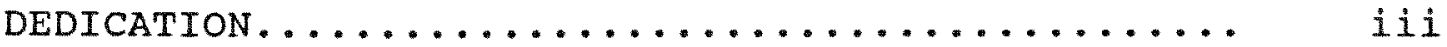

ACKNOWLEDGEMENTS.................... iv

LIST OF FIGURES..................... $\mathrm{x}$

LIST OF TABLES...................... xi

CHAPTER

I. THE PROBLEM

Introduction.................. 1

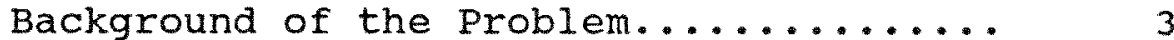

Statement of the Problem............ 5

Purpose of the study............... 7

Significance of the study........... 8

Rationale and Theoretical Framework..... 9

Statement of Hypotheses............ 10

Importance of the study.............. 11

Definition of Terms............... 12

Delimitations of the study............ 13

Limitations of the study.............. 14

Outline of the Remaining Chapters...... 15

II. REVIEW OF THE LITERATURE

Introduction................ 16

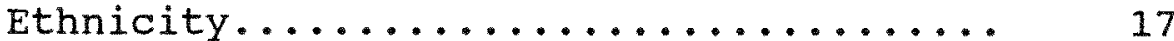

Definitions................ 17

Theories of Ethnicity........... 20

Summary of ethnicity........... 23

Classroom Interactions.............. 25

Elementary and Secondary Schools... 25

Higher Education.............. 29

Summary.................. 32

Counseling of Minorities............ 32

Cultural commitment............ 33

Preferences in Counselor......... 34

summary.................. 35

Student Ratings of Instructors........ 36

Reliability and validity........ 38

Instructor Characteristics........ 44

Course Variables.............. 52

Student Characteristics.......... 57

conclusion.................... 63 
III. RESEARCH DESIGN AND METHODOLOGY

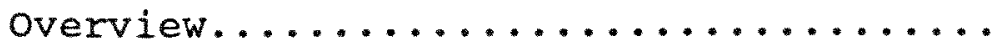

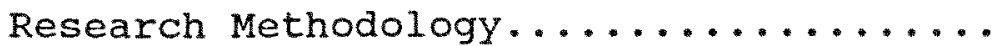

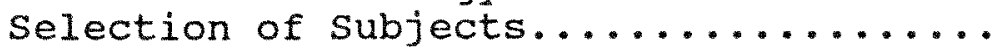

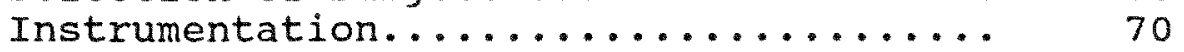

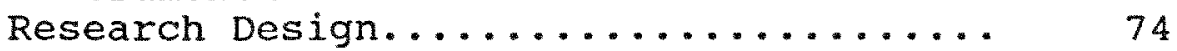

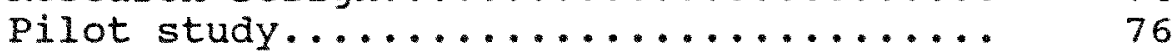

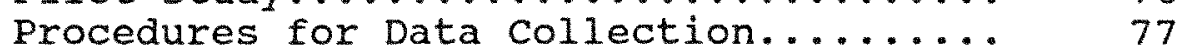

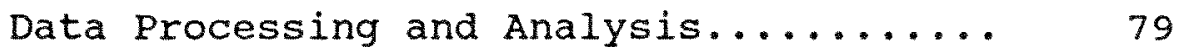

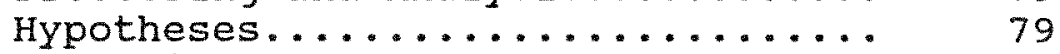

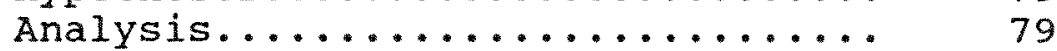

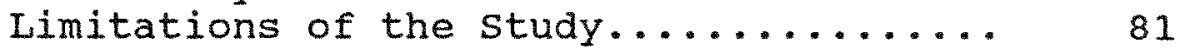

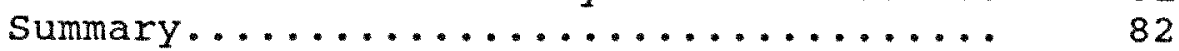

IV. ANALYSIS OF DATA AND FINDINGS

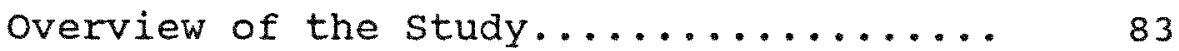

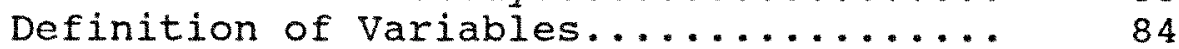

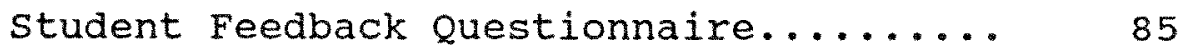

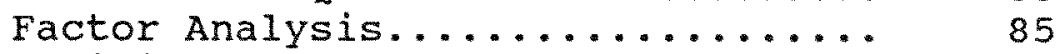

Validity and Reliability of the

student Feedback Questionnaire.....

Descriptive statistics for the Group.... 91

Multivariate and Univariate Analyses.... 94

Test of Hypothesis 1............ 95

Separation of Faculty into Higher and

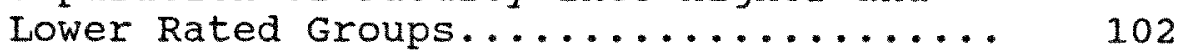

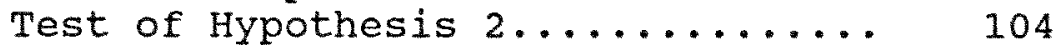

Test of Hypothesis $3 \ldots \ldots \ldots 107$

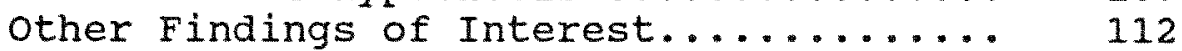

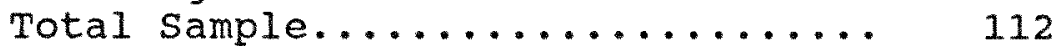

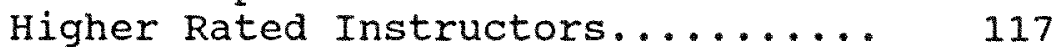

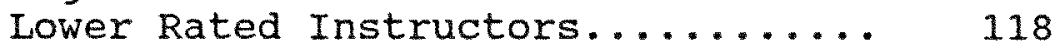

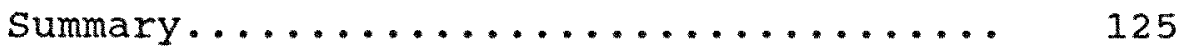

V. SUMMARY, CONCLUSIONS AND RECOMMENDATIONS

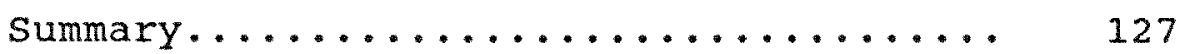

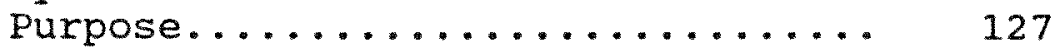

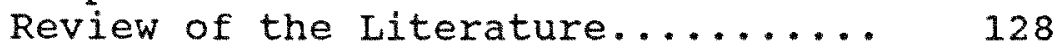

Research Design and Methodology.... 131

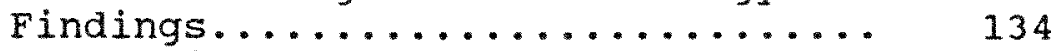

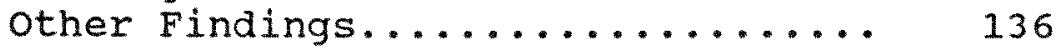

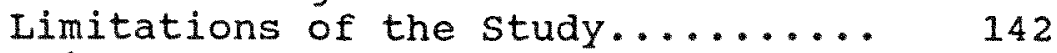

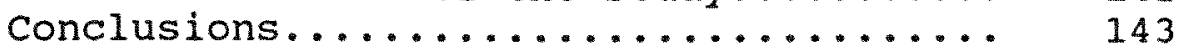

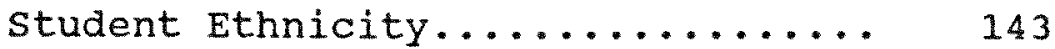

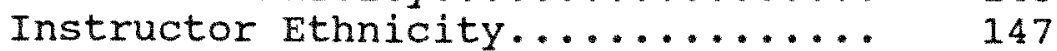

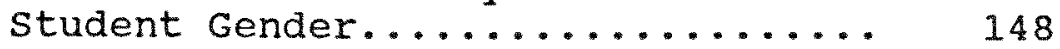

Implications for Policy/Practice... 150

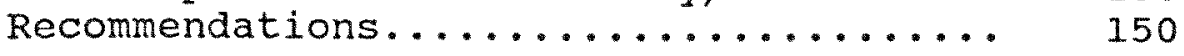




\section{APPENDICES}

APPENDIX A: Faculty Excellence Document..... 169

APPENDIX B: Student Feedback Questionnaire..

APPENDIX $C$ : Instructions for students......

179

182 
1. Total Sample

F3: Approach to Material............ 100

2. Total Sample

3. Total Sample

F5: Listening to students........... 117

4. Lower Rated Instructors

F2: Competence in Classroom.......... 121

5. Lower Rated Instructors

F3: Approach to Material........... 123 
1. Instructor Performance Factors

Factor Loadings for student Feedback

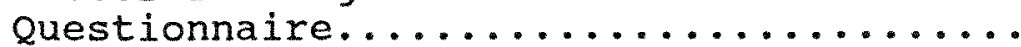

86

2. Communality for Items 1 through 23

Student Feedback Questionnaire..........

3. Reliability of Factors in the

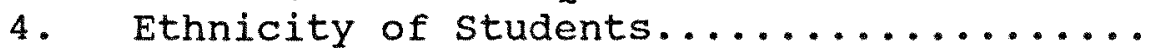

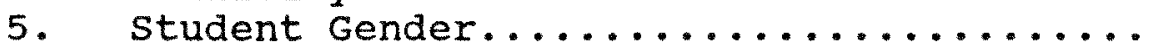

92

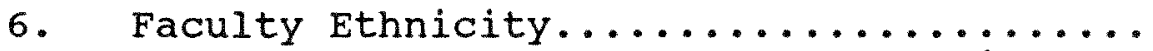

7. Number of Students Enrolled According to Ethnicity of student and Faculty........

8. Hypothesis 1: Multivariate Analysis

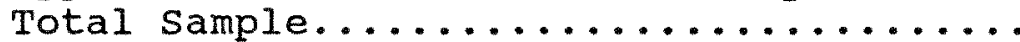

9. Hypothesis 1: Univariate Analysis

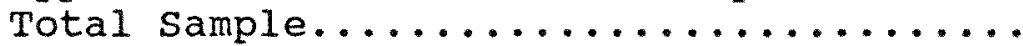

10. Hypothesis 1: Total sample

F3: Approach to Material..............

11. Faculty Separated into Higher Rated and Lower Rated Groups By Total score........

12. Hypothesis 2: Ethnicity of Higher Rated

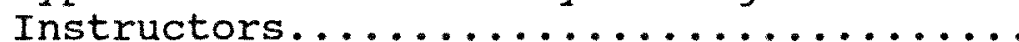

13. Hypothesis 2: Student Ethnicity versus Faculty Ethnicity - Number of students

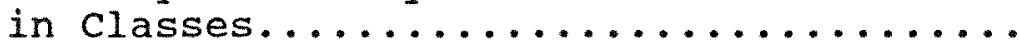

14. Hypothesis 2: Multivariate Analysis

Higher Rated Instructors.............

15. Hypothesis 3: Ethnicity of

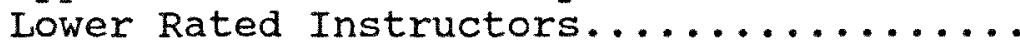

16. Hypothesis 3 : Student Ethnicity versus Faculty Ethnicity

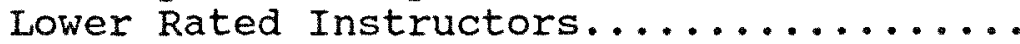

17. Hypothesis 3: Multivariate Analysis

Lower Rated Instructors..............

18. Hypothesis 3: Univariate Analysis

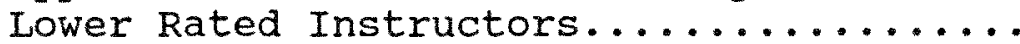

19. Hypothesis 1: Total Sample

F2: Competence in classroom............

20. Hypothesis 1: Total Sample

Univariate statistics for student Gender.

21. Hypothesis 1: Total Sample

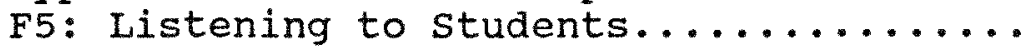

22. Hypothesis 3: Lower Rated Instructors

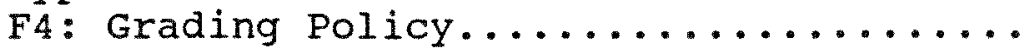

23. Hypothesis 3: Lower Rated Instructors

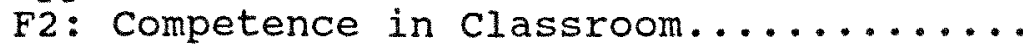

24. Hypothesis 3: Lower Rated Instructors

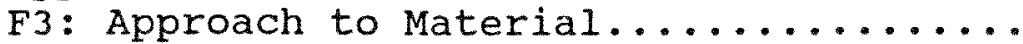

25. Hypothesis 3: Lower Rated Instructors

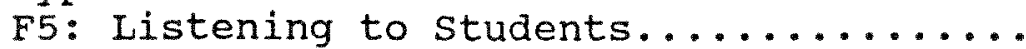

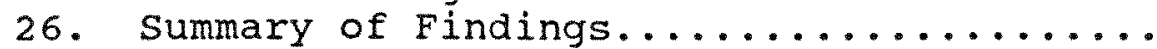


CHAPTER I

THE PROBLEM

Introduction

The United States is in the midst of an educational crisis at all levels and lawmakers in many states have responded with laws and regulations that demand that public institutions ensure that students are learning. Yet institutions are receiving students who are less prepared for college work than ever before. There is also an increasing number of students from racial and cultural backgrounds that traditionally have not had access to higher education. This is due to an advancement in civil rights legislation in the United States and an increase in immigration from non-European countries. It is estimated that in ten years the population of blacks, Hispanics, and other minorities in the United States will be greater than twenty-five percent (Kappner, 1990).

As increased numbers and percentages of minority students embark on post secondary studies, institutions in which they enroll will have to increasingly address the needs of these students. Most of the black and Hispanic students will be first-generation college students. In fact, their parents are unlikely to have completed high school and are less informed about what their children will 
encounter and will be required to accomplish in college. Therefore, minority students will need more academic and personal guidance than traditional students require.

At the same time, minority students, who are more likely to enroll in urban community colleges due to their low cost and open door policy, will probably be working part-time or full-time while trying to complete their studies. Learning styles will vary depending on the culture in which a student is raised. These students are more likely to externalize, placing responsibility for failure on others rather than on themselves. All of these circumstances may cause black and Hispanic students to perceive instructors and their efforts in the classroom differently than white non-Hispanic students.

student evaluation of instructor performance in higher education has been discussed, studied and reported extensively in the literature. However, there is little data available on minority students' ratings of instructors. This has been the case because most of the studies on student evaluation of faculty have been conducted in institutions with a majority of white non-Hispanic students and because until recently minority students have not participated in higher education in large numbers. Many believe that students can assess a faculty member's teaching effectiveness through survey-type instruments. In higher education institutions' quest for 
accountability of instruction, many such instruments have been developed, their reliability and validity determined, and are currently in use as a source in determining the retention, tenure granting, and promotion of faculty members.

However, there is still controversy surrounding this issue since research has also shown that certain factors may bias students' ratings of faculty. Studies have been conducted to determine whether certain characteristics of the faculty member, such as expressiveness and gender, play a role in how students rate the instructor. Other studies have attempted to determine whether certain students' characteristics or situations such as class size, gender, age, expected course grade, required versus elective course, upper division versus lower division course, learning styles, and cultural differences affect ratings. other studies have considered interactions between students and instructors and whether these interactions, personality and attitude similarities, provide for differences in ratings.

Background of the problem

Partially in response to pressures of accountability, the need for improved teaching effectiveness, and the everincreasing numbers of minority students at the institution, Miami-Dade Community college embarked four years ago on a 
project to improve the teaching/learning environment at the institution. A concept paper by the college President provided a framework that became the Teaching/Learning Project with the following goals:

1. To improve the quality of teaching and learning at Miami-Dade Community College (M-DCC) .

2. To make teaching at M-DCC a professionally rewarding experience.

3. To make teaching and learning the focal point of college activities and decision-making processes. Committees were established to focus on institutional values, the teaching/learning environment, faculty excellence, and new faculty. The committee on faculty excellence drafted a document which was extensively discussed and subsequently revised. In October 1988 the statement of Faculty Excellence was adopted by the President's Council and the District Board of Trustees. This Statement of Faculty Excellence (Appendix A) is in narrative form and describes twenty-nine characteristics organized under the categories of motivation, interpersonal skills, knowledge base, and application of knowledge base. It guides the process for hiring, granting tenure, and promoting faculty at the institution. A new committee was instituted to develop policies and procedures to implement the standards within the Faculty Excellence document. These new policies and procedures were adopted by referendum of 
the full-time faculty at the institution. The importance of faculty evaluation at the college is evidenced by the sixtynine percent faculty approval of the subcommittee recommendations.

The Faculty Advancement Procedures Committee, composed of eight faculty members and three administrators, developed an instrument for student feedback, the student Feedback. Questionnaire. This instrument was designed to fit within the framework of the statement of Faculty Excellence. All full-time faculty at the institution were surveyed as to which of the twenty-nine characteristics were appropriate for students to rate, to differentiate from those characteristics that are more appropriate for the immediate supervisor, self, and peers to assess. The instrument was piloted during the spring and summer 1990 terms. The committee reviewed the results of the pilot and revised the Student Feedback Questionnaire (Appendix B), which was used in one course section for each full-time faculty during the Fall 1990 term.

Statement of the Problem

Due to an advancement in civil rights legislation in the United States and an increase in immigration from nonEuropean countries, there is now a growing number of students from racial and cultural backgrounds that have not 
previously participated in higher education in significant numbers. Minority students are more likely to be firstgeneration-in-college students than those of white nonHispanic background. Black and Hispanic students are likely to have different learning styles than students who have traditionally attended post-secondary institutions. The community colleges, due to their open door policy and low cost, have generally been the institutions of choice for members of minority and ethnic groups who are now finally embarking on their higher education experience.

Miami-Dade Community College has one of the most diverse student bodies in the United states. This is partly due to its geographic location and the political unrest in nearby Caribbean countries. This is shown in the composition of the student body for the Fall 1990 term: $54.9 \%$ are Hispanic (including Cubans, Nicaraguans, Salvadorans, Colombians, Venezuelans, etc.); $26.3 \%$ are white non-Hispanic; and $16.5 \%$ are black.

The faculty is not as diverse as the student body, consisting of $16.3 \%$ Hispanic, $70.5 \%$ white non-Hispanic and $12.1 \%$ black faculty members. It can be seen that there is an imbalance in the ethnic mix of students - with the increasing numbers of minorities now attending the institution - and faculty - the majority of whom were hired twenty or more years ago and are predominantly white nonHispanic. 
Since large numbers of minority students have not previously been enrolled in post-secondary institutions, there is very little information available on these students' expectations of classroom instruction and their assessment of instructors. Affirmative action laws and the emphasis on providing role models for minority students have placed pressure on institutions to increase the number of faculty from ethnically diverse groups (Andrews \& Marzano, 1990). The question arises as to whether minority students believe that they have a more positive experience in classes taught by minority faculty, and are therefore learning more. on the other hand, experienced instructors in community colleges with diverse student populations may have adapted their teaching strategies to serve the needs of black and Hispanic students.

\section{Purpose of the study}

The purpose of this study is to explore the relationship between student and faculty ethnicity and possible effects upon student ratings of faculty performance in an urban community college setting characterized by extensive ethnic diversity. 
Through this study, the effects of students' ethnic origin on the ratings they assign to their instructors will be determined. Most of the studies on student evaluation of faculty have been conducted in institutions with a majority of white non-Hispanic students. As will be shown in chapter II, there is very little research on the assessment of faculty by students from other cultural backgrounds. Since there is a growing number of minority students in post secondary institutions, it is important to determine whether these students believe that their instructors are aware of, and sensitive to ethnic characteristics, and are thus providing them with the appropriate instruction.

The study will also determine if there are differences in assessment by students of higher rated and lower rated instructors. Instructors who receive high ratings from students are assumed to be competent; therefore, it is expected that most students, regardless of ethnicity, are learning and achieving in these courses, consequently rating these instructors uniformly high. However, instructors who receive lower ratings are generally not considered to be as competent as higher rated instructors. The ratings these instructors receive may not be uniformly low, but may indicate differences in how students' ethnicity affect the ratings. The primordialist theory of ethnicity, discussed 
in chapter II, would predict an interaction effect between student and instructor ethnicity, whereby students of the same ethnicity as an instructor may rate this particular instructor differently than other students.

Rationale and Theoretical Framework

Ethnicity has been defined as a condition of belonging to a particular ethnic group, one defined by descent, and sharing a common history and experience (Glazer, 1975). Four major theories of ethnicity, as identified by Thompson (1989) are as follows: sociobiological, which explains ethnicity as a genetic condition; primordialist, which asserts that humans have a psychological need for identity and group affiliation; assimilationism, focusing on the eventual disappearance of ethnic differences; and worldsystem, which treats race and ethnic relations as particular forms of social organization within a capitalistic world (see Chapter II).

of the four major theories of ethnicity, the most applicable one to the classroom is the primordialist theory. This theory views human beings as having basic, primordial needs for group affiliation, feelings of belonging. Students' ethnicity, their identification with a particular ethnic group, and the solidarity which this group identity creates may cause students to perceive an instructor of 
their own ethnicity in a different manner than other instructors. There may be an interaction effect produced by mutual feelings of affiliation. These students may feel more comfortable in the classroom and, therefore, may be able to learn more. Or they may be exhibiting ethnocentrism, whereas they view others in relation to themselves and their own ethnic group. Consequently the instructor is rated higher by these students. However, if the instructor is extremely competent, effective, and compassionate, instructor ethnicity may be less important, as all students may be able to feel comfortable, and learn more, in that particular classroom (see Chapter II). There is some research on the effects of ethnicity in the classroom, particularly as it affects student-teacher interactions, but it does not appear that there are any studies on the effect of ethnicity on student ratings of instruction. To provide further insights into ethnicity as it affects relationships, studies of mixed ethnicity clientcounselor interactions were reviewed and discussed in Chapter II.

Statement of Null Hypotheses

The hypotheses to be tested in this study are:

1: There is no significant difference in the mean ratings given to instructors according to student ethnicity. 
2: For higher rated instructors, there is no significant difference in the mean ratings according to student ethnicity.

3: For lower rated instructors, students of the same ethnicity as their instructor do not give significantly different ratings than students whose ethnicity is not the same as their instructor.

\section{Importance of the study}

In general, the study will enhance the understanding of the teaching/learning process. It will provide new insights into the dynamics of student ratings of instructors, particularly the effects that may be produced by students' ethnic backgrounds. It will open up for further inquiry the matter of student ethnicity as a factor in faculty ratings. If differences are found in the ratings provided faculty by students of different ethnic backgrounds, further research should be conducted to determine what specific factors determine that outcome, and whether those factors affect students' learning. This data may also allow for better interpretation of student ratings and provide institutions with a rationale for increasing efforts towards the recruiting of more minority faculty. 
Ethnicity: A condition of belonging to a particular ethnic group, with certain group identity, which may be physical, cultural, language, or national origin. Ethnicity gives rise to feelings of affiliation and loyalty towards other group members, particularly in groups which perceive a need for economic or political advancement. The ethnic groups, as self-reported in the student Feedback Questionnaire are as follows: black, Hispanic, white non-Hispanic or other (American Indian, Asian, or Pacific Islander).

Instructor: Classroom teacher, also called faculty, faculty member, teacher.

M-DCC: Miami-Dade Community College, located in Miami, Florida, one of the largest and the most diverse community college in the United states.

Minority Student: Black or Hispanic student. Also referred as ethnically diverse.

Performance Review: Annual evaluation of faculty prepared by his/her immediate supervisor. It must include as sources of information student feedback, selfassessment, and supervisor's assessment.

Student Feedback Questionnaire: Instrument developed by the Faculty Advancement Procedures Committee for student evaluation of faculty performance. It contains twenty- 
three questions (using a four-point Likert-type scale) on the instructor's performance, twenty questions about the student or the course, and a request for written anonymous comments on the instrument, the instructor, and the course.

Teaching/Learning Project: Project being conducted at Miami-Dade Community College. Its goal is to improve and reward excellent teaching.

Delimitations of the study

Among the restrictions in this study was the selection of Miami-Dade Community College as the institution in which the study was conducted. This choice was predicated by: (1) the fact that this institution is possibly the most ethnically diverse of all community colleges in the United States, reflecting the ethnic mix that many other community colleges will encounter in ten or twenty years; (2) the unique opportunities afforded by the Teaching/Learning Project, representing the quest for excellence in teaching that is becoming more prevalent at all institutions of higher learning. The population to be studied was limited to students enrolled in randomly selected English composition credit courses at Miami-Dade Community College during the Fall 1990 term. 


\section{Limitations of the study}

This study is limited due to the fact that random selection of students into course sections was not possible. It is also limited by the fact that only one class was randomly selected for each full-time faculty member, limiting the number of students that had the opportunity to participate. A further limitation is that of the need to assume that higher rated and lower rated faculty, as determined by student ratings, will have a proportionate mix of instructors of different ethnicities.

Any conclusions drawn may apply only to institutions that resemble Miami-Dade community college, in the ethnic diversity of their student bodies, such as community colleges in California, Texas, and New York, where minority students may actually be the majority.

While the instrument was developed and has only been administered at Miami-Dade Community College, this is not perceived as a limitation due to the manner in which it was developed, since the instrument is based on the statement of Faculty Excellence. The majority of students at Miami-Dade Community College are not native speakers of English and, even though the committee developing the instrument was very careful about the language construction of the items, second language problems may affect the students' responses. 
outline of the Remaining Chapters

Chapter Two expands on the major theories of ethnicity, reviews studies of classroom interactions and counseling of minorities. Chapter Two also provides a historical perspective on the issue of student evaluation of faculty, including validity and reliability studies. Aspects of the class, the students, and the faculty member that may affect ratings will be analyzed. Chapter Three describes the methodology employed to collect and analyze the data, while Chapter Four provides a detailed analysis of the data. Chapter Five summarizes the findings of the study and provides conclusions and recommendations. 
CHAPTER II

REVIEW OF RELATED LITERATURE

Introduction

There is considerable interest in the topic of teaching effectiveness and its evaluation in higher education, as reflected in the extensive array of studies and reports on that subject in the literature. "More and more, higher education's various publics (students, parents, legislators, and others) are insisting that we pay more than lip service to this commitment, that teaching be evaluated seriously and substantively. The time has come for higher education to put its actions where its rhetoric is." (Cashin, 1989)

Through this study, the effects of students' ethnicity on the ratings they assign their instructors, and students' interactions with instructors of the same ethnicity, will be determined. Therefore, several theories of ethnicity will be reviewed. Studies of classroom interactions, particularly with minority students, will follow. Since research on classroom interactions at the post-secondary level, including possible racial bias, appears to be inadequate, several studies on counselor-client interactions among minorities will also be discussed. Finally, the effects of various student, instructor, and course characteristics on student ratings will be examined. 


\section{Ethnicity}

\section{Definitions}

\section{Ethnicity.}

The term ethnicity is relatively new to English language dictionaries. Glazer and Moynihan (1975) found the word ethnicity for the first time in the 1973 edition of the American Heritage Dictionary where it was described as a condition of belonging to a particular ethnic group. Glazer defines ethnic groups as groups defined by descent, real or mythical, and sharing a common history and experience.

Parsons (1975) describes ethnicity as a primary focus of group identity, that is, the organization of plural persons into distinctive groups and, second, of solidarity and the loyalties of individual members to such groups. He interprets ethnicity as having a biological base, with a presumed relative homogeneity, and voluntary membership. On the other hand, Bell (1975) and Patterson (1975) portray ethnicity with a definite social perspective. Bell states that it is one response, in many instances of disadvantaged groups, to the breakup of older and historically fused social and cultural, political and economic dominance structures. It represents an effort by these groups to use a cultural mode for economic and political advancement. Patterson defines ethnicity as a dynamic condition wherein certain members of a society, in a given social context, 
choose to emphasize as their most meaningful basis of primary extrafamilial identity certain assumed cultural, national, or somatic traits.

For the purposes of this study the following definition of ethnicity will be used. Ethnicity is defined as a condition of belonging to a particular ethnic group, with certain group identity, which may be physical, cultural, of language, or national origin. Ethnicity gives rise to feelings of affiliation and loyalty towards other group members, particularly in groups which perceive a need for economic or political advancement.

\section{Ethnogenesis.}

Roosens (1989) uses the term ethnogenesis to describe a process that has only been observed in the last twenty years. Before, there was the assumption that direct and continuous contact between groups of different cultures would lead to a decrease in their differences. And, in effect, acculturation does occur, causing many cultural differences to fade away. Yet new cultural differences appear, sometimes deliberately introduced. He concludes that ethnic groups affirm themselves more when there is intense spatial-geographical and social contact between groups. Ethnic groups generally are most clearly delineated in areas that have one or another form of overarching political organization. The works of De Vos and RomanucciRoss (1975) and Glazer and Moynihan (1975) support Roosens' 
assertions.

Most anthropologists and sociologists concur in the inclusion of racial groups under the general rubric of ethnic group, just as groups that are of religious or national-origin composition (Gordon, 1975; Glazer, 1975, Patterson, 1975). Others, such as van den Berghe (in Thompson, 1989) and Ringer and Lawless (1989), argue that racial minorities have had different experiences than white ethnic minorities.

\section{Ethnocentrism.}

A third term that merits a definition is ethnocentrism as defined by Noel (1972) as a universal characteristic of autonomous societies or ethnic groups. It is a view of things in which one's own group is the center of everything, and all others are scaled and rated with reference to it. There is rejection or downgrading of all out-groups to some degree as a function of the extent to which they differ from the in-group. It does not necessarily lead to interethnic conflict or ethnic stratification. This potential conflict can be neutralized by mutual respect and admission by each that the other is superior in certain respects, by the existence of some shared values and interests, and by the absence of competition due to economic complementarity and low population density.

Basic group identity

Harold Isaacs" (1975) "basic group identity" consists 
of the ready-made set of endowments and identifications which every individual shares with others from the moment of birth by the chance of the family into which he is born at that given time in that given place. These are:

1. person's body

2. person's name (individual \& family)

3. history and origin of one's group

4. nationality or tribal affiliation

5. language

6. religion

7. culture

8. geography and topography of one's birthplace.

Basic group identity is more basic than secondary identities such as occupation and class which are dependent on political-social-economic circumstances.

\section{Theories of Ethnicity}

Sociobiological.

Ethnicity is explained as a natural expression of our genetic nature. This theory asserts a universal genetic tendency for ethnically based forms of social organization, but cannot explain the absence of ethnic organization or its different forms except by reference to social and cultural processes. There is a tendency to favor kin - nepotism for the purpose of maximizing one's inclusive fitness (spreading one's genes indirectly by means of relatives with 
whom one shares a proportion of genes). Van den Berghe (in Thompson, 1989) argues that ethnic classifications and sentiments can be understood as extensions of kin selection or nepotism. Forms of social organization based on ethnicity or race are opposite to class-based forms of organization.

\section{Primordialist.}

This theory states that one should regard ethnicity as a natural, primordial sentiment that is basic to human selfdefinition. It fulfills a human psychological need for identity, that human beings have a basic, primordial need for group affiliation that is best satisfied by the maintenance of an ethnic identity. There are actually two branches to this primordialist theory, the "natural" school, advocated by Edward Shils, and clifford Geertz's "sociohistorical" school.

Shils (in Thompson, 1989) formulates two basic assumptions:

1. a group identity is an indispensable aspect of a person's personal identity, which is based on interpersonal relationships that are long-lasting and intimate.

2. ethnic attachments are a natural kind of group affiliation.

Geertz (in Thompson, 1989) believes that ethnicity is an historically important cultural identity that, in some 
areas of the world, has become crucial or salient politically:

1. Ethnic bonds and sentiments become politically significant when formerly autonomous, pre-state societies are forced to reorganize into state-level social systems.

2. When a community's autonomy is threatened by the present-day necessity of forging a new unstable state order, then primordial sentiments may serve to define politically significant social movements.

Primordialist theories provide us with insight concerning the strength of ethnic and racial sentiments and how such sentiments can become important elements of individual and group identification.

Assimilationism.

This was the dominant paradigm until the 1970's. It focuses on change rather than persistence. Gordon (1975) defines assimilation as a process or series of stages through which people pass in the course of adapting to a new society. Assimilation has identified such processes as acculturation and structural assimilation that describe the gradual disappearance of ethnic organizations but has difficulty accounting for both the maintenance and the creation of racial or ethnic organizations in advanced industrial societies.

Gordon explains that there could be varying rates of 
progress toward assimilation among various dimensions. These dimensions may be cultural, structural, marital, identificational, attitude receptional, behavior receptional, and civic. Gordon also predicts an indefinite continuance of structurally separate ethnic groups.

World-system theory.

Wallerstein (in Thompson, 1989) explains that the world economy is capitalistic, even in socialist countries, due to the fact that production for profit in the world market is the defining characteristic common to all nations. This theory states that the capitalistic world economy transcends the political boundaries of the world's states. It treats race and ethnic relations as particular forms of social organization connected to the international division of labor.

World-system theory divides the world into three zones - core, semiperipheral, and peripheral - depending on each nation's level of industrialization. According to Thompson, this world-system perspective grossly underestimates the differences between and among states with different modes of production and different social formations.

Summary of ethnicity

Glazer \& Moynihan (1975) view ethnic groups as pressure groups. They assert that mobilization of ethnic groups is only possible because political leaders are able to rely on 
profound affective factors related to origin, such as sharing 'the same blood' and being faithful to a tradition handed down from one generation to another. Each individual belongs to several social units: nation, profession, family, political party, ethnic group, religious organization, etc. Those who identify with an ethnic group can find psychological security in this identification, a feeling of belonging. As groups interact, processes of change affect their boundaries. When people compete as individuals, boundaries dissolve. When they compete as groups, boundaries are reinforced.

De Vos \& Romanucci-Ross (1975) believe that ethnic identity can be used to express one's humanness, or to deny the humanness of others. Its use depends on the reality of external pressure and oppression. Many cultural effects only become self-consciously contrastive when contact with strangers suggests alternatives. Maintenance of one's ethnic loyalty is very often an expressive, emotional need. Affiliation, harmony, nurturance, and appreciation are very important factors of ethnic relations.

of the four major theories of ethnicity, the primordialist theory appears to be most applicable to the classroom since it views human beings as having basic, primordial needs for group affiliation, feelings of belonging. This identification with a particular ethnic group may cause a student to perceive an instructor of the 
same ethnicity in a different manner than other instructors. Mutual feelings of affiliation may produce a special relationship between student and instructor. This student may feel more comfortable in the classroom and, therefore, be able to learn more. On the other hand, a student may exhibit ethnocentrism, thereby judging others in relation to his/her own ethnic group. Consequently, the instructor of the same ethnicity is rated higher by this student only because they share a common background, while instructors of other ethnicities could be rated lower. However, an effective instructor may overcome these ethnicity factors, so that all students may be able to feel comfortable, and learn more, in that particular classroom.

\section{Classroom Interactions}

\section{Elementary and Secondary schools}

A 1973 Civil Rights Commission study on MexicanAmerican and Anglo elementary school students' interactions with their teachers, based on classroom observations, addressed the issue of bias in the classroom (Jackson and Cosca, 1974). The study was conducted in California, Texas and New Mexico among fourth, eighth, tenth and twelfth grade English language arts classes. Staff members of the U.S. Commission on Civil Rights visited the schools, interviewed school personnel, and observed classes. Seven categories of 
teacher behavior - accepts students' feelings, praises or encourages, accepts or uses ideas of students, asks questions, lectures, gives directions, and criticizes or justifies authority - were observed. The major question asked was whether Mexican American and white non-Hispanic children were equally involved in each category of interaction. The study showed statistically significant disparities in the following: praise or encouragement given (35\% more white non-Hispanic), acceptance of students' ideas ( $40 \%$ more white non-Hispanic), positive feedback - directing questions (21\% more white non-Hispanic).

Another study that appears to indicate racial bias on the part of white non-Hispanic teachers towards black children was reported by Rosenbaum, Kulieke, and Rubinowitz (1987). When black families participated in a housing desegregation program and attended predominantly white suburban schools, the black children's parents reported that the suburban teachers were more helpful to the children than previous teachers. Yet it was also found that these teachers allowed racist behavior on the part of other children and even exhibited racism themselves. Interestingly enough, the children's grades did not suffer even though the academic standards at the suburban school were higher than those of the previous school. It suggests an ability on the part of these children to respond to higher demands even when confronted with a new situation 
that has some negative aspects.

When white non-Hispanic teachers were asked to rate the behavior of white non-Hispanic and Mexican American elementary school children, it was concluded that the children's ethnicity influenced the behavior ratings (Elliott and Argulewicz, 1983). Mexican American children were rated lower in comprehension, creative initiative, and closeness to the teacher. In a Canadian study of minority junior high students - in this case the students were Canadian Indian, British, Filipino, French, German, or Portuguese - ethnicity, together with the student's academic performance and gender, played an important role in teachers' normative and cognitive expectations of these students (Clifton, Perry, Parsonson, and Hryniuk, 1986). Gottlieb (1964) conducted a study similar to the two above, but instead of having a single teacher ethnicity with two types of students, in this study black and white nonHispanic teachers rated black students in an inner city school in the midwest. The black teachers described the students as happy, energetic, and fun-loving. On the other hand, the white non-Hispanic teachers described the same black students as talkative, lazy, and rebellious. Gottlieb explained that the black teachers were more likely to have come from a similar background as the students, and were therefore more realistic in their expectations and less dissatisfied with their roles as teachers. 
While comparing the reading achievements of Mexican American students in a large, urban, southwestern school district, Vierra (1984) found no statistically significant difference in reading achievement whether these Mexican American students were in classes taught by white nonHispanic or Hispanic teachers. Therefore there was no interaction between teacher ethnicity and student achievement. A similar outcome was found by Sheehan \& Marcus (1977) when they compared improvement in test scores in mathematics and vocabulary for children who were matched with a teacher on the basis of race. The results indicated that white non-Hispanic teachers were more effective than black teachers except for teachers with less than 5 years experience, where the reverse was true in the area of vocabulary achievement. Therefore, there was no advantage, as far as academic achievement, in matching student and teacher by race.

Farkas, Sheehan, Grobe, and Shuan (1990), in a study of cultural resources and school success, showed an interesting effect in the interactions between student and teacher ethnicity. Black teachers judged black students as more disruptive than white non-Hispanic teachers did; however, the data also indicated that black students had lower absenteeism rates and had better work habits when they were in classes with black teachers. This suggests a positive interaction, whereby black teachers demand more of the black 
students, and get it.

\section{Higher Education}

Allen \& Niss (1990), while researching the literature for a study on classroom interactions, found information on the issue of sex bias. However, they were unable to find comparable work on racial bias at the postsecondary level. Moreover, they found that the issue of possible bias against the growing number of foreign students remained unaddressed. In their study, psychology students were trained to observe classroom behavior, then attended several lectures given by university professors. They recorded several prescribed instructor behaviors and found "no overtly racist behaviors... But they (instructors) displayed subtle negative reactions to minority students (almost all of whom were black)." They concluded that university classrooms are probably as chilly for minority students as they are for women.

Pascarella (1980), in a critical review and synthesis of previous research, found a positive association between student-faculty informal nonclass contact and various outcomes of college, including academic achievement and institutional persistence. Conversely, in a study of community college students, Pascarella, Duby, and Iverson (1983) determined that high levels of social integration, which may include interaction with faculty, had a negative 
influence on students' persistence in college. They theorized that these students with high levels of social integration were also high in affiliation needs, which may not be as easily fulfilled in a commuter institution. Oliver, Smith, and Wilson (1989) examined the academic performance of blacks attending predominantly white nonHispanic state-supported universities. In their review of the literature they encountered studies documenting that blacks experience a sense of social estrangement in predominantly white non-Hispanic settings. The importance of social integration to help individuals during socially stressful situations, and the importance of other blacks in the institutional structure, were also suggested in previous studies. Oliver et al., in their study which consisted of mailed questionnaires to blacks at six predominantly white non-Hispanic four-year public universities, showed:

that black students involved in extracurricular activities were the most well-adjusted, even though their academic performance suffered; that when black students perceive that there are a sufficient number of black students in the university (a critical mass), their adjustment is enhanced; that the availability of black faculty support did not produce a significant effect on either adjustment or academic performance. Wilson, Wood, and Gaff (1974) classified faculty as 
being high, medium, and low interactors, on the basis of the frequency of their informal contact with students. Faculty who were high interactors showed a significantly greater willingness than low interactors to solicit the views of students in class, discuss a variety of points of view, and allow students to express their ideas through essay exams and term paper assignments. The degree of faculty interaction was not found to be affected by membership and participation in professional organizations, nor productivity in publishing. Characteristics found to be associated with out-of-class interactions were: faculty attitudes in viewing education as an interactive process; faculty behaviors which invite discussion both within and beyond the classroom; degree of adherence to office hours, since it provides accessibility to the student. The importance of this study is reflected in that of Volkwein, King, and Terenzini (1986), who found that students perceived greater intellectual growth when they had good faculty-student relationships, both inside and outside the classroom.

Two studies at Miami-Dade Community College provide information on differences in level of satisfaction with the institution and on a program that attempts to retain students. The first study indicates that blacks at the institution are the most satisfied group (among blacks, Hispanics, and white non-Hispanics) with most aspects of the 
institution, including the academic program and its faculty (Vorp, 1988). Another study (Ingold, 1990) demonstrated that an orientation program had a positive effect on the retention and graduation rates for white non-Hispanics and Hispanics, yet it had no statistical significance on the retention and graduation rates for black students.

Summary of the Research Related to Classroom Interactions

Since ethnocentrism is a factor in ethnic relations, and group and personal interactions, it is important for both instructor and student to recognize their differences and accept and respect each other, thereby facilitating the learning environment. Interactions between faculty and student, and the quality of those interactions, appear to be very important to a student's achievement and persistence. In and outside the classroom, a good instructor can foster relations between the student and him/herself, and among students, that minimize ethnocentrism and optimize alternatives.

Counseling of Minorities

Since the literature appears to be incomplete in its studies of interactions among instructors and students in higher education, the psychological and sociological literature was surveyed to determine the effects of 
counselor - client interactions among minorities. Particular attention was paid to studies dealing with counselor preference by minority clients.

While discussing several reviews, including his own, of the research on counseling minorities, Atkinson (1985) commented that blacks appeared to be somewhat consistent in their preference for counselors of their own race, but found no documentation of a similar effect among other racial or ethnic groups. However, he cautioned that most of the studies reviewed only examined between-group differences and not within-group differences. "Such within-group differences as racial self-identification, racial identity development, social class background, and cultural commitment affect preference for counselor race or ethnicity" (Atkinson, 1983).

\section{Cultural commitment}

Johnson and Lashley (1989) studied whether the degree of cultural commitment among Native Americans affected their choice of counselor. They found that counselees with strong cultural commitment showed a greater preference for counselors of the same race. They also determined that those persons with strong cultural commitment expected more nurturance, facilitative conditions, and counselor expertise than those with weak cultural commitment. Racial identity also affects counselor preference (Ponterotto, 1986). 
Preferences in counselor

Backner (1970) conducted two surveys of black and Puerto Rican students in a SEEK (Search for Education, Elevation, and Knowledge) program designed for students from designated poverty areas who would not normally be eligible to attend the city colleges of New York. The first survey included a question that asked which SEEK teachers, counselors, and tutors were more effective and helpful. only $4.9 \%$ of the 115 respondents believed that the same ethnic and racial background was the most important consideration. $40.5 \%$ expressed a preference for those having experience with similar students, while $12.6 \%$ considered a good personality as the best quality. A total of $42.0 \%$ felt that those with the ability to be good teachers, counselors, and tutors were the most helpful and effective.

In a second study a survey was mailed to all 408 puerto Rican and black SEEK students enrolled in 1968. $44.8 \%$ returned them indicating that $25.3 \%$ preferred a counselor to be of the same ethnic background while $68.4 \%$ indicated that it did not matter. What is more significant is that for the three white non-Hispanic counselors rated highest by students, only six out of fifty-six students (10.7\%) responded that the ethnic background of student and counselor should be the same. Conversely, for the three white non-Hispanic counselors with the lowest overall 
student ratings of effectiveness, twenty-two out of fiftyfive $(40 \%)$ would want their counselor to be of the same ethnic background.

These findings led Backner to conclude that "when a black student and a white counselor become involved with one another, their own evaluation of that relationship still depends much more upon the intrinsically human qualities that they each possess than upon the fact of their different skin colors and backgrounds."

In an article on the counseling of black students, Schmedinghoff (1977) stated that the belief that, unless counselor and counselee share the same cultural background counseling is not as effective, is actually a myth. He believes that there are differences between blacks and white non-Hispanics, a product of racism rather than race, and that continued interaction between the two races should remove those differences.

\section{Summary Related to the Counseling of Minorities}

Higgins and Warner (1975) summarize as follows: "All good counselors must provide empathic understanding, must understand the language and culture of their clients, and must respect their clients. These factors are true regardless of the race of counselor or client. While recognizing the many special problems facing blacks and other minority groups, in terms of providing good counseling 
services, perhaps we should spend more time finding out the common core of effective counseling than placing emphasis on racial and ethnic differences."

\section{Student Ratings of Instructors}

One of the most extensively used methods to evaluate teaching effectiveness is the student ratings instrument. Research has been conducted on the validity and reliability of student ratings. Many of the studies have focused on sources of potential bias to these ratings. Some researchers interpret that any significant correlation between students' evaluations and certain background characteristic implies a bias, while others argue that ratings are only biased to the extent that they are affected by variables that are not under the control of the instructor - an oversimplication since factors such as grading practices and course difficulty, which are under the control of the instructor, would then not be classified as bias. Marsh (1984, p.735) provides a good definition of bias by stating that "student ratings are biased to the extent that they are influenced by variables unrelated to teaching effectiveness and, perhaps, to the extent that this influence generalizes across all rating factors rather than being specific to the particular factors most logically related to the influence". Cashin (1988) agrees that bias 
should be restricted to variables that are not a function of the instructor's teaching effectiveness.

Feldman (1984) provides a very complete discussion on bias and states that "one or more factors directly and somehow inappropriately influence students' judgments about and evaluation of teachers and courses. The question of bias asks, in essence, whether some influence on the teaching situation such as class size actually affects teachers and their instruction, which is then accurately reflected in students' evaluation (nonbias), or whether, in some way it only affects students' attitudes toward the course and students' perceptions of instructors (and their teaching) such that evaluation does not accurately reflect the instruction that students receive (bias)."

Characteristics of the instructor, such as gender, ethnicity, and years of experience may provide for differences in student ratings. Other factors which may also affect student ratings, including expressiveness, enthusiasm, communication ability, and the quality of the organization and planning of a course, are controllable by the faculty member.

Variability in student ratings may occur due to the characteristics of the course being taught: the academic field; whether a course is required or elective; the level of the course, such as freshman versus senior level; and the difficulty of the course. Further complications may arise 
from class size and the time of day in which the course is offered. The type of ratings instrument being used, the conditions under which it is administered, including the anonymity of the rater, and how early or late during the term it is administered, may also have an effect on student responses.

Not surprisingly, students' differences may also provide for differences in their rating of instructors. Students' gender, ethnic background, age, achievement level and expected grade, prior interest in the subject, and attitudes may all provide variability of ratings.

In this chapter the above-mentioned potential sources of variability, some of which may be considered bias, will be examined by discussing research findings in journal articles, reports, and books on the subject. Although the majority of the studies that have been conducted have studied actual classroom conditions, there are several reports of experiments, particularly in the areas of teacher expressiveness and gender.

\section{Reliability and Validity of student Ratings}

\section{Reliability}

Reliability of an instrument is concerned with its consistency, stability and generalizability. In student ratings, consistency relates to the agreement among raters, 
which usually improves as the number of raters and the number of items in the instrument increase. stability refers to the agreement in the ratings of the same student over time: weeks, months, or even years later. Generalizability provides the confidence with which the data accurately reflects the instructor's teaching effectiveness in general, not just in a particular course.

In discussing his extensive review of previous studies, Feldman (1977) notes that the reliabilities of average (20 to 25 students in a class averaged together) student ratings tended to be in the range of 0.70 's to 0.90 's, yet cautioned that this did not indicate that students within classes were highly consistent in their ratings. Actually, interrater consistency within a class is generally in the 0.10's to $0.30^{\prime} \mathrm{s}$, at best a moderate association. Feldman cautioned that, although students are asked to fill out rating instruments independently, without discussion with other students, students have in effect been conferring with one another throughout the semester, perhaps 'tainting' results by providing a higher than real reliability index. Another example of consistency of ratings is presented by Marsh, Overall, and Kesler (1979), who found a positive correlation $(0.77)$ between student ratings and faculty selfevaluations on twenty-four specific items descriptive of faculty behavior.

Feldman (1977) assessed the stability of a student 
ratings instrument by giving the instrument at the end of the course and 15 months later. He found a correlation of 0.94. Comparisons of student ratings during a course and later when the students were graduating seniors (Aleamoni, 1987 ) or even a year or longer after graduation (Overall \& Marsh, 1980) provide correlations as high as 0.83 .

Another method for assessing the reliability, and particularly the generalizability, of ratings is by comparing two sets of class ratings for teachers who have taught the same course. Feldman (1978) reports correlations in the 0.60 's and up to 0.80 for ratings when comparing the same instructor teaching the same course; however, the correlations dropped to a range of 0.29 to 0.54 for the same instructor teaching different courses. As expected, correlations were even smaller $(0.04$ to 0.20$)$ when the same course was taught by different instructors. Similarly, when Marsh (1982) compared instructors to themselves in different courses and to other instructors in the same and different courses, he obtained the following correlations:

for the same instructor, same course $(0.71)$

for the same instructor, different course (0.52)

for different instructor, same course (0.14)

for different instructor, different course $(0.06)$

This data indicates that there is greater consistency in ratings for the same instructor, even while teaching different courses which may have unique characteristics such 
as course content and different populations of students, than for separate instructors, where a low correlation would be expected since two different individuals are being rated.

Miller (1987) concludes that, as long as statistically reliable student ratings forms are used, students can be expected to assess classroom instruction reliably, both during a course and even years later.

\section{validity}

Validity, in general, concerns itself with whether an instrument measures what it is supposed to measure. Validity and reliability are intertwined according to Aubrecht (1979). "In order for student ratings to be valid, they must be both reliable (they measure consistently whatever they do measure) and relevant (what they measure is what they ought to measure for the purposes they serve)." Teaching effectiveness, "the degree to which one has facilitated student achievement" (Mckeachie, 1979), should be what provides high or low scores in student ratings. And, indeed, that appears to be the case. Yet, the issue is very complex since teaching effectiveness necessary to achieve cognitive goals - such as knowledge, skill in problem-solving, and ability to evaluate - may differ from that needed to achieve motivational and attitudinal goals that translate to lifelong learning. For example, Frey (1978) found that student ratings for the dimension of 
instructor skill are more highly related to student learning than are the ratings on the rapport factor, indicating that rapport is not highly related to student achievement.

McKeachie (1979) states that "to validate a measure of teaching effectiveness, such as student ratings, we must have a number of teachers teaching the same course to comparable groups of students." That is exactly what cohen (1981) did. According to him, correlations of student learning in multisection courses taught by different instructors, as determined by a common external exam, with various student rating items provides an indication of the validity of an instrument. Cohen's analysis shows correlations from as low as 0.22 for student achievement with ratings on teacher interaction dimensions (rapport), to as high as 0.50 for ratings on teacher skill dimensions (explains clearly). Cashin (1988) argues that even though these correlations may seem low, they are useful within a field such as social sciences, where complex phenomena are often studied.

A report that makes the validity of student ratings suspect is Yamamoto and Dizney's study (1966) which indicates that they had found evidence that student evaluations tend to reflect the personal and social qualities of an instructor, 'who he is', rather than 'what he does'. A second study that places suspicion on the validity of ratings is centra's (1975). He compared peer's 
ratings after classroom visits and found little agreement among these ratings. The study was conducted in a relatively new school to minimize the effect of student feedback on other faculty.

Rodin and Rodin (1972) found negative correlations between mean student ratings of effectiveness of instruction and mean performance of students on a math exam. Their explanation was that perhaps students resent instructors who force them to work too hard and to learn more than they wish. Or that as students learn more, they become better able to detect the weaknesses of their instructors. Many researchers have criticized the Rodin's methodology and dispute their findings.

According to McKeachie (1979), replications of Rodin and Rodin's study with better research designs show substantial positive correlations between mean student ratings and mean student performance, providing support for validity of student ratings. He also argues "that in courses in which students learn more the grades should be higher and the ratings should be higher so that a correlation between average grades and ratings is not necessarily a sign of invalidity."

Gleason (1986) affirms the validity of student ratings. He determined that students are in a position to identify the factors that make instruction effective since, in general, students agree with each other as to the factors 
that contribute positively to instructional impact. He goes on to state that "teachers rated as effective by students are generally those teachers whose students achieve more, they can better apply course materials, and they are more inclined to pursue the subject subsequently."

The majority of studies (Aleamoni, 1987; Aubrecht, 1979 \& 1981; Cashin, 1988; Centra, 1977; Frey et. al., 1975; Kulik \& McKeachie, 1975; Marsh et. al., 1979; Marsh, 1984; McKeachie, 1979), and in particular Cohen's (1981) and Feldman's (1977, 1978, 1984) analyses, present generally a positive outlook on the question of the validity of student ratings of instructors, with the caveat that certain instructor, course, and student factors may affect ratings. Many argue that, as long as student ratings are not used as the sole source of data on faculty performance, they are useful instruments for both formative and evaluative purposes.

\section{Instructor Characteristics}

An instructor's gender, ethnic background, and years of teaching experience are all characteristics which may affect student ratings, yet are outside the control of the instructor. Other factors which may also affect student ratings, including expressiveness, enthusiasm, communication ability, and the quality of the organization 
and planning of a course, are controllable by the faculty member. Most of the above characteristics have been studied, some of them extensively; however, there do not appear to be any studies on whether an instructor's race or ethnic background has an effect on how students rate instruction.

\section{Teaching experience}

Abaneme (1987) determined that teaching experience had a statistically significant positive effect on student ratings - the greater the experience the higher the ratings - while the instructor's gender did not produce any significant effects. In a study comparing pedagogically trained community college instructors with other instructors with greater amounts of graduate level subject matter preparation, pedagogically trained instructors received higher student ratings in the dimension of course organization and planning (Haugen, 1984). Years of teaching experience had no effect on student ratings.

Aleamoni and Graham (1974) found no differences in student ratings received by teaching assistants, instructors, assistant professors, associate professors, and professors, a ranking system that is to a great extent dependent on years of teaching experience. Cashin (1988) summarizes that most studies find no difference but that a few do show a negative correlation, i.e., older faculty 
receive lower ratings (Feldman, 1983).

\section{Gender}

\section{Classroom studies.}

Gender effects have been studied extensively. Bennett (1982) found that female instructors at Bryn Mawr college were rated more highly than men on overall teaching effectiveness. Bennett explains this finding as due to the perception that female instructors are warmer and less authoritarian than male instructors, and that they are more willing to give time and personal attention to students. However, Bennett's data also revealed that students are less tolerant of female instructors in a number of respects, expecting more of them than of their male colleagues in both educational and interpersonal aspects of teaching.

Additionally, McKeachie and Lin (1971) found that high teacher warmth (taking a personal interest in students, calling students by name, being friendly) in male teachers "resulted in relatively high achievement for women students but not for men". For female teachers, "high warmth teachers seem to be more effective with both sexes of students than teachers with low warmth. In fact, low warmth women with low achievement standards were the least effective of any of the teachers in our studies."

Another finding of differences in student ratings for male and female instructors was obtained by Unger (1979). 
Women who were perceived as difficult graders were judged more negatively than women perceived as easy graders, but perceived difficulty of grading did not affect the ratings of male instructors. Rosenfeld and Jarrard (1985) found that student perceptions of classroom climate depend on the professor's gender, with males receiving higher ratings than females.

\section{Experimental studies.}

Kierstead, D'Agostino, and Dill (1988) conducted an experiment to try to determine whether out-of-class socializing and smiling by instructors had an effect on student ratings. For the socializing effect, students read descriptions of teaching situations. Male instructors were rated higher. Women with social contact received ratings similar to those of the men, but women who did not socialize received relatively unfavorable ratings. The students' gender was not statistically significant.

In the 'smiling' experiment, twenty male and twenty female students watched a slide presentation on the anatomy of the eye. The slides showed a man or a woman, both in either a smiling or unsmiling presentation. The unsmiling man was rated more favorably than the smiling man, while the smiling woman was rated much more favorably than the unsmiling woman. The unsmiling woman appeared to make little impression on the students as far as her knowledge was concerned, but she did strike most as being unfriendly, 
humorless, dry, and monotonous. Kierstead et al. concluded that "socializing with students outside of class improved a female instructor's SRI (Student Rating Inventory), but social contact did not affect the ratings given to male instructors. Smiling slightly depressed ratings given to male instructors, but it elevated those given to female instructors." since these findings were obtained under experimental conditions, there is some question about their generalizability to actual educational settings.

Interaction of faculty gender with student gender.

Elmore and LaPointe (1984) studied the influence of faculty gender and student gender in teacher evaluation and found no interactions. They only found two differences, that men spoke understandably and that women more promptly returned homework assignments and tests.

Basow and Distenfeld (1985) found that student sex did not interact with teacher sex on any measure in a study with expressive female, nonexpressive female, expressive male and nonexpressive male instructors videotaped teaching local history. Students rated instructors and also took an achievement test. The expressive teacher received the highest student evaluations, while students who watched a nonexpressive female teacher had the highest achievement. The nonexpressive female may have been paid more attention because she seemed out of role and unusual. the nonexpressive male may have seemed typical and, therefore, 
paid the least attention. His students had the lowest recall scores. The authors concluded that other studies (Kaschak, 1978) that found an interaction between teacher sex and student sex all used written stimuli instead of video or slide presentations, which simulate classroom conditions more closely.

In a followup study in which she used the same videotapes of expressive and nonexpressive male and female instructors, Basow (1990) found, just as before, that expressive instructors received more positive ratings than did those who portrayed nonexpressive behavior. However, expressiveness appeared to enhance the ratings of scholarship for female instructors, while it impaired the ratings of male instructors. Student achievement, as determined by a multiple-choice test following the seven minute videotape, indicated no significant correlation with student ratings.

\section{Summary of instructor gender effects.}

In many studies, no gender bias has been found (Ahmadi, 1981; Cashin, 1988; Kocher, 1983; Yamamoto \& Dizney, 1966), although female teachers sometimes are rated higher than male teachers by students of both sexes on a global rating, but only if described as highly competent and/or warm (McKeachie \& Lin, 1971; Bennett, 1982). However, as mentioned above, several studies indicate that male professors often appear to have an advantage over female 
insructors in reference to student ratings (Unger, 1975;

Basow \& Silberg, 1987; Rosenfeld \& Jarrard, 1985).

Rapport

Students can differentiate among expertness, friendliness, and teaching skills (Beatty \& Behnke 1980, Cohen, 1981). Beatty and Zahn (1990) concluded from their study that students do not appear to base their evaluations on teachers' sociability. Factor analyses indicated that students discriminated between sociability and qualification-related aspects of teacher performance.

\section{Expressiveness}

Expressiveness in an instructor appears to improve student ratings, though whether that expressiveness leads to greater learning or not is disputed. In Basow and Distenfeld's study (1985) the expressive teacher received the highest student evaluations yet those students who watched a nonexpressive female teacher had the highest achievement on a followup exam. In her subsequent study, Basow (1990) still found that expressiveness was correlated with more positive student ratings. Student achievement, as determined by a multiple-choice test following the seven minute videotape, indicated no significant correlation with student ratings.

In discussing the Dr. Fox studies conducted by Naftulin, Ware and Donnelly (1973) in the early 1970's - 
where students were lectured by a witty, expressive actor who had very little worthwhile information to partake Marsh (1980) stated that "current conclusion, based on instructional settings more closely resembling classrooms, supports the contention that instructor 'expressiveness' matters - as it affects ratings - but that effect does not operate independent of content considerations. In other words, students can and do tell the difference." Cashin (1988) asserts that making the course interesting is part of an instructor's teaching effectiveness. Murray (1985) concurs - "expressive behavior plays a very positive and pivotal role in classroom teaching - namely, that of eliciting and maintaining student attention to the material presented."

\section{Communication Ability}

Tied to expressiveness, to some extent, is the ability to communicate effectively. Generally teachers with high ratings seem to differ from those with low ratings on measures of communication ability (Kulik and McKeachie, 1975). Scheurich et. al. (1983), in an analysis of 9080 student evaluations, found that the item 'helps to understand' accounted for $52 \%$ of the variability. One can argue that helping to understand may be related to the ability of the instructor to communicate effectively. Similarly, in his analysis of research on student 
ratings of instruction, Feldman (1984) found that the dimension of communication and presentation ability had greater importance for students in forming their global opinions of teachers and courses than the dimension of interpersonal interactions.

\section{Organizational Ability}

Also related to expressiveness and communication ability is the ability to organize course content and its presentation. In a study comparing adult students with traditional undergraduates, Ross (1989) found a strong similarity in preferences. "Across age groups and for both sexes, the most frequently described characteristics of teaching incidents viewed favorably focused on teaching style, including clarity of presentations, organization of presentations, the ability to create student involvement, and interesting lectures."

\section{Course Variables}

Academic Field

When Feldman (1978) researched the literature as to differences in academic fields, he found that: English, humanities, the arts, and languages had mostly high and medium ranks in class ratings of teachers: social sciences were in the medium or low third; and science, math and 
engineering (with the exception of certain biological science areas) were in the lower two thirds of the rankings, more frequently in the lower than the medium third. There is the possibility that course, teacher, or student characteristics are important to the association between field and rating.

Feldman also noted that none of the studies controlled for the proportion of men and women in the class, while fields with higher ratings tend to be those in which women are proportionately overrepresented. Cashin (1988) suggests that these differences in academic fields contributed to the assumption that course difficulty affects ratings since science and mathematics courses are considered to be more rigorous than other courses.

\section{Elective Versus Required}

A review of studies of the relationship between the percentage of students taking a course as an elective and the ratings of the instructor shows generally a positive correlation, even when controlling for expected grade, class size, level of the course, gender and rank of instructor (Feldman, 1978).

\section{Level of the course}

Aleamoni and Graham (1974) found highly significant differences in ratings assigned by students in freshman, 
sophomore, junior, senior, and graduate level courses. In particular, freshman and graduate level courses were rated highest on the method of instruction and lowest on course content, while junior and senior level courses were rated lowest on method of instruction and highest on course content.

Feldman (1978) found in his review of the literature many articles that reported that the higher the course level, the higher the rating of the teacher. But some studies showed course level unrelated to class ratings. He surmised that perhaps the differences are not really with course level but with other course-level differences, such as class size, in grades given and expected, the degree of 'electivity', students' academic motivation, and instructor characteristics.

\section{Difficulty of Course}

An interesting finding, one that many faculty would dispute, is a positive correlation of student ratings with difficulty of a course. What this means is that students give higher ratings in difficult courses where they have to work harder (Marsh, 1984).

\section{Class size}

A very weak inverse association exists between the size of class enrollment in a college course and students' 
overall rating of the course and the teacher. There is a larger inverse relationship between class size and evaluation of specific instructional dimensions pertaining to the instructor's interactions and interrelationships with students. The average correlation between class size and overall evaluation of the teacher or the course is -.09 (Feldman, 1984).

In some studies (Marsh, 1976; Delaney, 1976) investigators used a polynomial trend analysis to see whether a second-degree (parabolic) curve fitted the data better than did a straight line - it did. A U-shaped curve was obtained, showing that both relatively smaller and relatively larger classes tended to receive higher ratings than did the medium-sized classes. A few studies showed an inverted U-shaped curve - whereas medium-sized classes received the highest ratings (Feldman, 1984).

Several possible explanations for the U-shaped relationship was provided by Marsh (1984). He speculated that the higher ratings for very large classes (over 250 students) could be due to (a) the selection of very effective instructors to teach those courses; (b) the students selecting particularly effective instructors, thereby increasing class size; (c) an increased motivation for instructors to perform well in that setting; and (d) the development of special techniques that are effective in large class settings but not appropriate to small classes. 
Perhaps some colleges make available increased resource for large courses (Feldman, 1978).

For dimensions specific to communication and presentation of subject matter and course material, which have greater importance to students in forming their global opinions of teachers than the dimensions of interpersonal interactions, between one-fourth and one-half of the associations are inverse with class size. This inverse relation is small, accounting for as little as less than $1 \%$ to about $2 \%$ of the variance in these particular ratings. For instructional dimensions involving direct and indirect interpersonal interactions between student and teacher, twothirds to three-fourths of the associations are inverse and statistically significant. It accounts for approximately 5\% of the variance in evaluations (Feldman, 1984).

For most of the other rating dimensions as well as for overall evaluations, class size typically accounts for only a very small proportion of their variance. As Feldman (1984) explains: "size biases a student less in judging the teacher's communicative role than it does the teacher's facilitative role, and because the former is more important than the latter to global evaluations, it biases the overall evaluation less as well."

Marsh et al. (1979) believe that "class size should not be considered a bias that is specific to students' evaluation...class size can better be interpreted as a 
variable impacting, albeit slightly, on teaching effectiveness in a manner accurately reflected in the student ratings."

Time of Day

No differences in student ratings were found in many studies among classes that met at different times of the day or evening (Feldman, 1978); however, several studies did show slight differences but the pattern of the results were not consistent.

\section{Student Characteristics}

\section{Gender}

Sex bias in the college classroom has been described (Allen \& Niss, 1990), including differing treatment in math and science classes (Campbell, 1986). One might expect that these differences in classroom treatment would affect student ratings of instruction. However, many studies have reported no significant differences in student ratings due to the student's gender (Ahmadi, 1981; Bennett, 1982; Elmore \& Pohlmann, 1978; Elmore \& LaPointe, 1984; Kierstead et. al., 1988; Marsh, 1984; McKeachie, 1986), or in students' preferences when surveyed about the 'ideal professor' (Scheck \& Bizio, 1977; Yamamoto \& Dizney, 1966). 
Differences in ratings of instructors have not been found to be dependent on the age of the student (Ahmadi, 1981; Beatty \& Zahn, 1990). Ross (1989) found that adult students' conception of good college teaching revealed a relative consistency with results obtained in previous studies of traditional-age students' perceptions of effective teachers. "Across age groups and for both sexes, the most frequently described characteristics of teaching incidents viewed favorably focused on teaching style, including clarity of presentations, organization of presentations, the ability to create student involvement, and interesting lectures." In teacher-student relationships, assistance beyond class, showing concern for students, and creating a warm learning climate were the most positive statements.

In a study of non-traditional adult students enrolled in a graduate business degree program at locations away from the main campus, Shapiro (1990) found that class evaluations were affected in the same way as traditional courses in factors such as class size and average class grade. This consistency of findings led Shapiro to conclude that there are definite relationships between class evaluation and class size and grade and that student ratings of nontraditional older students are very similar to those of traditional, younger students. 


\section{Expected Grades}

Brandenburg, Slinde, and Batista (1977) determined that the following variables - expected grade in a course and whether a required or elective course - provided extremely large contributions to the prediction of total score on a rating form, with other variables such as class size, course level, and instructor's rank providing small contributions to the prediction. Abaneme (1987), in a study of 2,500 undergraduate students whose grade point averages were determined independently of the ratings form, found that "the variable of student achievement produced significant effect on the student ratings of instructional effectiveness of instructors." Aubrecht (1981) discusses the suspicion that student grades bias ratings, that teachers can 'buy' high ratings with high grades. Some (Hunter, 1980; Scheurich, 1983; Ahmadi, 1985) found little or no correlation between ratings of instruction and students' grade point average.

Powell (1977) conducted an experiment in which three sections of an Introductory Psychology course which he taught were provided with different grading standards, identified as stringent, moderate, and lenient. Other aspects of the course were the same for all sections. As expected, grade distributions were substantially different in the anticipated direction. Rating scores of the instructor and the course decreased as the grading criteria 
became more stringent.

Howard and Maxwell (1982) provide alternative models (analytic pathways) to the explanation that high grades result in high ratings. They suggest that teaching effectiveness leads to student performance, which then yields both higher grades and higher ratings. An alternative model suggests that student motivation improves student performance, which then gives both higher grades and higher ratings. Both of these models have a positive relationship between student grades and student ratings, but this relationship is seen as a legitimate outcome of student performance rather than as a 'bias'.

Three quite different explanations for the finding that class-average expected grades correlate positively with student ratings are provided by Marsh (1984). The 'grading leniency hypothesis' suggests that instructors who give higher-than-deserved grades receive higher-than-deserved ratings, a true bias in ratings. The 'validity hypothesis' proposes, just as Howard and Maxwell (1982) did, that better expected grades are an outcome of better student learning. The third hypothesis, a 'student characteristic hypothesis' uses prior student interest as the explanation for better learning, better grades, and greater teaching effectiveness.

In a very extensive study with almost 48,000 respondents in 2,381 courses, Theall (1990) concluded that "the results support the validity of student ratings and do 
not support the proposition that ratings can be raised by 'inflating' grades."

\section{Prior Subject Interest}

In his extensive study of the literature, Feldman (1977) determined that a student's interest in the subject prior to enrolling in a course correlated positively with the instructor ratings provided by that student later in the semester. Marsh (1987) found a similar trend and summarized as follows: "higher student interest in the subject apparently creates a more favorable learning environment and facilitates effective teaching, and this effect is reflected in student ratings as well as faculty self-evaluations."

\section{Attitudes}

Van Allen (1981) analyzed the relationship between student ratings of faculty and the similarity of educational attitudes between student and faculty and found that they were significantly related. Lavender (1977) found that when there were sincere differences between students and instructors concerning the expectations of a course, then these differences affected student ratings.

on the other hand, Abrami and Mizener's (1985) findings fail to support the claim that perceived attitude similarity is a substantial source of bias in student ratings. In their study students whose attitudes matched their 
instructor's received higher grades than did dissimilar students. But this small relation became insignificant when class-to-class differences in instructors were controlled. Hunter (1980) also found no differences in ratings due to students' preferences in learning styles.

\section{Ethnicity}

Ahmadi (1981) determined that students' opinion towards evaluation of faculty was different for international students than for native born Americans, implying that cultural differences may provide for differences in attitude which may then reflect in differences in student ratings.

A study of American Indian community college students (Griffin, 1981) identified several instructor behaviors that demotivate students. Among the behaviors were: talking down or ridiculing students; showing disinterest in students; requesting questions from the class yet not answering them; failure to return assignments; etc. These behaviors would probably be found to demotivate any student. Griffin found that the key to motivation or demotivation was the instructor's attitude toward instructional delivery and toward the student.

students' perceptions of the ideal professor were determined by scheck and Bizio (1977). The five characteristics selected as most important were: thorough knowledge of the subject; deep interest in the subject; 
sincere interest in teaching college students; inspiring and presenting material to meet students' interests; and sincerity and honesty. Minority students appeared to emphasize characteristics that were practical and relevant to real-life situations, yet only 39 of the 383 students involved in the study were Hispanic, black, or oriental, not a sufficient number to determine whether there was a significant difference.

Conclusion

Ethnicity has been defined as a condition of belonging to a particular ethnic group, with certain group identity, which may be physical, cultural, language, or national origin. Ethnicity gives rise to feelings of affiliation and loyalty towards other group members, particularly in groups which perceive a need for economic or political advancement. Four major theories of ethnicity, as identified by Thompson (1989) are as follows: sociobiological, which explains ethnicity as a genetic condition; primordialist, which asserts that humans have a psychological need for identity and group affiliation; assimilationism, focusing on the eventual disappearance of ethnic differences; and worldsystem, which treats race and ethnic relations as particular forms of social organization within a capitalistic world. Instructor ratings may be affected by a student's 
ethnicity. If the student and instructor belong to the same ethnic group, there may be an interaction produced by mutual feelings of affiliation. The student may feel more comfortable with that instructor and actually learn more in that classroom. However, if the instructor is competent, effective, and compassionate, instructor ethnicity may be unimportant, as all students may be able to feel at ease, and therefore be able to learn more, in that particular classroom.

There is some research on the effects of ethnicity in the classroom, particularly as it affects student-teacher interactions, but it does not appear that there are any studies on the effect of ethnicity on student ratings of instruction. Therefore, studies of counselor-client interactions from the fields of psychology and sociology were reviewed. These studies indicate that differences in counselor and client ethnic backgrounds do not preclude effective counseling from occurring and one hopes that the same is true in the classroom.

Rating instruments have generally been determined to be reliable and valid. Certain characteristics of the instructor, the student, the course, the rating instrument itself and how it is administered, may have an effect on the ratings that students give faculty. Many studies demonstrate that most of these characteristics have a very small, or no effect on student ratings. However, there is 
enough evidence to indicate that some variability in ratings may be produced by the instructor's expressiveness, the instructor's gender, the academic field being taught, the level of difficulty of the course, class size, and expected grades.

There is a dearth of appropriate studies in the area of education to conclude whether the ethnicities of the instructor and/or student have an effect on student ratings of instruction. Therefore, it seems reasonable to conclude that there is a need for additional research dealing with the question of student and instructor ethnicity. As increased numbers of minority students embark on post secondary studies, institutions in which they enroll will have to address the needs of these students. These minority students will most likely be first-generation college students who will need more academic and personal guidance than traditional students require (Padron, 1991). Probably they will enroll in urban community colleges due to the low cost and open door policy, and will be working part-time or full-time while trying to complete their studies. Their learning styles will vary depending on the culture in which they were raised. As their needs are different from those of white non-Hispanic students, black and Hispanic students may perceive instructors and their efforts in the classroom differently than traditional students.

The null hypotheses to be tested in this study are: 
1: There is no significant difference in the mean ratings given to instructors according to student ethnicity.

2: For higher rated instructors, there is no significant difference in the mean ratings according to student ethnicity.

3: For lower rated instructors, students of the same ethnicity as their instructor do not give significantly different ratings than students whose ethnicity is not the same as their instructor. 


\section{CHAPTER III}

RESEARCH DESIGN AND METHODOLOGY

Overview

The purpose of this study was to explore the relationship between student and faculty ethnicity and possible effects upon student ratings of faculty performance in an urban community college setting characterized by extensive ethnic diversity. This chapter provides an explanation of the methodology, instrumentation, research design, and statistical analysis used in this study. In addition, data from a pilot study conducted in the summer of 1990 is discussed to provide additional information about the development of the instrument and its usage.

The methodology includes a description of the selection of courses involved in the study, thereby providing the population of faculty and students. To begin with, several extraneous variables were controlled for by limiting the course selection to English composition courses. The delimitations that were designed and the limitations that were encountered in the process of data collection will also be addressed. A description of the instrument used in the study, including its development and modifications, will follow.

The research design allowed for the control of several 
variables, while determining whether student ethnicity affects students' ratings of instructors. Interactions among the variables of student and faculty ethnicity are also tested. The statistical analysis addresses the hypotheses of the study.

\section{Research Methodology}

This study involved data collection utilizing a surveytype instrument. The instrument used provides for the assessment by students of an instructor's teaching performance. It also provides self-reported students' demographic information and the opportunity for the students to give written comments about the instructor and about the course. The ethnicity of the instructor was obtained from personnel records maintained by the Human Resources Department at Miami-Dade Community College.

Selection of subjects

Since this study involved students' ratings of instructors' classroom performance, the subjects were selected through the courses in which they enrolled. One class was selected for each full-time faculty member teaching English composition (ENC 1100, ENC 1101, ENC 1102, and ENC 2301) at all five campuses and two outreach centers 
of Miami-Dade Community College. The course sections used in the study were randomly selected, yet random assignments cannot be assumed, as in an experimental study, since the students actually selected specific class times and, in some cases, they also selected the instructor teaching the course. The random selection of courses was done by computer, using the data in the Faculty Assignment Management Information System (FAMIS) at Miami-Dade Community college.

By selecting English composition courses, many sources of variability, including that of comparing ratings in different academic fields, were minimized or eliminated. For example, all English composition classes at the institution are limited to a maximum of twenty-eight students; hence, the variability in student ratings that may occur due to differences in the number of students in a course was removed. Workload in these courses is equalized throughout the institution since the Florida state Board of Education, through the Gordon Rule, mandates that students write a total of 6000 words in each English composition course (Gordon, 1988); therefore, this variable was also controlled. All degree-seeking students at the institution are required to complete these English composition courses with a grade of $c$, ensuring that the course is not considered an elective by any enrolled student. Thus the type of course (e.g. elective or required) was controlled. 
To facilitate the distribution and collection of the questionnaires, the following campuses and relatively large outreach centers were involved in the project: Homestead Campus, Homestead Air Force Base Center, Interamerican Center, Medical Center Campus, North Campus, South Campus, and Wolfson Campus. It is believed that the exclusion of several small outreach centers did not result in the elimination of any full-time English composition faculty from the study.

In effect, there were two populations in this study faculty teaching an English composition course which was randomly selected for inclusion in this study and the students enrolled in those English composition courses.

Instrumentation

The instrument used in this study was the student Feedback Questionnaire (Appendix B) developed and modified by the Faculty Advancement Procedures Committee of the Teaching/Learning Project at Miami-Dade Community College. This subcommittee is composed of eight faculty members and three administrators from throughout the institution.

The committee used the statement of Faculty Excellence (Appendix A), as the base upon which to develop the questionnaire. The statement of Faculty Excellence describes twenty-nine characteristics of excellent teachers. 
These characteristics are organized under the categories of motivation, interpersonal skills, knowledge base, and application of knowledge base. All full-time faculty at the institution were surveyed as to which characteristics of the Statement of Faculty Excellence should be rated by each of the following: students, peers, immediate supervisor, and self. Over two hundred and fifty faculty responded to the survey. Any characteristic that was suggested by seventy percent or more of the respondents as appropriate for students to rate was selected to be included in the questionnaire.

Twenty of the twenty-nine characteristics from the statement of Faculty Excellence were incorporated into the student Feedback Questionnaire. They are the following: Motivation Are enthusiastic about their work. Set challenging performance goals for students. Project a positive attitude about students' ability to learn.

Are concerned with the many aspects of students as individuals not just in their roles as learners. 
Interpersonal skills

Treat all individuals with respect.

Are available to students.

Listen attentively to what students say.

Are responsive to students' needs.

Are fair in their evaluations of students.

Present ideas clearly.

Create a climate that is conducive to learning. Knowledge Base

Provide perspectives that include a respect for diverse views.

Do their work in a well-prepared and wellorganized manner.

Application of Knowledge Base

Provide students with alternative ways of learning.

Stimulate intellectual curiosity.

Encourage independent thinking.

Encourage students to be analytical listeners. Provide cooperative learning opportunities for students.

Give constructive feedback promptly to students. Give consideration to feedback from students and others.

To formulate the characteristics into proper surveytype items, several forms used at the different campuses of 
Miami-Dade Community college and at other institutions, such as Florida International University and the University of Miami, were used as references. The instrument has twentythree items regarding the instructor's teaching performance and eighteen items related to the student, such as: class attendance; performance in the course; the perceived difficulty of the course; whether the course is required or elective; gender; age; ethnicity; other family and/or work responsibilities; and the number of credits enrolled during the term.

Responses to the items relating to the instructor's teaching performance are based on a common four-point scale (Strongly agree, Agree, Disagree, Strongly disagree) to ensure a forced-choice response from the students. The student was also asked about the length and difficulty of the instrument. Open-ended questions the instructor and the course are also included in the questionnaire. 
Factor analysis was conducted on the twenty-three items related to the instructor's teaching performance from the instrument administered to students in the randomly selected English composition course. Marsh (1987, 1991) argues that since effective teaching is a multidimensional construct, a single score should not be utilized to describe an instructor's rating. But rather, several factors should be elicited from student ratings to provide a better descriptor of the instructor's classroom performance. The student Evaluation of Educational Quality (SEEQ) produced nine first order factors (Marsh, 1987, 1991). These factors are as follows:

Learning/value Instructor enthusiasm organization/clarity Group interaction Individual rapport Breadth of coverage Examinations/grading Assignments/readings Workload/difficulty Haugen (1980) reported on Centra's development of the Student Instructional Report. Six highly intercorrelated factors were obtained, suggesting a single underlying 
factor, but it was determined that the ratings on the six factors were more useful for teaching improvement than obtaining a single score. These factors are:

1. Teacher-student relationship

2. Course objectives and organization

3. Lectures

4. Reading assignments

5. Course difficulty and workload

6. Examinations

Several other researchers have taken a similar approach. Frey (1978) developed a two-factor model. He called these global factors Pedagogical Skill and Rapport. Feldman (1976) proposed twenty categories of effective teaching but also combined these categories into three higher-order clusters that are related to the instructor's role as Presenter, Facilitator and Manager.

Marsh (1991) attempted to fit the nine factors from SEEQ into one, two, three, or four higher-order factors. The four-factor model was the best fit since it accounted for more variation than the other models. However, his results indicate that the nine factors are better at summarizing student evaluations of teaching effectiveness than the higher-order factors' model.

Through the process of factor analysis, it was possible to identify a limited number of factors, representing various combinations of the twenty-three items. The factors 
were then treated as dependent variables and a mean rating was obtained for each of these factors. The relationship between these factors and student ethnicity was examined by means of multivariate analysis of variance.

A total student rating score for all twenty-three items related to instructor's teaching performance was obtained for each instructor by simple addition of the individual mean scores on each item. This total score was used to split the faculty at the median into two categories, higher and lower rated instructors. Multivariate analysis of variance, using the same factors as above as dependent variables, was conducted separately on each group of faculty (higher and lower rated) to determine relationships between instructor and student ethnicity.

\section{Pilot study}

A slightly different version of the instrument was used to conduct a pilot during the spring and summer terms, June and July 1990. Approximately 130 faculty volunteered to participate, generating 2456 completed questionnaires. The instrument's reliability was assessed using the statistical Package for the Social sciences reliability analysis - scale (alpha), providing correlations of individual items to the total mean of as low as .37 to as high as .71 and an overall alpha of .93 . Three of the four items with the lowest 
correlations were items that were negatively phrased. The same items were also phrased as positive statements to determine whether students were carefully reading the questionnaire. Since it was determined that students were, in fact, responding appropriately to the negatively phrased items, the committee chose to remove those items for the Fall Term administration of the student Feedback Questionnaire.

Univariate statistics on whether student ethnicity (Hispanic, black, and white non-Hispanic) provided for differences in the overall score on the twenty-three items related to instructor performance from the student Feedback Questionnaire, resulted in an F-ratio of 2.68 and a significance of .0685 . Student gender provided a $t$-value of 1.02 with a two-tailed probability of .308 . Therefore, it was concluded that, if no other variables were controlled for, student ethnicity and student gender did not contribute to the variability of instructor ratings

Procedures for Data Collection

One course for each full-time faculty was randomly selected from the Faculty Assignment Management Information system (FAMIS). Labels were generated in which information about the course, including the instructor's name, class days and times, and number of students, was printed. 
Using these labels, the campuses' testing departments prepared packets of materials - questionnaires (Appendix B), optical scanning answer sheets, and administration instructions (Appendix C) to the instructor. These packets were distributed by department.

The instructor distributed the materials in class and read the instructions (Appendix C) to the students. The instructions directed students to mark the following on the answer sheet; campus location code, course sequence number, and term. The instructor then selected a student to collect the materials and return them in the original envelope to the testing department or to an alternative location for evening classes. Students were specifically instructed not to provide their name nor student number on the form or answer sheet. To further ensure anonymity, the instructor left the classroom while the students completed the questionnaire.

The completed questionnaires were processed by the campuses' testing departments. The data from the answer sheets were transmitted to the college's mainframe computer to be analyzed and stored. The comments' section of the questionnaires were stored at the campuses' testing departments until the beginning of the following semester, when they were returned to the faculty. 


\section{Data Processing and Analysis}

\section{Hypotheses}

There are three hypotheses tested in this study. The first hypothesis is that there is no significant difference in the mean ratings given to instructors according to student ethnicity. The second hypothesis states that for higher rated instructors, there is no significant difference in the mean ratings according to student ethnicity. The third hypothesis indicates that, for lower rated instructors, students of the same ethnicity as their instructor do not give significantly different ratings than students whose ethnicity is not the same as that of their instructor.

\section{Analysis}

A data file was prepared with the following information; an identification number for each course selected, the instructors' ethnicity and gender, and each student's responses to the questionnaire.

The statistical treatment of the data was conducted using the statistical Package for the Social Sciences (SPSS$\mathrm{X})$ and Statistical Analysis system (SAS). Initial data analysis was conducted, including a frequencies program to validate the data and the determination of the instrument's reliability. The English composition courses (ENC 1100, ENC 
1101, ENC 1102, and ENC 2301) were selected from the data base and utilized in this study.

Factor analysis was conducted on the twenty-three items related to the instructor's teaching performance from the instrument administered to students in the randomly selected English composition course. Maximum likelihood factorial analysis was employed to determine the number of factors with a communality of less than one. The factors selected were then treated as dependent variables and a mean rating was obtained for each of these factors. The relationship between these factors and student ethnicity was examined by means of multivariate analysis of variance.

A total mean student rating score for all twenty-three items related to instructor's teaching performance was obtained for each instructor. This mean rating score was used to split the faculty at the median into two categories, higher and lower rated instructors. Multivariate analysis of variance (MANOVA), using the same factors as above as dependent variables, was conducted separately on each group of faculty (higher and lower rated) to determine relationships between instructor and student ethnicity. 


\section{Limitations of the study}

This study is limited since random selection of students into course sections was not possible. It is also limited because only one class was randomly selected for each full-time faculty member, limiting the number of students that had the opportunity to participate.

Any conclusions drawn may apply only to institutions that resemble Miami-Dade Community College, in the ethnic diversity of their student bodies, such as community colleges in California, Texas, and New York, where minority students may actually be the majority.

While the instrument was developed and has only been administered at Miami-Dade Community College, this is not perceived as a limitation due to the manner in which it was developed, since the instrument is based on the statement of Faculty Excellence. The majority of students at Miami-Dade Community College are not native speakers of English and, even though the committee developing the instrument was very careful about the language construction of the items, second language problems may affect the students' responses.

An assumption in this study is that higher rated and lower rated faculty, as determined by student ratings, will have a proportionate mix of instructors of different ethnicities. 


\section{Summary}

The methodology employed in this study will permit the determination of differences in ratings of instructors due to student ethnicity. The methodology will also allow for the determination of differences, if any, in instructorstudent interactions due to ethnicity. The instrument's reliability will be assessed and recommendations for the future may be developed. 
CHAPTER IV

ANALYSIS OF DATA AND FINDINGS

Overview of the study

In this chapter the statistical analyses of the data collected are presented. Data was analyzed based on the results of a factor analysis of the twenty-three items from the student Feedback Questionnaire that relate to the instructor's teaching performance. The resulting eight Instructor Performance Factors were employed in a multivariate analysis of variance, with faculty ethnicity, student ethnicity, and student gender as independent variables of the analysis. The instrument's validity and reliability are discussed in this chapter.

As mentioned previously, this study was an exploration of the relationship between student and faculty ethnicity and student ratings of faculty performance in an urban community college setting characterized by extensive ethnic diversity. One class was selected for each full-time faculty member teaching English composition (ENC 1100, ENC 1101, ENC 1102, and ENC 2301) at the five campuses and two outreach centers of Miami-Dade Community College. English composition courses were selected in order to minimize or eliminate many sources of variability, such as that of comparing ratings in different academic fields, class sizes, 
workload levels, and electivity of the courses. The instrument used in this study was the student Feedback Questionnaire developed and modified by the Faculty Advancement Procedures subcommittee of the Teaching/Learning Project at Miami-Dade Community College. This instrument consists of twenty-three items regarding the instructor's teaching performance and eighteen items related to student demographics.

Definition of Variables

ETHF Ethnicity of the faculty member - Hispanic, black, or white non-Hispanic

ETHS Ethnicity of the student - Hispanic, black, or white non-Hispanic

SEXS Student gender

F1 Factor 1: Focus on the Individual

F2 Factor 2: Competence in classroom

F3 Factor 3: Approach to Material

F4 Factor 4: Grading Policy

F5 Factor 5: Listening to students

F6 Factor 6: clarity in Course objectives

F7 Factor 7: Fairness of Exams

F8 Factor 8: Active Learning

GRP High and Low Groups of faculty according to a total score on Items 1-23 of the student Feedback 
Questionnaire.

TOTAL Sum of scores on Items 1 through 23

Student Feedback Questionnaire

Factor Analysis

During the Fall 1990 term, 12,729 student Feedback Questionnaire forms were collected by the Institutional Research Department of Miami-Dade Community College, corresponding to one class each for approximately seven hundred full-time instructors. Maximum likelihood factor analysis was employed on the twenty-three items related to the instructor's teaching performance as measured through the student Feedback Questionnaire. This procedure statistically determines whether additional factors are needed during successive trials. As a result of this analysis, eight factors were obtained (Belcher, 1991b). Table 1 shows the eight Instructor Performance Factors with the individual items associated with each factor and the Pearson product moment correlation coefficient for each item. Only items with Pearson $r$ values greater than .30 were selected. Only one item loaded on two factors (Item 12 - "The instructor makes the grading system clear to me."), while one item (Item 23 - "The instructor starts class on time.") did not load on any factor. Its greatest weight (.24) was on Factor 2: 'Competence in the Classroom'. 


\section{TABLE 1}

INSTRUCTOR PERFORMANCE FACTORS

FACTOR LOADINGS FOR STUDENT FEEDBACK QUESTIONNAIRE

Factor 1: Focus on the Individual

.78 Concerned with my progress (Item 5)

.60 Informs regularly about progress (Item 19)

.39 Shows how material benefits outside class (Item 6)

.34 Available for individual help (Item 8)

Factor 2: Competence in classroom

.70 Instructor shows interest in subject (Item 2)

.56 Instructor is prepared for class (Item 1)

.50 Demonstrates knowledge of subject (Item 15)

Factor 3: Approach to Material

.75 Creates atmosphere encouraging learning (Item 14)

.74 Makes course interesting (Item 7)

.45 Presents material clearly (Item 13)

.32 Uses variety of teaching method (Item 16)

Factor 4: Grading Policy

.78 Discussed grading at beginning (Item 22)

.53 Grading system was clear (Item 12) 


\section{TABLE 1 (cont.)}

INSTRUCTOR PERFORMANCE FACTORS

FACTOR LOADINGS FOR STUDENT FEEDBACK QUESTIONNAIRE

Factor 5: Listening to students

.68 Pays attention to my comments (Item 20)

.60 Treats me with respect (Item 21)

.32 Encourages questions in class (Item 9)

Factor 6: Clarity in Course Objectives

.76 objectives and what is taught agree (Item 4)

.55 Distributed course objectives (Item 3)

Factor 7: Fairness of Exams

.78 Exams graded fairly (Item 11)

.36 Evaluation related to material (Item 10)

.31 Grading system clear (Item 12)

Factor 8: Active Learning

.52 Assignments help learning (Item 17)

.49 Encourages thinking for self (Item 18)

Item 23 (Starts class on time) did not load above .30 on any factor. The greatest weight was .24 on Factor 2. 
The amount of variance which is accounted for by the eight Independent Performance Factors, the communality, was calculated for items 1 through 23. Table 2 lists those values. Item 14, 'The instructor creates a classroom atmosphere that encourages me to learn.', with a value of 0.73 , has the highest communality.

\section{TABLE 2}

COMMUNALITY FOR ITEMS 1 THROUGH 23

STUDENT FEEDBACK QUESTIONNAIRE

ITEM

COMMUNALITY

1. Prepared for class

.51

2. Shows interest in subject

3. Distributed course objectives

.50

4. Agreement between objectives and what is taught

.69

5. Concerned with my progress

Shows how material can benefit me

.49

7. Makes course interesting

.70

8. Available for individual help

.43

9. Encourages questions in class

10. Evaluation related to material

11. Evaluation graded fairly

12. Makes grading system clear

13. Presents material clearly

14. Creates atmosphere encouraging learning

15. Demonstrates knowledge of subject

16. Uses variety of teaching methods

.36

17. Assignments help learning

.51

18. Encourages thinking for myself

19. Informs me about my progress

20. Pays attention to my comments

21. Treats me with respect

22. Discussed grading at beginning

23. Starts class on time 
Other items with high communalities are: item 5, 'The instructor is concerned with my progress.', 0.71 ; item 7 , 'The instructor makes the course interesting.', 0.70; and item 4, 'There is agreement between the objectives/ competencies in this course and what is taught.', 0.69 .

Validity and Reliability of the student Feedback Questionnaire

Validity

The similarity of the Instructor Performance Factors (F1 to F8) obtained on the student Feedback Questionnaire with those of the student Evaluation of Educational Quality (SEEQ) (Marsh, 1987, 1991) and of the student Instructional Report (SIR) (Haugen, 1980), provides evidence for the content validity of the student Feedback Questionnaire. These factors also demonstrate that student ratings measure distinct components of teaching effectiveness. Content validity is also supported by the similarity of the process of development of these instruments. The student Feedback Questionnaire, as well as other instruments, was constructed in the following manner. Findings from previous research were employed to construct a first draft, which was administered to a group of classes. Feedback was obtained from faculty and students, then the instrument was revised and administered to a larger group of students. Further feedback was obtained before finalizing the instrument. 


\section{Reliability}

The instrument's reliability (Questions 1-23 -

'instructor's teaching performance') was assessed using the statistical Package for the Social sciences reliability analysis - scale (alpha). An overall alpha of 0.94 was obtained. The reliability of the eight Instructor Performance Factors was also determined, producing an overall alpha of 0.79 . Individual factors' reliabilities are reported in Table 3 .

\section{TABLE 3}

RELIABILITY OF FACTORS IN THE STUDENT FEEDBACK QUESTIONNAIRE

Factor 1: Focus on the Individual

Factor 2: Competence in Classroom

Factor 3: Approach to Material

Factor 4: Grading Policy

Factor 5: Listening to students

Factor 6: Clarity in course objectives

Factor 7: Fairness of Exams

Factor 8: Active Learning
$=0.79$

$=0.66$

$=0.84$

$=0.73$

$=0.77$

$=0.73$

$=0.75$

$=0.69$ 
Descriptive statistics for the Group

This study was limited to randomly selected English composition courses taught by full-time faculty during the Fall 1990 term at Miami-Dade Community College. A total of 1147 Student Feedback Questionnaire forms were completed in 72 sections of English composition during the Fall 1990 term. Table 4 shows the ethnic composition of the students.

TABLE 4

ETHNICITY OF STUDENTS

\begin{tabular}{lccc}
\hline ETHNICITY & NUMBER & $\begin{array}{c}\text { PERCENT } \\
\text { STUDY }\end{array}$ & $\begin{array}{c}\text { PERCENT } \\
\text { M-DCC }\end{array}$ \\
HISPANIC & 605 & 54.0 & 54.9 \\
BLACK & 175 & 15.6 & 16.5 \\
WHITE NON-HISPANIC & 235 & 21.0 & 26.3 \\
OTHER & 106 & 9.4 & 2.3 \\
TOTAL & 1121 & 100.0 & 100.0 \\
MISSING 26 & & & \\
& & &
\end{tabular}

By selecting only English composition courses many sources of variability were minimized or eliminated. These sources included differences on student ratings that may occur due to the academic field being taught, class size, workload and difficulty level, and the electivity of the 
course - all students are required to successfully complete English composition courses.

Table 5 gives the breakdown for students by gender. There are more females than males in the study, which is similar to the general population at the institution.

TABLE 5

STUDENT GENDER

\begin{tabular}{lccc}
\hline GENDER & NUMBER & $\begin{array}{c}\text { PERCENT } \\
\text { STUDY }\end{array}$ & $\begin{array}{c}\text { PERCENT } \\
\text { M-DCC }\end{array}$ \\
MALE & 450 & 40.0 & 42.5 \\
FEMALE & 675 & 60.0 & 57.5 \\
TOTAL & 1125 & 100.0 & 100.0 \\
MISSING 22 & & & \\
\hline
\end{tabular}


Table 6 provides the breakdown for faculty ethnicity. The percentage of Hispanic instructors teaching English composition is lower than the percentage for Hispanic faculty throughout the institution.

TABLE 6

FACULTY ETHNICITY

\begin{tabular}{lccc}
\hline ETHNICITY & NUMBER & $\begin{array}{c}\text { PERCENT } \\
\text { STUDY }\end{array}$ & $\begin{array}{c}\text { PERCENT } \\
\text { M-DCC }\end{array}$ \\
HISPANIC & 8 & 11.1 & 16.3 \\
BLACK & 12 & 16.7 & 12.1 \\
WHITE NON-HISPANIC & 52 & 72.2 & 70.5 \\
TOTAL & 72 & 100.0 & 100.0 \\
\hline
\end{tabular}

Table 7 consists of a crosstabulation for faculty ethnicity versus student ethnicity. It shows the number of students (and percentages) that were taught by faculty of each ethnicity. For example, for Hispanic faculty there were only 16 white non-Hispanic students in their classes. This represents a 6.8 percent of all white non-Hispanic students, a lower than expected number, since Hispanic faculty taught approximately 11 percent of the course sections included in this study. On the other hand, while white non-Hispanic faculty taught an average of 72.5 percent 
of all students, they taught 80 percent of the white nonHispanic students.

TABLE 7

NUMBER OF STUDENTS ENROLLED ACCORDING TO ETHNICITY OF STUDENT AND ETHNICITY OF FACULTY

\begin{tabular}{|c|c|c|c|c|c|c|c|}
\hline \multicolumn{2}{|c|}{$\begin{array}{l}\text { FACULTY } \\
\text { ETHNICITY }\end{array}$} & \multirow{2}{*}{$\begin{array}{l}\text { HISPANIC } \\
5(10.9 \%)\end{array}$} & \multicolumn{2}{|c|}{$\begin{array}{l}\text { STUDENT } \\
\text { BLACK }\end{array}$} & $\begin{array}{l}\text { ETHNICITY } \\
\text { WHITE N-H }\end{array}$ & \multicolumn{2}{|c|}{ TOTAL } \\
\hline HISPANIC & 66 & & 24 & $(13.7 \%)$ & $16(6.8 \%)$ & 106 & $(10.4 \%)$ \\
\hline BLACK & 116 & $(19.1 \%)$ & 27 & $(15.4 \%)$ & $31(13.2 \%)$ & 174 & $(17.1 \%)$ \\
\hline $\begin{array}{c}\text { WHITE } \\
\mathrm{N}-\mathrm{H}\end{array}$ & 425 & $(70.0 \%)$ & 124 & $(70.9 \%)$ & $188(80.0 \%)$ & 737 & $(72.5 \%)$ \\
\hline TOTAL & 607 & $(100.0 \%)$ & 175 & $(100.0 \%)$ & $235(100.0 \%)$ & 1017 & $(100.0 \%)$ \\
\hline
\end{tabular}

Multivariate and Univariate Analyses

Multivariate analysis of variance was carried out using the eight Instructor Performance Factors listed in Table 1 as the dependent variables. The independent variables in the analysis were the ethnicity of the student (ETHS), the ethnicity of the instructor (ETHF), and the gender of the student (SEXS). Because of the large number of tests performed, the statistical analysis was set at the .01 level.

As a precautionary measure, student gender was added as a post-hoc test even though the pilot study from the summer 
term did not indicate that student gender affected ratings. However, the data from the spring/summer term pilot study was only analyzed for gender differences using a simple ttest with no control for variables such as academic field, class size, and workload or difficulty level. In this study only English composition courses were analyzed, thereby controlling for many variables.

The analysis was carried out using every instructor and all of the students who reported their ethnicity as black, white non-Hispanic, or Hispanic. Students who classified themselves as American Indian, Asian, Alaskan Native, or who did not mark the question have been excluded from this analysis.

\section{Test of Hypothesis 1}

The first hypothesis states that there is no significant difference in the mean ratings given to instructors according to student ethnicity. The analysis for this hypothesis included the total sample of 948 students in 72 sections of English composition courses who had self-identified as Hispanic, black, or white nonHispanic.

\section{Multivariate Analysis for Hypothesis 1}

Multivariate statistics were examined to provide an analysis of the effects of the different independent 
variables, student ethnicity (ETHS), faculty ethnicity (ETHF) and student gender (SEXS) on student ratings. Table 8, which gives the Wilk's Lambda, F-ratio and significance level for the independent variables and their interactions, shows that only student gender is significant at the .01 level when the eight Instructor Performance Factors are analyzed simultaneously. Student gender produced a Wilk's Lambda of .979 with an F-ratio of 2.61 (.0079).

TABLE 8

HYPOTHESIS 1

MULTIVARIATE ANALYSIS

TOTAL SAMPLE ( $N=948$ STUDENTS)

WILK'S LAMBDA, F-RATIOS AND SIGNIFICANCE LEVELS

\begin{tabular}{lccc}
\hline FACTOR & WILK'S LAMBDA & F-RATIO & SIGN. LEVEL \\
ETHF & .979 & 1.23 & .235 \\
ETHS & .974 & 1.54 & .0787 \\
SEXS & .979 & 2.61 & $.0079 *$ \\
ETHS*ETHF & .959 & 1.21 & .198 \\
ETHS*SEXS & .986 & 0.80 & .683 \\
ETHF*SEXS & .983 & 0.96 & .494 \\
ETHS*ETHF*SEXS & .981 & 0.56 & .977 \\
* Significance IesS than .01 & & \\
\end{tabular}




\section{Univariate Analysis for Hypothesis 1}

Univariate statistics indicate that when the analysis was carried out on the total sample $(N=948)$ in 72 course sections, there were no significant differences on factors F1 to F8 due to student ethnicity. Table 9 shows the factors.

\section{TABLE 9 \\ HYPOTHESIS 1 UNIVARIATE ANALYSIS \\ TOTAL SAMPLE ( $\mathrm{N}=948$ STUDENTS) \\ INSTRUCTOR PERFORMANCE FACTORS \\ SIGNIFICANT DIFFERENCES \\ F-RATIOS AND SIGNIFICANCE LEVELS}

\section{FACTOR}

F1 Focus on the Individual

F2 Competence in Classroom

F3 Approach to Material

F4 Grading Policy

F5 Listening to students

F6 Clarity in Course objectives

F7 Fairness of Exams

F8 Active Learning

* Significance less than .01
NO SIGN. DIFF.

ETHF * ETHS

$2.81(.0246)$

ETHF * ETHS

$3.38(.0093)$

SEXS

$4.89(.0272)$

ETHF * ETHS

$2.40(.0483)$

SEXS

$5.75(.0167)$

NO SIGN. DIFF.

NO SIGN. DIFF. 
There was an interaction effect for student ethnicity with instructor ethnicity (ETHS*ETHF) for F3: 'Approach to Material' at the .01 level. The remaining Instructor Performance Factors provided no significant differences at the .01 level for the independent variables of student ethnicity, faculty ethnicity, and student gender. However, for F2: 'Competence in Classroom' and F5: 'Listening to Students', there was an interaction effect for student ethnicity with instructor ethnicity (ETHS*ETHS) at the .05 level. Additionally, for student gender there was a difference at the .05 level for factors F4: 'Grading Policy', and F6: 'Clarity In Course objectives'. To provide additional information, these factors are discussed in a later section of this chapter.

\section{F3: 'Approach to Material'}

As shown in Table 9, there was a significant difference (F-ratio of 3.38 at a significance level of .0093) for Factor 3: 'Approach to Material' on the means for the interaction of faculty ethnicity with student ethnicity (ETHF * ETHS). Table 10 shows the mean scores for Factor 3. 
TABLE 10

HYPOTHESIS 1

UNIVARIATE ANALYSIS

F3: 'APPROACH TO MATERIAL'

NOTE: HIGHER MEANS ARE LESS FAVORABLE RATINGS

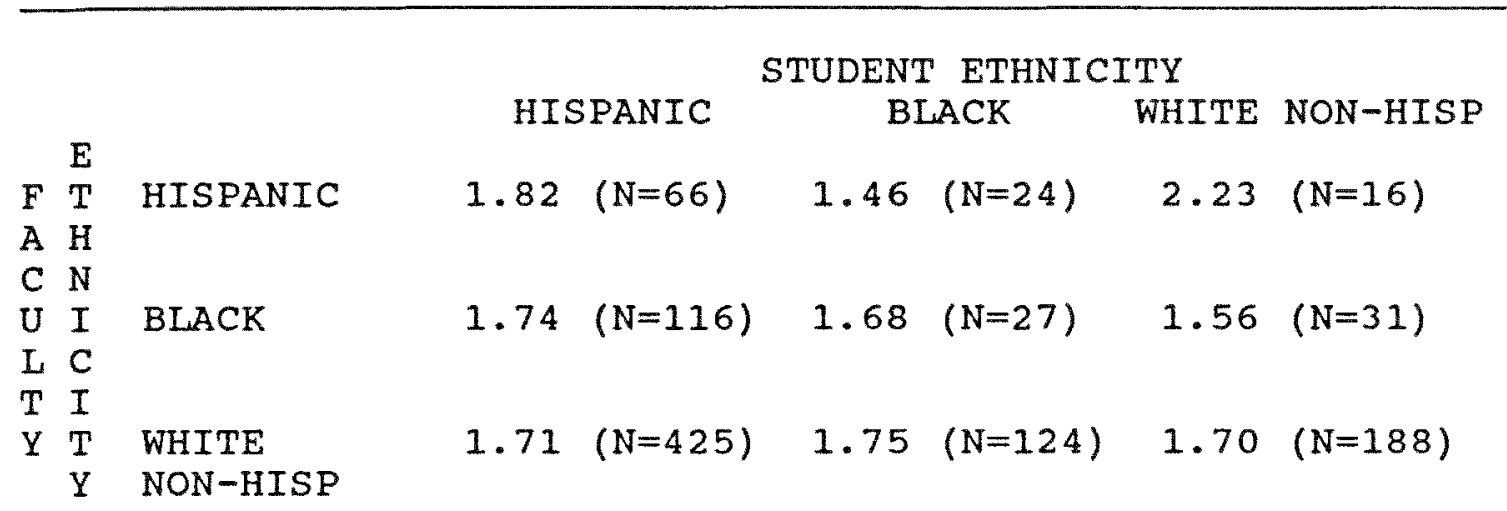

It was determined that there were no significant differences due to student ethnicity for black or white nonHispanic instructors on this factor. However, students of different ethnicities - Hispanic, black and white nonHispanic - differed on how they rated Hispanic faculty (means of 1.82 for Hispanic students, 1.46 for black students, and 2.23 for white non-Hispanic students). The significance of the pairwise differences are as follows:

For Hispanic faculty:

White non-Hispanic vs. Hispanic students $\quad .0371$ White non-Hispanic vs. black students $.0006 *$ Hispanic vs. black students $\quad .0470$

* Significance less than .01

Figure 1 shows the plot for faculty ethnicity by 
student ethnicity for mean scores for Factor 3.
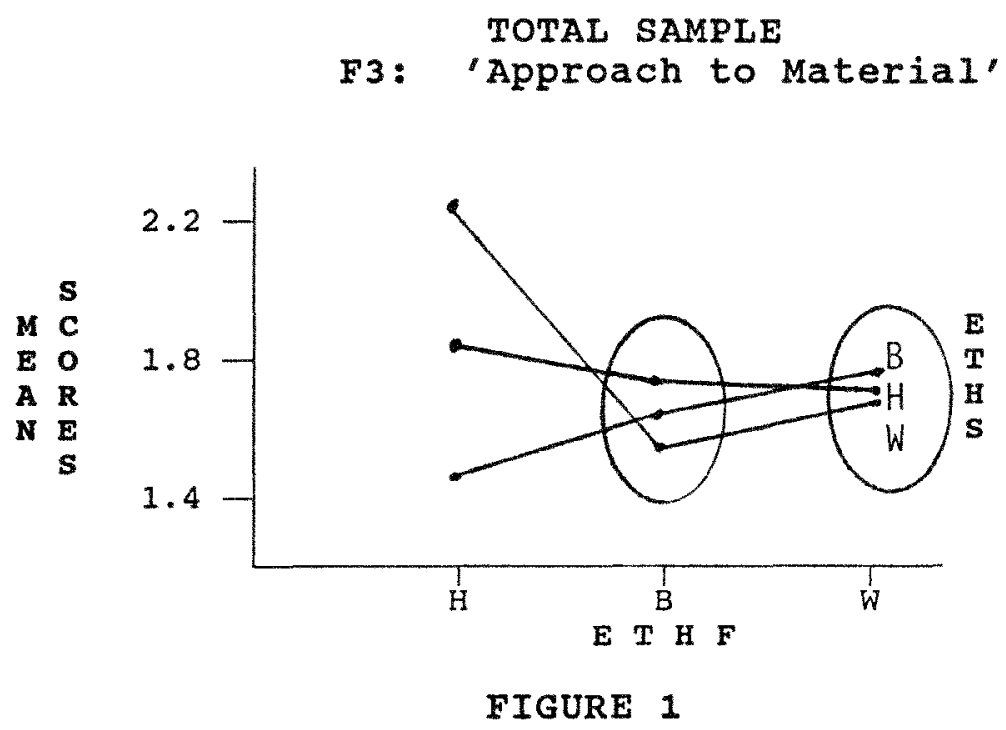

Only the difference in means provided by white nonHispanic students $(2.23)$ and black students $(1.46)$ is significant at the .01 level.

Summary of Hypothesis 1

Hypothesis 1 stated that there is no significant difference in the mean ratings given to instructors according to student ethnicity. The hypothesis fails to be rejected for the multivariate analysis, since student ethnicity provided no significant differences in the ratings of instructors when all factors were considered simultaneously. The univariate analysis demonstrates that the hypothesis is rejected only for Factor 3: 'Approach to Material' where there was found to be an interaction for student ethnicity with instructor ethnicity. Hispanic 
faculty appeared to be rated less favorably by white nonHispanic students (Mean $=2.23$ ) than they were rated by black students (Mean $=1.46)$ (only a very small sample of white non-Hispanic students, $N=16$, was enrolled in courses taught by Hispanic faculty). The results also. indicate that black students rated Hispanic instructors higher than Hispanic students. 
Separation of Faculty into Higher and Lower Rated Groups

For the second and third hypotheses, English composition faculty were separated into two groups depending on a total score obtained by adding the average ratings for each of the twenty-three items from the student Feedback Questionnaire that related to teaching performance. Table 11 shows the lists of scores and ethnicities for the higherrated and lower-rated groups of faculty. There are more instructors listed in the higher-rated group because it was decided that several instructors had very similar total scores (35.29. 35.50, and 35.55) that should not be separated into different groups.

The total scores ranged from a low (best score, since a score of 1 was given for the answer 'strongly agree') of 23.14 to a high (worse score) of 53.56. Note that the score of 23.14 on 23 items indicates an average of 1.006 , almost a 'perfect' score for that instructor. The score of 53.56 averages to a rating of 2.329 , indicating that this instructor received almost as many negative ratings ( 3 for 'Disagree' and 4 for 'Strongly disagree') as positive ratings. 


\section{TABLE 11}

FACULTY SEPARATED INTO HIGHER RATED

AND LOWER RATED GROUPS BY TOTAL SCORE (ITEMS 1-23)

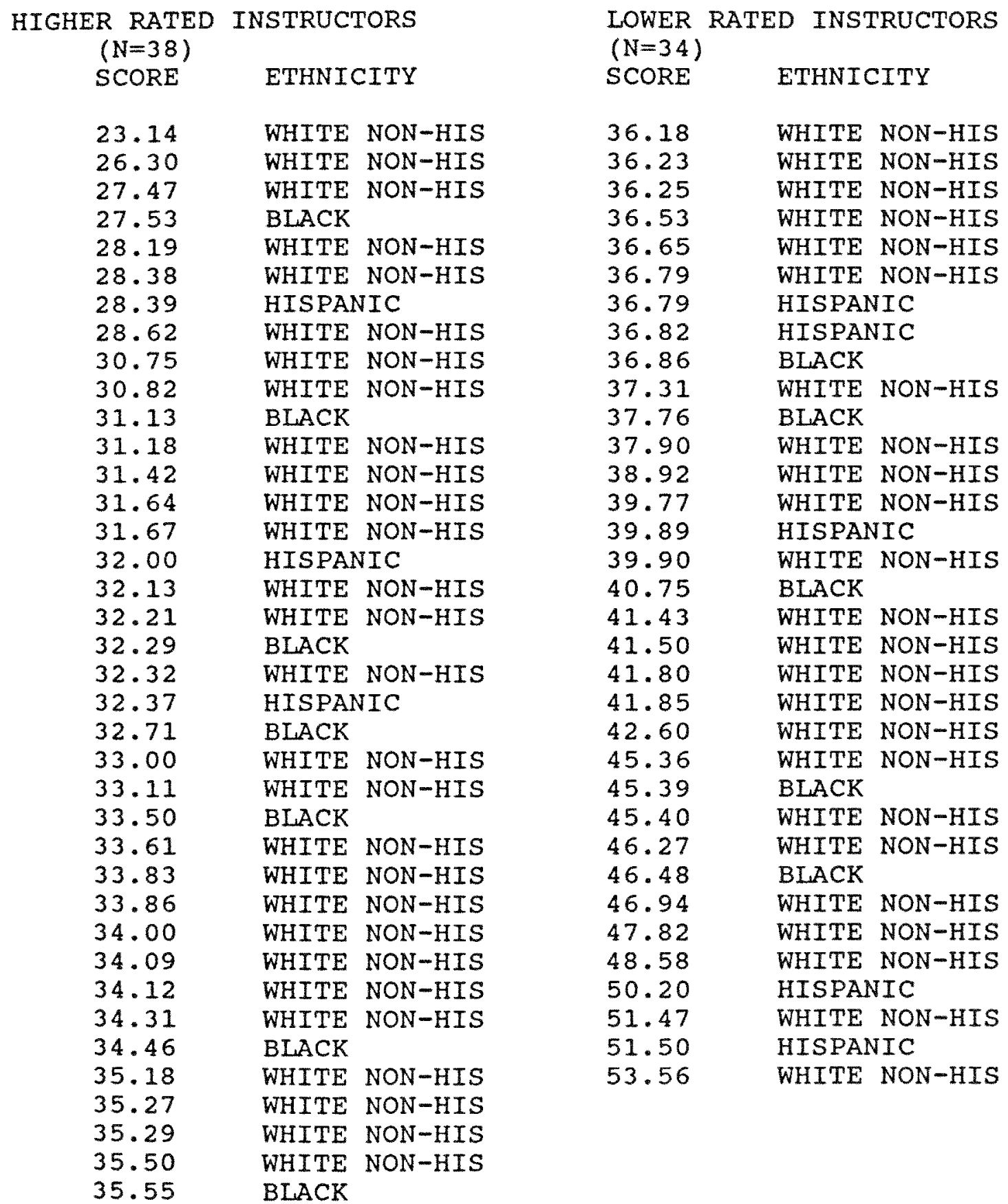


Test of Hypothesis 2

The second hypothesis states that for higher rated instructors, there is no significant difference in the mean ratings according to student ethnicity.

The distribution of ethnicity for higher rated instructors is shown in Table 12. The distributions are similar to those of the population of instructors collegewide except that Hispanic instructors appear to be underrepresented in this group, while the number of black instructors is slightly above the average.

TABLE 12

HYPOTHESIS 2

ETHNICITY OF

HIGHER RATED INSTRUCTORS

\begin{tabular}{lccc}
\hline ETHNICITY & NUMBER & $\begin{array}{c}\text { PERCENT } \\
\text { STUDY }\end{array}$ & $\begin{array}{c}\text { PERCENT } \\
\text { M-DCC }\end{array}$ \\
HISPANIC & 3 & 7.9 & 16.3 \\
BLACK & 7 & 18.4 & 12.1 \\
WHITE NON-HIS & 28 & 73.7 & 70.5 \\
TOTAL & 38 & 100.0 & 100.0 \\
\hline
\end{tabular}

Table 13 consists of a crosstabulation for faculty ethnicity versus student ethnicity for higher rated instructors. Since only three of the eight Hispanic faculty were in the higher rated group, there was a total of only 4 
white non-Hispanic students in those three classes. Due to unequal sample sizes, which require weighted means for comparisons to be valid, the statistical Analysis system (SAS) software was used throughout the multivariate analyses.

TABLE 13

HYPOTHESIS 2

STUDENT ETHNICITY VERSUS FACULTY ETHNICITY NUMBER OF STUDENTS IN CLASSES

FOR HIGHER RATED INSTRUCTORS

\begin{tabular}{lcccc}
\hline & \multicolumn{5}{c}{ STUDENT ETHNICITY } \\
FACULTY & HISPANIC & BLACK & WHITE NON-HISP & TOTAL \\
ETHNICITY & 20 & 12 & 4 & 36 \\
HISPANIC & 49 & 21 & 16 & 86 \\
BLACK & 228 & 62 & 85 & 375 \\
WHITE NON-HISP & 297 & 95 & 105 & 497 \\
TOTAL & & & & \\
\hline
\end{tabular}

\section{Multivariate Analysis for Hypothesis 2}

Multivariate statistics were examined to provide an analysis of the effects of the different independent variables, student ethnicity (ETHS), faculty ethnicity (ETHF) and student gender (SEXS) on student ratings for higher rated instructors. Table 14, which gives the wilk's Lambda, F-ratio and significance level for the main effects 
and interactions for the independent variables, shows that no independent variable is significant at an alpha of .01 when the eight Instructor Performance Factors are analyzed simultaneously. The only independent variable that may be of interest is that of student gender with a Wilk's Lambda of .966 with an F-ratio of $2.09(.0349)$. This factor will be discussed later in this chapter.

TABLE 14

HYPOTHESIS 2

MULTIVARIATE ANALYSIS

HIGHER RATED INSTRUCTORS ( $N=497$ STUDENTS)

WILK'S LAMBDA, F-RATIOS AND SIGNIFICANCE LEVELS

\begin{tabular}{lccc}
\hline FACTOR & WILK'S LAMBDA & F-RATIO & SIGN. LEVEL \\
ETHF & .973 & 0.80 & .682 \\
ETHS & .960 & 1.23 & .242 \\
SEXS & .966 & 2.09 & .0349 \\
ETHS*ETHF & .935 & 1.01 & .453 \\
ETHF*SEXS & .975 & 0.75 & .746 \\
ETHS*SEXS & .980 & 0.61 & .878 \\
ETHF*ETHS*SEXS & .951 & 0.74 & .851
\end{tabular}

Univariate Analysis for Hypothesis 2

Univariate statistics indicate that when the analysis was carried out on the higher rated instructors ( $N=38$ instructors with 497 students), there were no significant 
differences in the Instructor Performance Factors according to student ethnicity, faculty ethnicity, or student gender.

\section{Summary for Hypothesis 2}

Hypothesis 2 stated that for higher rated instructors, there is no significant difference in the mean ratings according to student ethnicity. The hypothesis fails to be rejected for the multivariate analysis, since student ethnicity provided no significant differences in the ratings of instructors. Moreover, for the univariate analysis, Hypothesis 2 is not rejected, since no independent variable was significant at the .01 level.

\section{Test of Hypothesis 3}

The third hypothesis states that for lower rated instructors, students of the same ethnicity as their instructor do not give significantly different ratings than students whose ethnicity is not the same as their instructor. The distribution of ethnicity for lower rated instructors is shown in Table 15. The distributions are similar to those of the population of instructors collegewide. 
TABLE 15

HYPOTHESIS 3

ETHNICITY OF

LOWER RATED INSTRUCTORS

\begin{tabular}{lccc}
\hline ETHNICITY & NUMBER & $\begin{array}{c}\text { PERCENT } \\
\text { STUDY }\end{array}$ & $\begin{array}{c}\text { PERCENT } \\
\text { M-DCC }\end{array}$ \\
HISPANIC & 5 & 14.7 & 16.3 \\
BLACK & 5 & 14.7 & 12.1 \\
WHITE NON-HIS & 24 & 70.6 & 70.5 \\
TOTAL & 34 & 100.0 & 100.0 \\
\hline
\end{tabular}

Table 16 consists of a crosstabulation for faculty ethnicity versus student ethnicity for lower rated instructors. In this case, only four black students were found in classes taught by black instructors while 11 black and 11 white non-Hispanic students were enrolled in classes taught by Hispanic faculty, very small numbers as in the higher rated group. 
TABLE 16

HYPOTHESIS 3

STUDENT ETHNICITY VERSUS FACULTY ETHNICITY

LOWER-RATED INSTRUCTORS

\begin{tabular}{lcccc}
\hline & \multicolumn{3}{c}{ STUDENT ETHNICITY } \\
FACULTY & HISPANIC & BLACK & WHITE & NON-HISP TOTAL \\
ETHNICITY & 41 & 11 & 11 & 63 \\
HISPANIC & 59 & 4 & 13 & 76 \\
BLACK & 168 & 56 & 88 & 312 \\
WHITE NON-HISP & 268 & 71 & 112 & 451 \\
TOTAL & & & \\
\hline
\end{tabular}

Multivariate Analysis for Hypothes is 3

Multivariate statistics were examined to provide an analysis of the effects of the different independent variables, student ethnicity (ETHS), faculty ethnicity (ETHF) and student gender (SEXS), on student ratings for lower rated instructors $(N=34$ instructors with 451 students). Table 17 gives the Wilk's Lambda, F-ratio and significance level for main effects and interactions. student ethnicity, instructor ethnicity and their interaction showed no significant difference at the .01 level when the eight Instructor Performance Factors were analyzed simultaneously. Student gender, with a wilk's Lambda of .955 and an F-ratio of 2.54 (.0104), was significant at an alpha of .01. Faculty ethnicity, with a 
Wilk's Lambda of .935 and an F-ratio of 1.82 at a significance level of .0248 , will be discussed in a subsequent section of this chapter.

\section{TABLE 17}

HYPOTHESIS 3

MULTIVARIATE ANALYSIS

LOWER RATED INSTRUCTORS ( $N=451$ STUDENTS)

WILK'S LAMBDA, F-RATIOS AND SIGNIFICANCE LEVELS

\begin{tabular}{lccc}
\hline FACTOR & WILK'S LAMBDA & F-RATIO & SIGN . LEVEL \\
ETHF & .935 & 1.82 & .0248 \\
ETHS & .960 & 1.09 & .356 \\
SEXS & .955 & 2.54 & $.0104 *$ \\
ETHF*ETHS & .919 & 1.13 & .279 \\
ETHF*SEXS & .955 & 1.24 & .230 \\
ETHS*SEXS & .970 & 0.80 & .683 \\
ETHF*ETHS*SEXS & .935 & 0.90 & .632 \\
* Significance 1 less than .01 & & \\
\end{tabular}

Univariate Analysis for Hypothes is 3

Univariate statistics indicate that when the analysis was carried out on the lower rated instructors, student ethnicity, instructor ethnicity and their interaction showed no significant difference at the .01 level for any of the eight Instructor Performance Factors. As shown in Table 18, only the independent variable student gender provided a 
significant difference at the .01 level for factor F4: 'Grading Policy'.

\section{TABLE 18 \\ HYPOTHESIS 3 \\ UNIVARIATE ANALYSIS \\ LOWER RATED INSTRUCTORS ( $=451$ STUDENTS) \\ INSTRUCTOR PERFORMANCE FACTORS \\ SIGNIFICANT DIFFERENCES \\ F-RATIOS AND SIGNIFICANCE LEVELS}

FACTOR

F1 Focus on the Individual

NO SIGN. DIFF.

F2 Competence in classroom

ETHF * ETHS

$2.41(.0486)$

F3 Approach to Material

ETHF * ETHS

$3.10(.0155)$

F4 Grading Policy

SEXS

$7.24(.0074) *$

F5 Listening to students

ETHF

$3.04(.0490)$

F6 clarity in course Objectives

NO SIGN. DIFF.

F7 Fairness of Exams

NO SIGN. DIFF.

F8 Active Learning

NO SIGN. DIFF.

* Significance less than .01

There were differences at the .05 level for instructor ethnicity or the interaction between student and instructor ethnicity on Instructor Performance Factors F2: 'Competence in Classroom', F3: 'Approach to Material', and F5: 
'Listening to students'. These will be discussed in a subsequent section of this chapter.

Summary for Hypothesis 3

Hypothesis 3 stated that for lower rated instructors, students of the same ethnicity as their instructor do not give significantly different ratings than students whose ethnicity is not the same as their instructor. The hypothesis is not rejected for the multivariate analysis since student ethnicity did not provide a significant difference. For the univariate analysis, the hypothesis is not rejected, since only student gender, as in the multivariate analysis, provided a significant difference at the .01 level.

other Findings of Interest

Several of the results were not significant at the .01 level or involved the independent variable student gender. These results will be discussed since they provide additional information and will help to formulate subsequent studies.

\section{Total Sample}

Univariate statistics indicate that when the analysis was carried out on the total sample ( $N=948$ students in 72 course sections), as shown in Table 9, the following 
independent variables led to differences at the .05 level with respect to Instructor Performance Factors: interactions between student and instructor ethnicity (ETHS * ETHF) for F2: 'Competence in Classroom' and F5: 'Listening to Students'; and student gender (SEXS) for F4: 'Grading Policy' and F6: 'Clarity on Course objectives'.

F2: 'Competence in the Classroom'

For Factor 2: 'Competence in the classroom', when the analysis was conducted on the total sample there was a significant difference (F-ratio of $2.81, p=.0246$ ) on the means for the interaction of faculty ethnicity with student ethnicity (ETHF * ETHS). Table 19 shows the mean scores for Factor 2 .

\section{TABLE 19}

HYPOTHESIS 1

TOTAL SAMPLE (N=948 STUDENTS)

F2: 'COMPETENCE IN CLASSROOM'

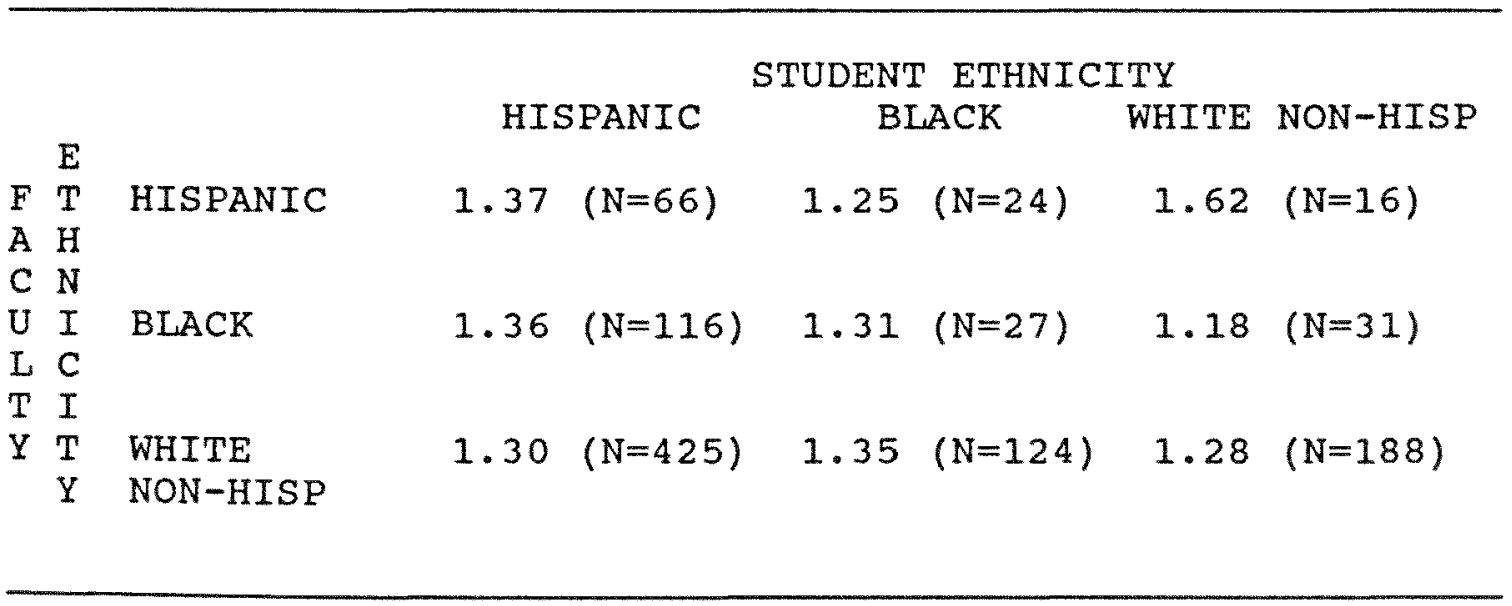


Using pairwise differences, it was determined that there were no significant differences due to student ethnicity for black and white non-Hispanic instructors. However, for Hispanic faculty, white non-Hispanic students $($ Mean $=1.62)$ rated these faculty significantly different (worse scores) than either Hispanic (Mean $=1.37$ ) or black students $($ Mean $=1.25)$. The significance of the pairwise differences are as follows:

For Hispanic faculty:

White non-Hispanic vs. Hispanic students $\quad .0491$ White non-Hispanic vs. black students .0123

Figure 2 shows the plot for faculty ethnicity by student ethnicity for mean scores for Factor 2 .

TOTAL SAMPLE

F2: 'COMPETENCE IN CLASSROOM'

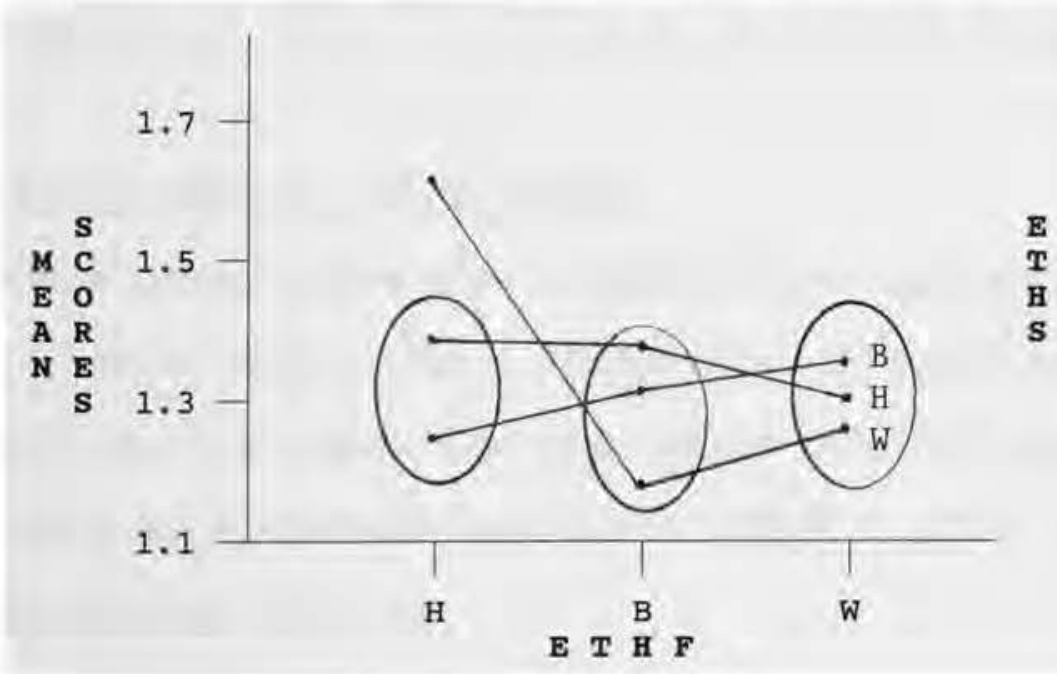

FIGURE 2 
F4: 'Grading Policy' and F6: 'Clarity in course

objectives'

For Factor 4 and Factor 6, student gender (SEXS) gave significant differences at the .05 level. For both of these factors, males gave worse scores (the lower the score the higher the rating since the statement 'strongly Agree' had a value of 1 in the questionnaire), as shown in Table 20.

\author{
TABLE 20 \\ HYPOTHESIS 1 \\ TOTAL SAMPLE (N=948 STUDENTS) \\ UNIVARIATE STATISTICS FOR STUDENT GENDER (SEXS)
}

\begin{tabular}{|c|c|c|c|c|}
\hline \multirow[b]{2}{*}{ FACTOR } & \multicolumn{2}{|c|}{ MEAN } & \multirow[t]{2}{*}{ F-RATIO } & \multirow[t]{2}{*}{ SIGN. } \\
\hline & MALE $\quad(N=450)$ & FEMALE $\quad(N=675)$ & & \\
\hline F4 & 1.698 & 1.522 & 4.89 & .0272 \\
\hline F6 & 1.646 & 1.487 & 5.75 & .0167 \\
\hline
\end{tabular}

F5: 'Listening to students'

Once again, when the analysis was conducted on the total sample, there was a difference (F-ratio of 2.81 , $\mathrm{p}=.0246$ ) on the means for the interaction of faculty ethnicity with student ethnicity (ETHF * ETHS) for F5: 'Listening to students'.

Table 21 shows the means scores for Factor 5 as plotted in Figure 3 . 
TABLE 21

HYPOTHESIS 1

TOTAL SAMPLE ( $\mathrm{N}=948$ STUDENTS)

F5: 'LISTENING TO STUDENTS'

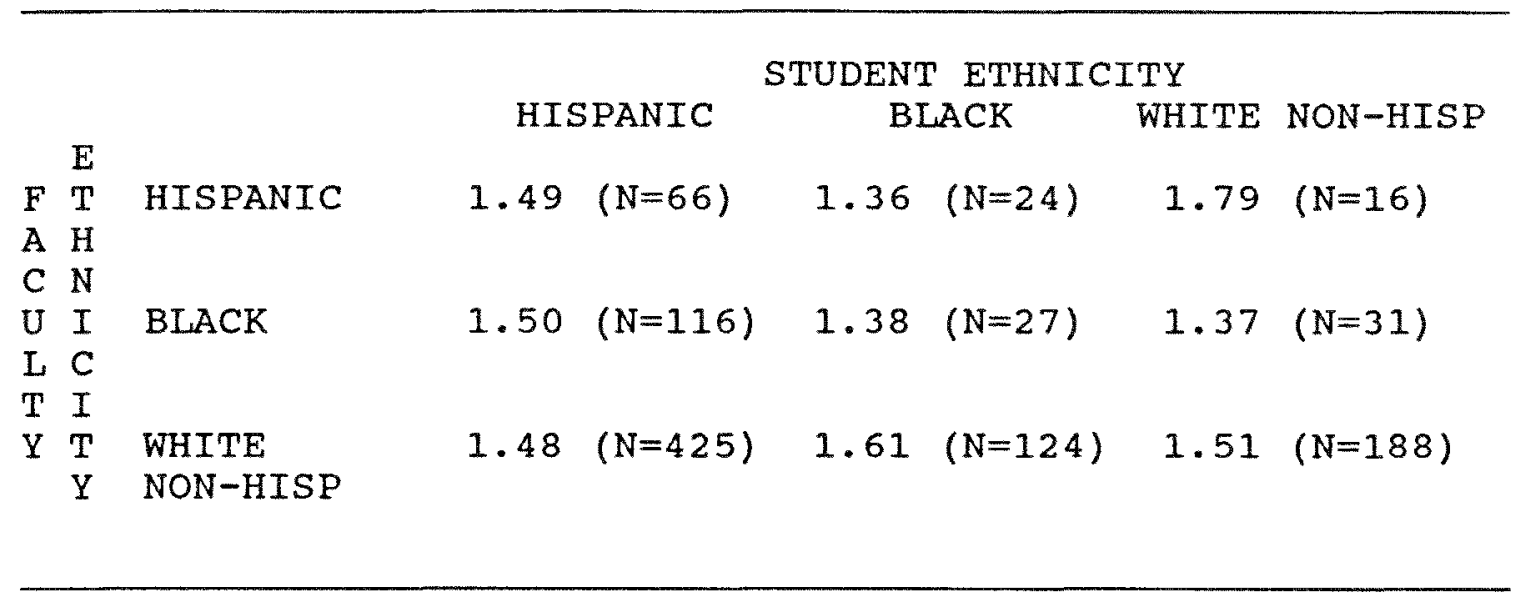

Pairwise differences indicate that black students (Mean $=1.36)$ and white non-Hispanic students $($ Mean $=1.79)$ differed on how they rated Hispanic faculty. Also Hispanic students $($ Mean $=1.48)$ and black students $($ Mean $=1.61)$ differed on the ratings they gave white non-Hispanic faculty for this factor. The significance of the pairwise differences are as follows:

For Hispanic faculty:

White non-Hispanic vs. black students .0223

For white non-Hispanic faculty:

Hispanic and black students

Figure 3 shows the plot for faculty ethnicity by student ethnicity for mean scores for Factor 5. 




FIGURE 3

Hispanic faculty appeared to be rated less favorably by white non-Hispanic students for the Instructor Performance Factors F2, F3, and F5, but since there were only 16 white non-Hispanic students in classes taught by Hispanic faculty, the sample is too small for definitive conclusions. Also, on Factor 5, Hispanic students (Mean $=1.48)$ gave better ratings to white non-Hispanic faculty than black students $($ Mean $=1.61)$ did.

\section{Higher rated instructors}

As previously stated, for those instructors that received better mean total scores (higher rated) on the twenty-three items of the student Feedback Questionnaire that relates to instructor performance, there was no independent variable that provided a significance at the .01 
level for the multivariate analysis. However, there was one independent variable that resulted in a significance of .05, student gender (SEXS), which gave an F-ratio of 2.09 with a significance of .0349. (Table 14). For the univariate analysis, none of the independent variables had an F-ratio with a significance of less than 0.5 on the eight Instructor Performance Factors (F1-F8).

\section{Lower rated instructors}

For instructors that were classified as lower rated due to their total score on the twenty-three items from the student Feedback Questionnaire concerned with instructor performance, only student gender (SEXS) had a significance at the .01 level for the multivariate analysis, while the ethnicity of the faculty (ETHF) had an F-ratio of 1.82 $(.0248)$ in the multivariate analysis (Table 17). Therefore, it appears that student ethnicity is not a factor in ratings of lower rated instructor while instructor ethnicity is. The univariate analysis (Table 18) showed which Instructor Performance Factors had significantly different scores due to the ethnicity of the instructor, or an interaction between instructor and student ethnicity.

For the univariate analysis, student gender provided a significant difference at the .01 level for the Instructor Performance Factor 4: 'Grading Policy'. There were differences at the .05 level for Instructor Performance 
Factors F2: 'Competence in Classroom', F3: 'Approach to Material', and F5: 'Listening to students'.

F4: 'Grading Policy'

For Factor 4: 'Grading Policy', student gender (SEXS) gave a significant difference (F-ratio of 7.24 with a significance of .0074 ). Males gave worse scores (Mean = 2.02) (the lower the score the higher the rating since the statement 'Strongly Agree' had a value of 1 in the questionnaire) than females $($ Mean $=1.67)$.

TABLE 22

HYPOTHESIS 3

LOWER RATED INSTRUCTORS ( $=451$ STUDENTS)

UNIVARIATE STATISTICS

FOR STUDENT GENDER (SEXS)

F4: 'GRADING POLICY'

$\begin{array}{ll} & \text { MEAN } \\ \text { MALE } & 2.02 \\ \text { FEMALE } & 1.67\end{array}$

F2: 'Competence in the classroom'

For Factor 2: 'Competence in the Classroom', when the analysis was conducted on the lower rated group, there was a difference (F-ratio of $2.41, p=.0486$ ) on the means for the interaction of faculty ethnicity with student ethnicity (ETHF * ETHS). Table 23 shows the mean scores for Factor 2. 


\section{TABLE 23}

\section{HYPOTHESIS 3}

LOWER RATED INSTRUCTORS ( $N=451$ STUDENTS)

F2: 'COMPETENCE IN CLASSROOM'

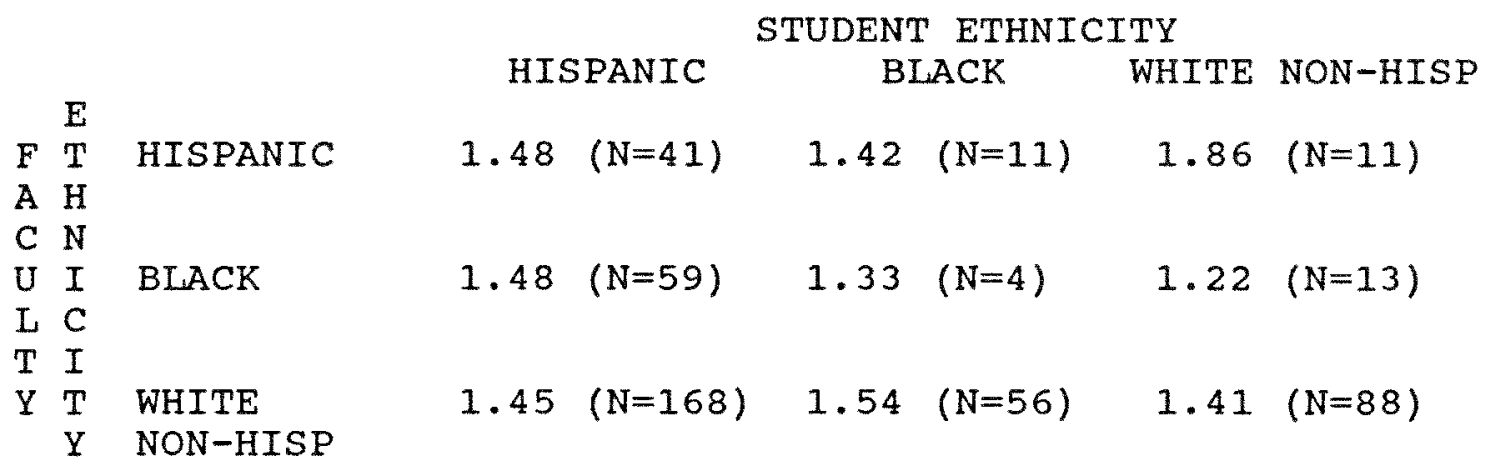

Using pairwise differences, it was determined that there were no differences due to student ethnicity for black and white non-Hispanic instructors. However, for Hispanic faculty, white non-Hispanic students $($ Mean $=1.86)$ rated these faculty differently (worse scores) than either Hispanic $($ Mean $=1.48)$ or black students $($ Mean $=1.42)$. The significance of the pairwise differences are as follows:

For Hispanic faculty:

$$
\begin{array}{ll}
\text { White non-Hispanic vs. Hispanic students } & .0416 \\
\text { White non-Hispanic vs. black students } & .0363
\end{array}
$$

Figure 4 shows the plot for faculty ethnicity by student ethnicity for the mean scores for Factor 2 for lower rated instructors. 
LOWER RATED INSTRUCTORS

F2: 'COMPETENCE IN CLASSROOM!

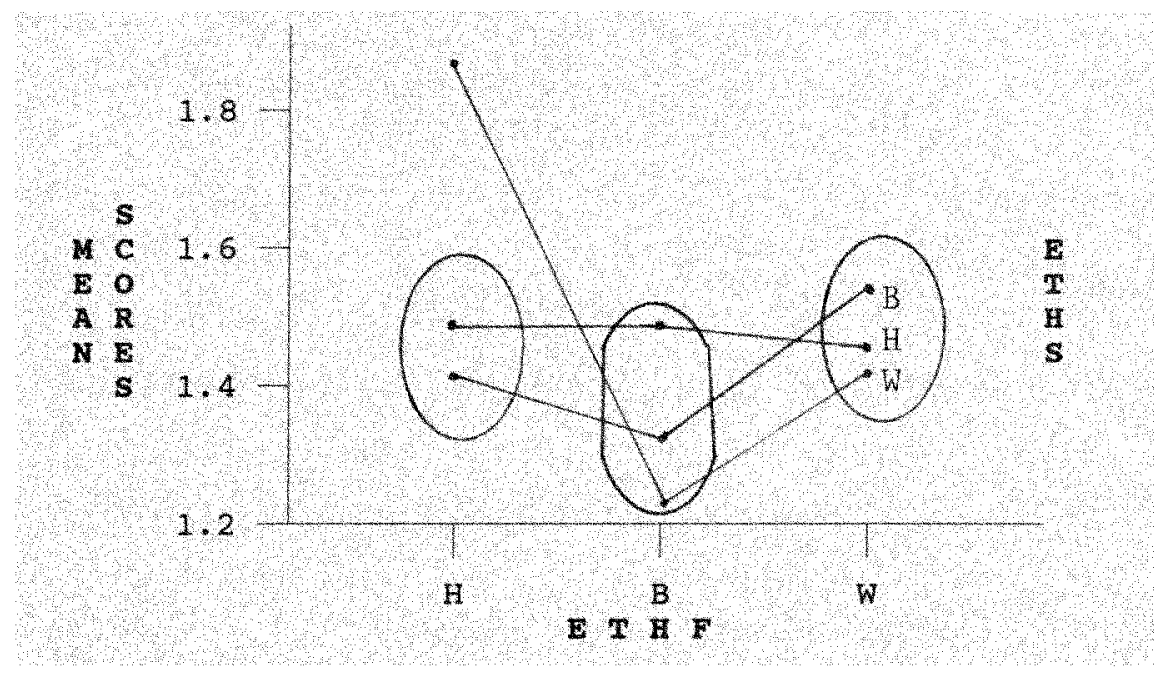

FIGURE 4

F3: 'Approach to Material'

For Factor 3: 'Approach to Material', when the analysis was conducted on the lower rated group, there was a difference (F-ratio of $3.10, p=.0155$ ) on the means for the interaction of faculty ethnicity with student ethnicity (ETHF * ETHS). Table 24 shows the mean scores for Factor 3. 
TABLE 24

HYPOTHESIS 3

LOWER RATED INSTRUCTORS ( $N=451$ STUDENTS)

F3: 'APPROACH TO MATERIAL'

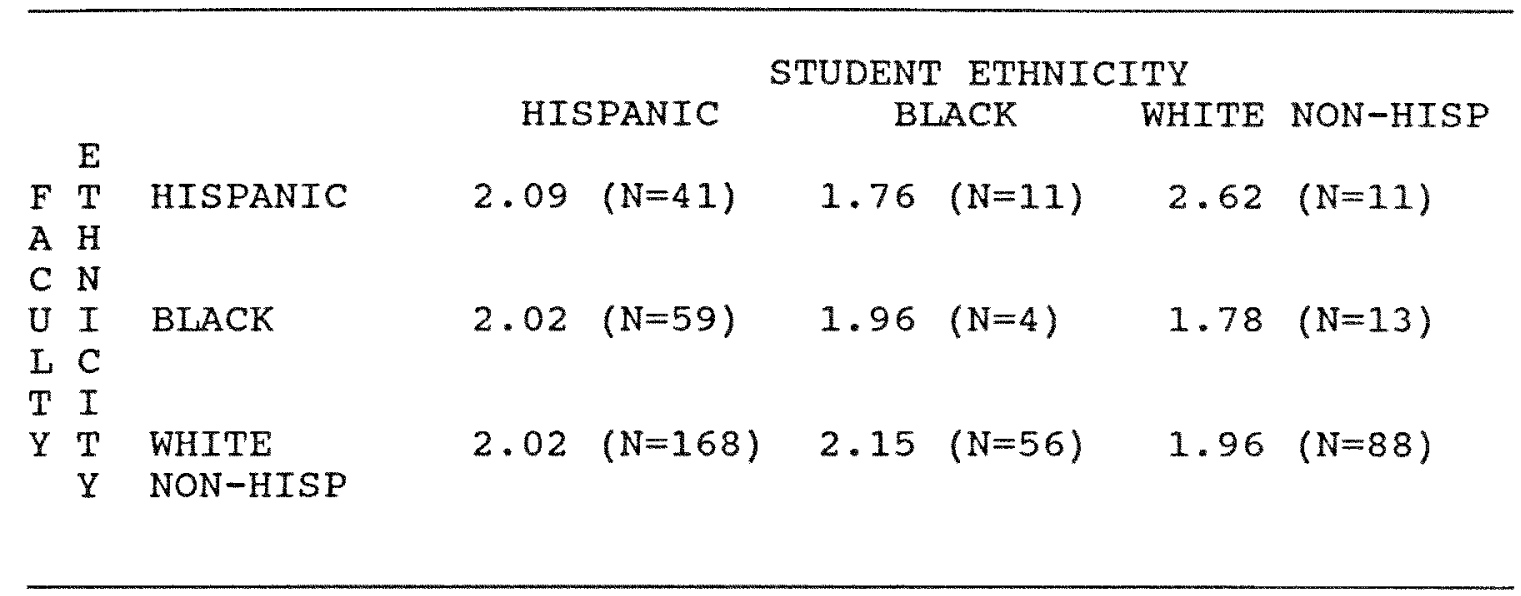

Using pairwise differences, it was determined that there were no significant differences due to student ethnicity for black and white non-Hispanic instructors. However, for Hispanic faculty, white non-Hispanic students $($ Mean $=2.62)$ rated these faculty significantly different (worse scores) than either Hispanic (Mean $=2.09$ ) or black students $($ Mean $=1.76)$. The significance of the pairwise differences are as follows:

For Hispanic faculty:

White non-Hispanic vs. Hispanic students $\quad .0368$

White non-Hispanic vs. black students .0031

Figure 5 shows the plot for faculty ethnicity by student ethnicity for mean scores for Factor 3 for lower rated instructors. 


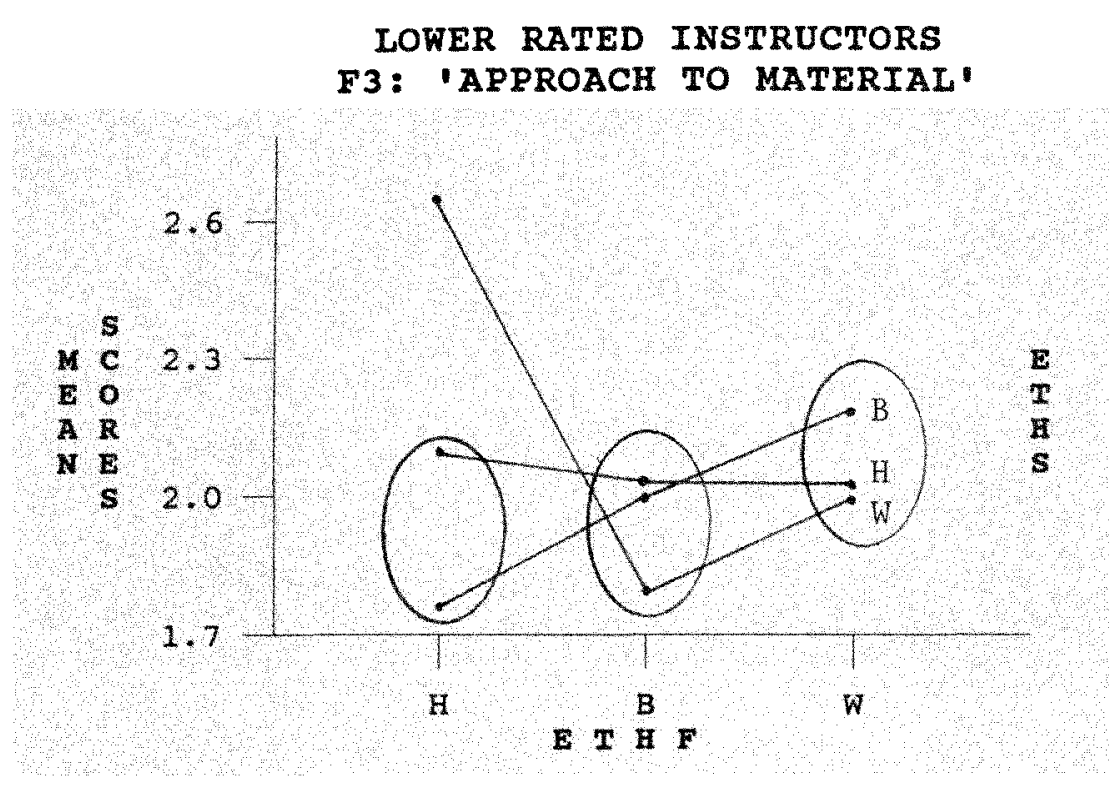

FIGURE 5

\section{F5: 'Listening to students'}

For F5: 'Listening to students', when the analysis was conducted on the lower rated instructors, there was a difference (F-ratio of $3.41, p=.0490$ ) on the means for faculty ethnicity. Table 25 shows the means given to each group of faculty. 
TABLE 25

HYPOTHESIS 3

LOWER RATED INSTRUCTORS ( $=451$ STUDENTS)

F5: 'LISTENING TO STUDENTS'

FACULTY ETHNICITY

$\begin{array}{lcc}\text { FACULTY } & \text { MEAN } & \text { N STUDENTS } \\ \text { ETHNICITY } & 1.74 & (\mathrm{~N}=63) \\ \text { HISPANIC } & 1.45 & (\mathrm{~N}=76) \\ \text { BLACK } & 1.79 & (\mathrm{~N}=312)\end{array}$

Black instructors received significantly better ratings (lower scores) $($ Mean $=1.45)$ than white non-Hispanic instructors $($ Mean $=1.79)$, regardless of student ethnicity. The significance of the pairwise differences are as follows:

Black vs. white non-Hispanic faculty $\quad .0147$

It is interesting to note this result for Factor 5: 'Listening to students'. When comparing the means given to higher and lower rated black faculty, it was determined that they received very similar scores on this factor (1.45 for the lower rated instructors versus 1.34 for the higher rated instructors) even though their total scores were evenly distributed (see Table 11). Where black students might give higher ratings to black faculty, in this case there is no interaction between student and faculty ethnicity, since there were only four black students taught by lower rated black faculty out of a total of 76 students giving ratings. 
Hypothesis 1 stated that there is no significant difference in the mean ratings given to instructors according to student ethnicity. The hypothesis is not rejected for the multivariate analysis, since student ethnicity provided no significant differences in the ratings of instructors. The univariate analysis demonstrates that the hypothesis is rejected only for Factor 3: 'Approach to Material' where there was found to be an interaction for student ethnicity with instructor ethnicity. Hispanic faculty appeared to be rated less favorably by white nonHispanic students (Mean $=2.23$ ) than they were by black students $($ Mean $=1.46)$, yet only a very small sample of white non-Hispanic students $(N=16)$ was enrolled in courses taught by Hispanic faculty.

Hypothesis 2 stated that for higher rated instructors, there is no significant difference in the mean ratings according to student ethnicity. The hypothesis fails to be rejected for the multivariate analysis, since student ethnicity provided no significant differences in the ratings of instructors. Moreover, for the univariate analysis, Hypothesis 2 is also not rejected, since no Instructor Performance Factor was significant at the .01 level.

Hypothesis 3 stated that for lower rated instructors, students of the same ethnicity as their instructor did not 
give significantly different ratings than students whose ethnicity is not the same as their instructor. The hypothesis is not rejected for the multivariate analysis since student ethnicity did not provide a significant difference. For the univariate analysis, the hypothesis is also not rejected, since student gender was the only variable that provided a significant difference at the .01 level. 
CHAPTER V

SUMMARY, CONCLUSIONS AND RECOMMENDATIONS

Summary

\section{Purpose}

The purpose of this study was to explore the relationship between student and faculty ethnicity and possible effects upon students' ratings of faculty performance in an urban community college setting characterized by extensive ethnic diversity. A second purpose of the study was to determine if there were differences in the assessment by students of higher rated and lower rated instructors. Instructors who receive high ratings from students are assumed to be competent and hence, to receive uniformly high ratings from all students, regardless of ethnicity. However, for low rated instructors, the ratings these instructors receive may not be homogeneous and may indicate differences in how the students' and the instructor's ethnicities affect the ratings.

Most of the studies on student evaluation of faculty have been conducted in institutions where the majority of the students are white non-Hispanic. There is very little research on the assessment of faculty by students from other ethnic backgrounds. The literature indicates that there are 
some differences in how teachers perceive and treat students of varied ethnicities in elementary and secondary schools, but few studies have been conducted at the post secondary level. If there is differential treatment in college courses, those differences may be reflected in student ratings that may then vary according to the student's ethnicity.

Minority students now enrolling in higher education differ from traditional students in their needs and aspirations. They are more likely to be working part-time or full-time while trying to complete their studies. Their learning styles will vary depending on the culture in which they were brought up. Studies demonstrate that minority students externalize more often than other students, placing responsibility for failure on others rather than on themselves. These characteristics indicate that these are non-traditional students with special needs. Therefore, black and Hispanic students may perceive instructors and their efforts in the classroom differently than white nonHispanic students.

\section{Review of the Literature}

Ethnicity has been defined as a condition of belonging to a particular ethnic group, one defined by descent, and sharing a common history and experience (Glazer, 1975). Four major theories of ethnicity have been identified by 
Thompson (1989). They are: sociobiological, which explains ethnicity as a genetic condition; primordialist, which asserts that humans have psychological needs for identity and group affiliation; assimilationism, focusing on the eventual disappearance of ethnic differences; and worldsystem, which treats race and ethnic relations as particular forms of social organization within a capitalistic world. of the four major theories of ethnicity, the primordialist theory appears to be most applicable to the classroom since it views human beings as having basic, primordial needs for group affiliation, and a sense of belonging. Mutual feelings of affiliation may produce a special relationship between a student and instructor of the same ethnicity.

Ethnocentrism is a factor in ethnic relations, and group and personal interactions, and may be a factor in how students perceive an instructor. Interactions between faculty and student, in and outside the classroom, and the quality of those interactions, appear to be very important to a student's achievement and persistence (Whitman \& Weiss, 1982). A good instructor can foster relations between the student and him/herself, and among students, that minimize ethnocentrism and optimize alternatives.

Since the literature appears to be incomplete regarding studies of interactions among instructors and students in higher education, and since it does not appear that there 
are any studies on the effect of ethnicity on student ratings of instruction, the psychological and sociological literature was surveyed to determine the effects of counselor-client interactions among minorities. Particular attention was paid to studies dealing with counselor preference by minority clients. These studies indicated that differences in counselor and client ethnic backgrounds do not preclude effective counseling from occurring.

Higgins and Warner (1975) summarized that good counselors must provide empathic understanding, must understand the language and culture of their clients, and must respect their clients. They found this to be true regardless of the race of counselor or client.

Many instruments for student ratings of instruction have been developed to assess an instructor's teaching effectiveness, and are currently in use as a source in determining retention, tenure granting, and promotion of faculty members. Rating instruments have generally been determined to be reliable and valid. However, there is still controversy surrounding the use of student ratings since research has shown that certain factors may bias students' ratings of faculty. Studies have been conducted to determine whether certain characteristics of the faculty member such as expressiveness and gender play a role in how students rate the instructor. Other studies have tried to determine whether certain students' characteristics or 
situations such as class size, gender, age, expected course grade, required versus elective course, upper division versus lower division course, learning styles, and cultural differences affect ratings. Another group of studies considered interactions between students and instructors and whether these interactions, personality and attitude similarities, provide for differences in ratings.

Many studies demonstrate that most of these characteristics have a very small, or no effect, on student ratings. However, there is enough evidence to indicate that some variability in ratings may be produced by the instructor's expressiveness, the instructor's gender, the academic field being taught, the level of difficulty of the course, class size, and expected grades.

Since there are few appropriate studies in the area of education regarding student and instructor ethnicity, and how it affects student ratings of instruction, it was reasonable to conclude that additional research was needed in this area.

\section{Research Design and Methodology}

This study involved data collection utilizing a surveytype instrument. The instrument used was the student Feedback Questionnaire (Appendix B) developed by a collegewide committee of faculty and administrators at Miami-Dade Community College. This instrument is based on 
twenty-nine characteristics of excellent teachers as described in the statement of Faculty Excellence (Appendix A). The instrument provides for the assessment by students of an instructor's teaching performance through twenty-three multiple choice items. It also provides for self-reported students' demographic information such as: class attendance; performance in the course; the perceived difficulty of the course; whether the course is required or elective; gender; age; ethnicity; other family and/or work responsibilities; and the number of credits enrolled during the term. Instructors' ethnicity was obtained from personnel records maintained by the Human Resources Department at the institution.

This study was limited to randomly selected English composition courses (ENC 1100, ENC 1101, ENC 1102, and ENC 2301) taught by full-time faculty during the Fall 1990 term at Miami-Dade Community college. Random assignments cannot be assumed, as in an experimental study, since the students actually selected specific class times and, in some cases, the instructor teaching the course. A total of 1147 student Feedback Questionnaire forms were completed in 72 sections of English composition during the Fall 1990 term. The student breakdown is as follows: 605 Hispanic (54.0\%), 175 black (15.6\%), 235 white non-Hispanic (21.0\%), and 106 other (American Indian, Asian, etc.) (9.4\%). The faculty ethnicity was 8 Hispanic (11.1\%), 12 black (16.7\%), and 52 
white non-Hispanic $(72.2 \%)$.

Many sources of variability were minimized or eliminated by selecting courses from only one academic discipline. The variability in student ratings due to differences in the number of students in a course was eliminated since all English composition classes at the institution are limited to a maximum of twenty-eight students. There is an equalization of workload in these courses throughout the institution since the Florida state Board of Education, through the Gordon Rule, mandates that students write a total of 6000 words in each English composition course (Gordon, 1988). All degree-seeking students at the institution are required to complete these English composition courses with a grade of $C$, ensuring that the course is not considered an elective by any enrolled student.

The statistical treatment of the data was conducted using the statistical Package for the Social sciences (SPSS$\mathrm{X})$ and the Statistical Analysis system (SAS). Initial data analysis included a frequencies program to validate the data, and the determination of the instrument's reliability. Factor analysis was conducted on the twenty-three items related to the instructor's teaching performance. The factors were treated as dependent variables and a mean rating was obtained for each factor. The relationship between these factors and student ethnicity was examined by 
means of multivariate analysis of variance.

A total mean student rating score for all twenty-three items related to an instructor's teaching performance was obtained for each instructor. This mean rating score was used to separate the faculty into two categories, higher and lower rated instructors. Multivariate analysis of variance was conducted separately on each group of faculty (higher and lower rated) to determine relationships between instructor and student ethnicity.

\section{Findings}

Factor Analysis

Maximum likelihood factorial analysis was employed on the twenty-three items related to the instructor's teaching performance in the student Feedback Questionnaire. The eight Instructor Performance Factors obtained are as follows:

Factor 1: Focus on the Individual

Factor 2: Competence in classroom

Factor 3: Approach to Material

Factor 4: Grading Policy

Factor 5: Listening to students

Factor 6: Clarity in course objectives

Factor 7: Fairness of Exams

Factor 8: Active Learning 


\section{Hypotheses}

Hypothesis 1 stated that there is no significant difference in the mean ratings given to instructors according to student ethnicity. The hypothesis is not rejected for the multivariate analysis, since student ethnicity provided no significant differences in the ratings of instructors. The univariate analysis demonstrates that the hypothesis is rejected only for Factor 3: 'Approach to Material' where there was found to be an interaction for student ethnicity with instructor ethnicity. Hispanic faculty appeared to be rated less favorably by white nonHispanic students $($ Mean $=2.23)$ than black students (Mean $=$ 1.46), yet only a very small sample of white non-Hispanic students ( $N=16$, a slightly lower percentage than expected) was enrolled in courses taught by Hispanic faculty.

Hypothesis 2 stated that for higher rated instructors, there is no significant difference in the mean ratings according to student ethnicity. The hypothesis fails to be rejected for the multivariate analysis, since student ethnicity provided no significant differences in the ratings of instructors. Moreover, for the univariate analysis Hypothesis 2 is not rejected, since there were no significant differences at the .01 level for student ethnicity on any of the eight Instructor Performance Factor.

Hypothesis 3 stated that for lower rated instructors, students of the same ethnicity as their instructor do not 
give significantly different ratings than students whose ethnicity is not the same as their instructor. The null hypothesis is not rejected for the multivariate analysis since student ethnicity did not provide a significant difference. For the univariate analysis, the hypothesis is not rejected, since student gender was the only variable that provided a significant difference at the .01 level.

\section{other Findings}

Several of the results at the .01 level did not relate to student ethnicity, and were therefore not part of the hypotheses. Other results gave differences at the .05 level. All of these may be of interest for information and to propose additional studies. Table 26 lists all of the effects and interactions that were found at both the .0I and .05 levels for the total sample, the higher rated instructors, and the lower rated instructors. 
TABLE 26

SUMMARY OF FINDINGS

$\begin{array}{lll}\text { TOTAL GROUP } & \text { HIGHER RATED } & \text { LOWER RATED } \\ \text { GROUP } & \text { GROUP }\end{array}$

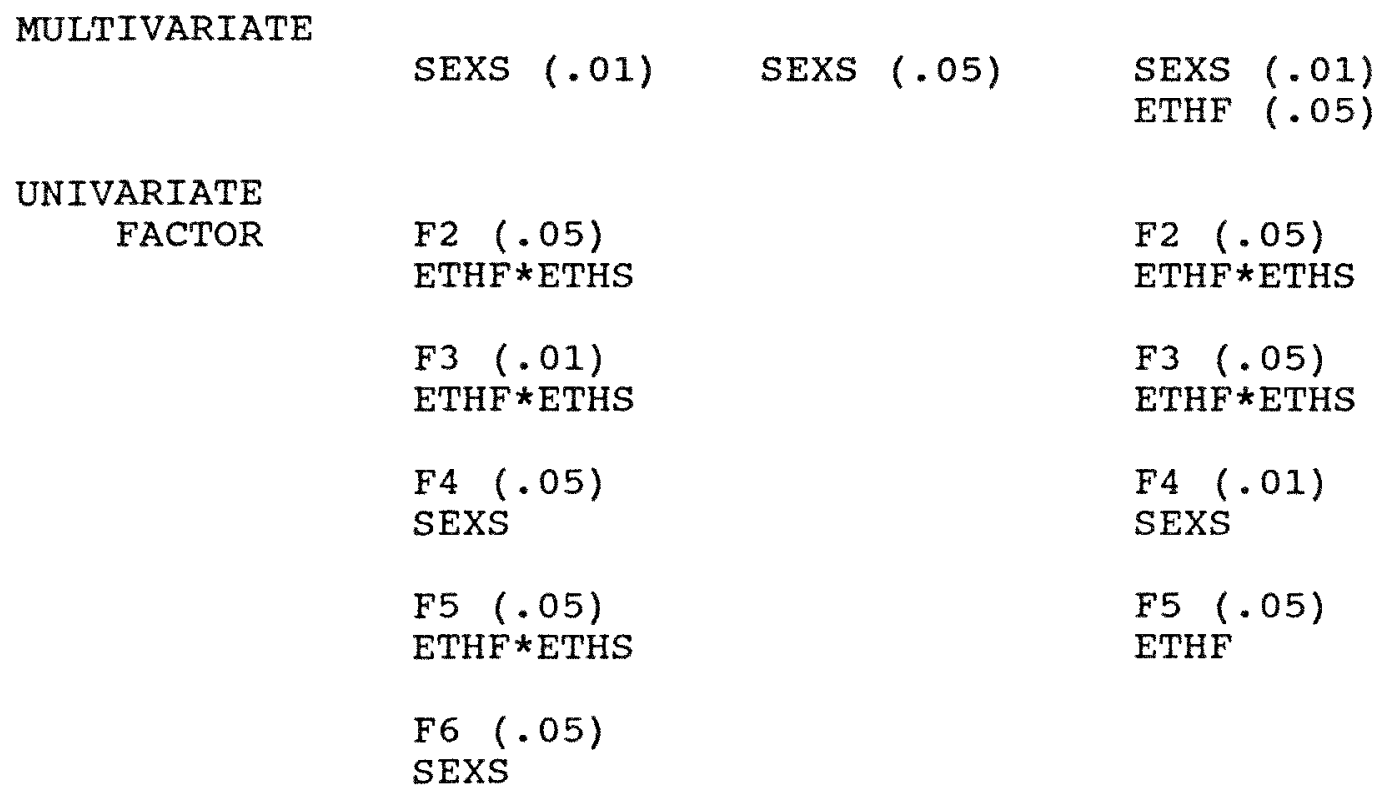

Hypothesis 1 - Total Sample

Multivariate statistics indicate that when the analysis was carried out on the total sample ( $N=948$ students in 72 course sections), only student gender was significant at the .01 level when the eight Instructor Performance Factors were analyzed simultaneously. Student gender produced a Wilk's Lambda of .979 with an F-ratio of $2.61(.0079)$. Univariate analysis shows that there were no significant differences on factors F1 to F8 due to student ethnicity. There was an 
interaction for student ethnicity with instructor ethnicity (ETHS*ETHF) for F3: 'Approach to Material' at the .01 level. There were no other significant differences at the .01 level for the independent variables of student ethnicity, faculty ethnicity, and student gender for the remaining Instructor Performance Factors. However, for F2: 'Competence in Classroom' and F5: 'Listening to students', there was an interaction for student ethnicity with instructor ethnicity (ETHS*ETHS) at the .05 level. Additionally, for student gender there was a difference at the .05 level for factors F4: 'Grading Policy', and F6: 'Clarity In Course objectives'.

\section{F2: 'Competence in the Classroom'}

For Factor 2: 'Competence in the Classroom', when the analysis was conducted on the total sample there was a difference (F-ratio of 2.81 at a significance level of .0246 ) on the means for the interaction of faculty ethnicity with student ethnicity (ETHF * ETHS). It was determined that there were no differences due to student ethnicity for black and white non-Hispanic instructors. However, for Hispanic faculty, white non-Hispanic students $($ Mean $=1.62)$ rated these faculty different (worse scores) than either Hispanic $($ Mean $=1.37)$ or black students $($ Mean $=1.25)$. F5: 'Listening to students'

Once again, when the analysis was conducted on the total sample, there was a difference (F-ratio of 2.81, 
$\mathrm{p}=.0246$ ) on the means for the interaction of faculty ethnicity with student ethnicity (ETHF * ETHS) for F5: 'Listening to students'. Black students (Mean $=1.36)$ and white non-Hispanic students (Mean $=1.79)$ differed on how they rated Hispanic faculty. Also Hispanic students (Mean = 1.48 ) and black students (Mean $=1.61$ ) differed on the ratings they gave white non-Hispanic faculty for this factor.

F4: 'Grading Policy' and F6: 'Clarity in Course objectives:

For Factors 4 and 6 , student gender (SEXS) gave differences at the .05 level. For both of these factors, males gave worse scores (the lower the score the higher the rating since the statement 'strongly Agree' had a value of 1 in the questionnaire) than females.

Hypothesis 2 - Higher rated instructors

Even though there was no independent variable that provided a significant difference at the .01 level for the multivariate analysis, there was one variable that resulted in a difference at the .05 level for the higher rated instructors. That variable was student gender (SEXS), which gave an F-ratio of 2.09 with a significance of .0349 . For the univariate analysis, none of the independent variables had differences on the eight Instructor Performance Factors $($ F1-F8). Therefore, even at the .05 level, hypothesis 2 fails to be rejected. 


\section{Hypothesis 3 - Lower Rated Instructors}

For lower rated instructors, only one independent variable was significant at an alpha of .01 when the eight Instructor Performance Factors were analyzed simultaneously. This variable was student gender with a Wilk's Lambda of .955 with an F-ratio of $2.54(.0104)$. Univariate statistics also indicate that for the independent variable of student gender the Instructor Performance Factor 4: 'Grading Policy' provided a significant difference at the .01 level (F-ratio of 7.24 with a significance of .0074). Males gave worse scores $($ Mean $=2.02)$ (the lower the score the higher the rating since the statement 'Strongly Agree' had a value of 1 in the questionnaire) than females (Mean $=1.67$ ).

If examined at the .05 level, instructor ethnicity provided differences for the multivariate analysis and for Factor 5: 'Listening to students' in the univariate. There were interactions between instructor and student ethnicity for Factor 2: 'Competence in Classroom' and Factor 3: 'Approach to Material' at the .05 level. Neither of these interactions was found for the higher rated group of instructors.

\section{F2: 'Competence in the Classroom'}

For Factor 2: 'Competence in the Classroom', when the analysis was conducted on the lower rated group, there was a difference (F-ratio of 2.41, $\mathrm{p}=.0486$ ) on the means for the interaction of faculty ethnicity with student ethnicity 
(ETHF * ETHS). It was determined that there were no differences due to student ethnicity for black and white non-Hispanic instructors. However, for Hispanic faculty, white non-Hispanic students (Mean $=1.86$ ) rated these faculty different (worse scores) than either Hispanic (Mean $=1.48$ ) or black students (Mean $=1.42)$.

\section{F3: 'Approach to Material'}

For Factor 3: 'Approach to Material', when the analysis was conducted on the lower rated group, there was a difference (F-ratio of $3.10, p=.0155$ ) on the means for the interaction of faculty ethnicity with student ethnicity (ETHF * ETHS). It was determined that there were no differences due to student ethnicity for black and white non-Hispanic instructors. However, for Hispanic faculty, white non-Hispanic students (Mean $=2.62$ ) rated these faculty different (worse scores) than either Hispanic (Mean $=2.09)$ or black students $($ Mean $=1.76)$.

\section{F5: 'Listening to students'}

For F5: 'Listening to students', when the analysis was conducted on the lower rated instructors, there was a difference (F-ratio of $3.41, p=.0490$ ) on the means for faculty ethnicity. Black instructors received better ratings (lower scores) (Mean $=1.45$ ) than white non-Hispanic instructors $($ Mean $=1.79)$, regardless of student ethnicity. 


\section{Limitations of the study}

Among the restrictions of this study was the selection of Miami-Dade Community college as the institution in which the study was conducted. The population to be studied was limited to students enrolled in randomly selected English composition credit courses at Miami-Dade Community College during the Fall 1990 term.

Another limitation was that random selection of students into course sections was not possible, and that only one class was randomly selected for each full-time faculty member, limiting the number of students that had the opportunity to participate. A further limitation was that of the need to assume that higher rated and lower rated faculty, as determined by student ratings, would have a proportionate mix of instructors of different ethnicities.

Any conclusions drawn may apply only to institutions that resemble Miami-Dade Community college, in the ethnic diversity of their student bodies, such as community colleges in California, Texas, and New York, where minority students may actually be the majority.

While the instrument was developed and has only been administered at Miami-Dade community college, this is not perceived as a limitation due to the manner in which it was developed, since the instrument is based on the statement of Faculty Excellence. The majority of students at Miami-Dade Community college are not native speakers of English and, 
even though the committee developing the instrument was very careful about the language construction of the items, second language problems may affect the students' responses.

Conclusions

Analysis of the individual Instructor Performance Factors (F1 to F8) provided more and richer information than that obtained by multivariate statistics. Since teaching is a complex activity, it is reasonable to expect this finding. Table 26 listed the effects and interactions that were found at both the .01 and .05 levels for the total sample, the higher rated instructors, and the lower rated instructors. As can be seen from Table 26, the results for the total sample are almost identical as those for the lower rated instructors, while the higher rated instructors only showed an effect for student gender. This leads to the conclusion that the results obtained for the total sample, with the exception of student gender, are generated solely from the lower rated instructors.

\section{Student ethnicity}

From the results obtained for the higher rated instructors, it is concluded that student ethnicity has no effect whatsoever on student ratings for competent instructors. It appears that higher rated instructors with 
teaching experience in ethnically diverse community colleges have successfully adapted their teaching strategies to serve the needs of both traditional and non-traditional students. This result is parallel to that of Backner (1970). He found that black and Puerto Rican students who had been counseled by highly rated white counselors considered the ethric background of a counselor unimportant. Additionally, Higgins and Warner (1975) stated that more time should be spent in identifying the core of effective counseling than in placing emphasis on ethnic differences. Similarly, institutions should identify those characteristics and practices that provide for quality teaching and strive to have their instructors adopt them.

For lower rated instructors, results (as summarized in Table 26) indicate that interactions existed between instructor ethnicity and student ethnicity. But those interactions were not the expected ones. The premise in this study was that there would be a special relationship between students and instructors of the same ethnicity, as suggested by the primordialist theory of ethnicity, whereas feelings of affiliation toward one's group would distort the perception a student had towards a poor instructor of the same ethnicity. However, the interactions found in this study were across ethnic groups. Some of these interactions were negative, while others were positive. 


\section{White non-Hispanic students}

An example of a negative interaction was that obtained for Hispanic instructors with white non-Hispanic students. Whether for the total sample, or for the lower rated group, Hispanic instructors were rated significantly lower by white non-Hispanic students in several of the Instructor Performance Factors - F2: 'Competence in Classroom', F3: 'Approach to Material', and F5: 'Listening to students'.

This result warrants further study, since only 16 white non-Hispanic students were enrolled in English compositions courses taught by Hispanic faculty. This low number may in itself be significant. Since Hispanic faculty taught $11.1 \%$ if the course sections, it would be reasonable to assume that they would also have taught $11.1 \%$ of the white nonHispanic students. However, only $6.8 \%$ of the white nonHispanic students were taught by Hispanic faculty. It is important to note that the instrument was administered late in the semester, approximately the tenth week of a sixteen week semester. The institution has an extended 'drop' policy - the student can withdraw with no penalty through the twelfth week. Therefore, it is possible that a higherthan-normal percentage of white non-Hispanic students withdrew throughout the term.

Perhaps white non-Hispanic students are exhibiting a form of ethnocentrism, in that they may prefer to be taught English composition by instructors who are native speakers, 
just 1 ike them, rather than by faculty whose native language is not English. There are anecdotal reports of international students expressing a belief that native English speakers are better teachers of English as a Second Language courses than instructors whose native language is not English. Caution should be used in reaching conclusions in this area, as the number of students in the study was too small.

\section{Black students}

A positive result was obtained on Factor 3: 'Approach to Material', where black students gave Hispanic faculty significantly better ratings than white non-Hispanic students. Could Hispanic faculty be more patient and more understanding of difficulties faced by black students in English composition classes? Further study should be conducted to determine whether this effect is true for other academic areas. Additionally, a larger group of black students taught by Hispanic faculty should be included in the study, since only $24 \mathrm{black}$ students rated Hispanic faculty in this study. Yet these 24 students represent a higher-than-expected percentage $(13.7 \%)$ of black students. Since Hispanic faculty taught $11.1 \%$ if the course sections, the assumption would be that $11.1 \%$ of the black students would be enrolled in these course sections. 


\section{Hispanic students}

There was only one factor for which Hispanic students differed in ratings of instructors. This was for F5: 'Listening to Students', where Hispanic students gave significantly higher ratings than black students to white non-Hispanic instructors. For all other factors, and for the multivariate analysis, Hispanic students rated all faculty without regard to instructor ethnicity. This conclusion has a high level of confidence, since there were large numbers of Hispanic students for instructors of each ethnicity. Yet, caution should be exercised since this result may only be applicable to institutions where the minority student is in fact the majority as it is at MiamiDade Community College where almost 55\% of all students are Hispanic. This finding relates to that of oliver, Smith, and wilson (1989) who determined that black students at predominantly white non-Hispanic institutions had a better adjustment, thereby improving their retention, when there was a sufficient number (critical mass) of other black students at the institution.

\section{Instructor ethnicity}

Black instructors received significantly better ratings (lower scores) (Mean $=1.45$ ) than white non-Hispanic instructors $($ Mean $=1.79)$ on Factor 5 when the analysis was conducted on the lower rated instructors, regardless of 
student ethnicity. It is interesting to note this result for Factor 5: 'Listening to students'. When comparing the means given to higher and lower rated black faculty, it was determined that they received very similar scores on this factor ( 1.45 for the lower rated and 1.34 for the higher rated) even though their total scores were evenly distributed (see Table 11, Chapter 4). Perhaps black instructors are more skilled in listening skills or are perceived as having greater empathy than other instructors. Since only four black students were taught by lower rated black faculty out of a total of 76 student giving ratings, this higher mean for black instructors was not produced by a positive interaction between student and faculty ethnicity.

\section{Student gender}

Multivariate analysis for the total sample and for the lower rated instructors produced significant differences at the .01 level for student gender. The data indicated that males, regardless of ethnicity, gave worse ratings to all instructors. At least two possibilities exist to explain this difference.

The first possibility relates to the academic field in question. The research literature has shown that males tend to select mathematically related careers more often than females. Perhaps males are not as adept or do not enjoy the English composition courses as much as females do. Data 
from the College Level Academic Skills Tests (CLAST), an exit exam for the sophomore level administered in Florida, shows that males at Miami-Dade Community College perform better in the Mathematics section, while females obtain higher scores on the Essay portion of the exam (Belcher, 1991a).

A second possibility is that male students may not be as well-prepared as the females in the sample, in general. The review of the literature indicated that students will give higher ratings to instructors in whose courses they are performing we11. It is possible that the male population at Miami-Dade Community College is not as well-prepared, and therefore does not perform as well in courses, as the female population.

In the Hispanic culture, university-eligible males are more likely than females to be allowed to go to college away from home. The female population at Miami-Dade Community College may include a larger percentage of universityeligible students than the male population. Black males that are university-eligible are much sought after by post secondary institutions across the nation; so few university eligible black males enroll in community colleges. In any case, the results of this study in reference to student gender require verification from future studies. 


\section{Implications for Policy and Practice}

This study demonstrates that higher rated instructors with teaching experience in ethnically diverse community colleges have successfully adapted their teaching strategies to serve all students. Therefore, while it is important to provide role models for minority students, and wile it is commendable and desirable for institutions to strive toward a faculty composition that is similar to that of its student body, this study indicates that instructor ethnicity is not as important a factor as having competent, experienced instructors, regardless of instructor ethnicity.

The study underscores the importance of institutions identifying those characteristics and practices that provide for quality teaching. Programs should then be established for the continued development of instructors to ensure that the practices that the institution has determined as beneficial for students are continued throughout the instructors' careers.

Recommendations

The findings of this study suggest that future studies should be conducted to determine whether a bias exists for white non-Hispanic students with Hispanic faculty, and whether that bias is only related to the area of English composition or affects Hispanic instructors in other 
disciplines. Therefore, the study should be replicated using other academic fields. To be more confident of the results, it will be important to include a larger group of white non-Hispanic students taught by Hispanic faculty. It is possible that student ethnicity is a factor in ratings of instruction in subject areas with affective competencies, as in the humanities and social sciences, while content-laden courses, such as the sciences and mathematics, may not show differences.

While most of the literature shows that student gender does not affect student ratings of instruction, a comprehensive study should be conducted in this area. This study showed that males gave significantly worse ratings than females. A determination should be made as to whether it was truly a gender difference or due to other causes such as the academic field, student performance, or difficulty of the course.

Another area for further investigation was suggested by the result related to Factor 5: 'Listening to students', where black faculty, even lower rated ones, received similar, relatively positive scores on this factor. It should be determined whether black instructors have developed greater listening skills than others and why. Is it due to the black experience in America (Poussaint 1971)? or could it be that these instructors have a sense of insecurity within the institution, so that they compensate 
by being more attentive to students than other instructors?

Since there were few differences in the ratings that Hispanic students gave to instructors of all ethnicities, this study should be replicated at other institutions with large minority populations, such as historically black institutions, where minority students have actually become the majority at the institution. Will those studies also show no differences in ratings?

Additionally, comparisons of instructor ratings according to student ethnicity at two types of institutions should be conducted. One type of institution should have small numbers of minority students. The other type of institution should have a student population that includes a large number of minority students (a critical mass as described by oliver et al., 1989), but not large enough to constitute a majority.

Another study could explore the relationship between instructors' perceptions of their students' abilities and those students' ratings of their instructors. Do instructors' attitudes translate into different classroom behaviors so that they receive different ratings depending on their beliefs of students' ability to succeed?

As the enrollment of minority students in post secondary institutions increases, whether their needs are being met should become a question of increasing importance at these institutions. 
REFERENCES

153 


\section{REFERENCES}

Abaneme, M. K. C. (1987). The influence of motivation and achievement on student ratings of instruction: a comparative study of full-time and part-time teaching. Dissertation Abstracts International. 49, 05A, p. 1070. (University Microfilms No. $88-12,410$.

Abrami, P. C., \& Mizener, D. A. (1985). student/instructor attitude similarity, student ratings, and course

performance. Journal of Educational Psychology, 77(6), 693702 .

Ahmadi, G. (1981). A study of student opinions toward faculty evaluation by students (Doctoral dissertation, Kansas State University, 1981). Dissertation Abstracts International, $42,11 \mathrm{~A}, \mathrm{p} .4653$.

Aleamoni, L. M. (1987). Typical faculty concerns about student evaluation of teaching. In L. M. Aleamoni (Ed.) . New Directions for Teaching and Learning: Techniques for Evaluating and Improving Instruction, 31 (pp. 25-31). San Francisco: Jossey-Bass.

Aleamoni, L. M., \& Graham, M. H. (1974). The relationship between CEQ ratings and instructor's rank, class size, and course level. Journal of Educational Measurement, 11, 189202 .

Aleamoni, L. M., \& Thomas, G. S. (1980). Differential relationships of student, instructor, and course characteristics to general and specific items on a course evaluation. Teaching of Psychology, I, 233-235.

Alexander, K. L., Entwistle, D. R., \& Thompson, M. S. (1987). School performance, status relations, and the structure of sentiment: Bringing the teacher back in. American Sociological Review, 52, 665-682.

Allen, B. P., \& Niss, J. F. (1990). A chill in the college classroom? Phi Delta Kappan, 71(8), 607-609.

Andrews, H. A., \& Marzano, W. (1990). Meeting the looming faculty shortage. Community, Technical, and Junior college Journal, 61 (3), 26-29.

Arreola, R. A. (1983). Establishing successful faculty evaluation and development programs. In A. Smith (Ed.). New Directions for Community Colleges: Evaluating Faculty and Staff, 41 (pp. 83-93). San Francisco: Jossey-Bass. 
Atkinson, D. R. (1983). Ethnic similarity in counseling psychology: A review of research. Counseling Psychologist, 11(3), 79-92.

Atkinson, D. R. (1985). A meta-review of research on crosscultural counseling and psychotherapy. Journal of Multicultural counseling and Development, 13(4), 138-153.

Aubrecht, J. D. (1979). Are student ratings of teacher effectiveness valid? IDEA paper No.2. Manhattan, KS: Kansas State University. Center for Faculty Evaluation \& Development.

Aubrecht, J. D. (1981). Reliability, validity and generalizability of student ratings of instruction. IDEA Paper No.6. Manhattan, KS: Kansas State University. Center for Faculty Evaluation \& Development.

Backner, B. L. (1970). Counseling black students: Any place for whitey? Journal of Higher Education, 41, 630-637.

Banks, J. A. (1988). Ethnicity, class, cognitive, and motivational styles: Research and teaching implications. The Journal of Negro Education, 57(4), 452-466.

Basow, S. A. (1990). Effects of teacher expressiveness: mediated by teacher sex-typing? Journal of Educational Psychology, 82(3), 599-602.

Basow, S. A., \& Distenfeld, M. S. (1985). Teacher expressiveness: more important for male teachers than female teachers. Journal or Educational Psychology, 77(1), 45-52.

Basow, S. A., \& Silberg, N.T. (1987). Student evaluations of college professors: Are female and male professors rated differently? Journal of Educational Psychology, 79, 308-314.

Beatty, M. J., \& Zahn, C. J. (1990). Are student ratings of communication instructors due to "easy" grading practices?: an analysis of teacher credibility and student-reported performance levels. Communication Education, 39, 275-282.

Belcher, M. J. (1991). CLAST results for spring 1991: M-DCC and statewide. (Information Capsule 91-09C). Miami, FL: Miami-Dade Community College, office of Institutional Research.

Belcher, M. J. (1991). Factor analysis of Student Feedback Questionnaire: Fall 1990 administration. Manuscript submitted for publication. 
Bell, D. (1975). Ethnicity and social change. In N. Glazer \& D. P. Moynihan (Eds.). Ethnicity: Theory and experience (pp. 141-174). Cambridge, MA: Harvard University Press.

Bennett, S. K. (1982). Student perceptions of and expectations for male and female instructors: Evidence relating to the question of gender bias in teaching evaluation. Journal of Educational Psychology, 74, 170-179.

Brandenburg, D. C., Slinde, J. A. \& Batista, E. E. (1977). student ratings of instruction: Validity and normative interpretations. Research in Higher Education, 7, 67-78.

Braskamp, L. A., Brandenburg, D. C., \& Ory, J. C. (1984). Evaluating Teaching Effectiveness: a Practical Guide.

Beverly Hills, CA: Sage.

Burke, P.J. (1989). Academic identity and race differences in educational aspirations. Social Science Research, 18(2), 136-150.

Byrkit, D. R. (1987). Statistics today A comprehensive introduction. Menlo Park, CA: Benjamin Cummings.

Campbell, P. B. (1986). What's a nice girl like you doing in a math class? Phi Delta Kappan, 67(7), 516-520.

Carter, R. T., \& Helms, J. E. (1988). The relationship between racial identity attitudes and social class. Journal of Negro Education, 57(1), 22-30.

Cashin, W. E. (1983). Concerns about using student ratings in community colleges. In A. Smith (Ed.). New Directions for Community Colleges: Evaluating Faculty and Staff, 41 (pp. 57-65). San Francisco: Jossey-Bass.

Cashin, W. E. (1988). Student ratings of teaching. A summary of the research. IDEA Paper No.20. Manhattan, KS: Kansas State University. Center for Faculty Evaluation and Development.

Cashin, W. E. (1989). Defining and evaluating college teaching. IDEA Paper No. 21. Manhattan, KS: Kansas state University. Center for Faculty Evaluation and Development.

Cashin, W. E. (1990). Student ratings of teaching: recommendations for use. IDEA Paper No.22. Manhattan, KS: Kansas State University. Center for Faculty Evaluation and Development.

Centra, J. A. (1975). Colleagues as raters of classroom instruction. Journal of Higher Education, 46, 327-337. 
Centra, J. A. (1977). Student ratings of instruction and their relationship to student learning. American Educational Research Journal, 14, 17-24.

Centra J. A. (1979). Determing faculty effectiveness: assessing teaching, research, and service for personnel decisions and improvement. San Francisco: Jossey-Bass.

Centra, J., Froh, R. C., Gray, P.J., \& Lambert, L. M. (1987). A guide to evaluating teaching for promotion and tenure. Syracuse University. Center for Instructional Development. R. M. Diamond (Ed.). Littleton, MA: Copley.

Chandler, T. A. (1978). The questionable status of student evaluations of teaching. Teaching of Psychology, 5, 150-152.

clifton, R. A., Perry, R. P., Parsonson, K., \& Hryniuk, S. (1986). Effects of ethnicity and sex on teachers' expectations of junior high school students. Sociology of Education, 59(1), 58-67.

clinton, R. J. (1930). Qualities college students desire in college instructors. School and society, 32, 702 .

Cohen, P. A. (1981). Student ratings of instruction and student achievement. A meta-analysis of multisection validity studies. Review of Educational Research, 51, 281309 .

Crittenden, K. S., \& Norr, J. L. (1975). Some remarks on "Students' Ratings": The validity problem. American Educational Research Journal, 12, 429-434.

Crittenden, K. S., Norr, J. L., \& LeBailly, R. K. (1975) . Size of university classes and student evaluation of teaching. Journal of Higher Education, 10, 461-470.

Cross, K. P. (1986). A proposal to improve teaching - or what "taking teaching seriously" should mean. AAHE Bulletin, 39(1), 9-14.

De Vos, G. (1975). Ethnic pluralism: conflict and accomodation. In G. De Vos \& L. Romanucci-Ross (Eds.). Ethnic identity: Cultural continuities and change (pp. 541). Palo Alto, CA: Mayfield Pub. Co.

De Vos, G. \& Romanucci-Ross, L. (1975). Ethnicity: Vessel of meaning and emblem of contrast. In G. De Vos \& L. RomanucciRoss (Eds.). Ethnic identity: Cultural continuities and change (pp. 363-390). Palo Alto, CA: Mayfield Pub. Co. 
Eaton, J. S. (1988). Minorities, transfer, and higher education. Peabody Journal of Education, 66 (1), 58-70.

Elliott, S. N. \& Argulewicz, E. N. (1983). The influence of student ethnicity on teachers' behavior ratinbs of normal and learning disabled children. Hispanic Journal of Behavioral sciences, $5(3), 337-345$.

Elmore, P. B., \& LaPointe, K. A. (1974). Effects of teacher sex and student sex on the evaluation of college instructors. Journal of Educational Psychology, 66, 386-389.

Elmore, P. B. \& \& Pohlmann, J. Y. (1978). Effect of teacher, student, and class characteristics on the evaluation of college instructors. Journal of Educational Psychology, 70, $187-192$.

Farkas, G., Sheehan, D., Grobe, R. P., \& Shuan, Y. (1990) Cultural resources and school success: Gender, ethnicity, and poverty groups within an urban school district. American Sociological Review, 55(1), 127-142.

Feldman, K. A. (1976). The superior college teacher from the student's view. Research in Higher Education, $\underline{5}, 243-288$.

Feldman, K. A. (1977). Consistency and variability among college students in rating their teachers and courses: a review and analysis. Research in Higher Education, 6 , 223274 .

Feldman, K. A. (1978). Course characteristics and college students' ratings of their teachers: what we know and what we don't. Research in Higher Education, 9, 199-242.

Feldman, K. A. (1983). Seniority and experience of college teachers as related to evaluations they receive from students. Research in Higher Education, 18, 3-124.

Feldman, K. A. (1984). Class size and college students' evaluations of teachers and courses: a closer look. Research in Higher Education, 21, 45-116.

Feldman, K. A. (1986). The perceived instructional effectiveness of college teachers as related to their personality and attitudinal characteristics: A review and synthesis. Research in Higher Education, 24, 139-213.

Frey, P. W. (1978). A two-dimensional analysis of student ratings of instruction. Research in Higher Education, 2, 6991. 
Frey, P. W., Leonard, D. W. \& \& Beatty, W. W. (1975). Students' ratings of instruction: Validation research. American Educational Research Journal, 12, 435-???.

Gage, N. L., \& Berliner, D. C. (1988). Educational Psychology (4th ed.). Boston: Houghton Mifflin.

Gillett-Karam, R., Roueche, S. D., \& Roueche, J. E. (1990). Underrepresentation and the question of diversity. Community, Technical, and Junior College Journal, 61(3), 2225 .

Glazer, N. \& Moynihan, D. P. (1972). Beyond the melting pot. In N. R. Yetman \& C. H. Steele, (Eds.). Majority \& Minority: The dynamics of Racial and Ethnic Relations (pp. 283-298). Boston: Allyn \& Bacon.

Glazer, N. \& Moynihan, D. P. (Eds.). (1975). Ethnicity: Theory and experience. Cambridge, MA: Harvard University Press.

Gleason, M. (1986). Getting a perspective on student evaluation (AAHE Bulletin; p. 10-13 Feb 1986). Washington, DC: American Association for Higher Education. (ERIC Document Reproduction Service No. ED 265 801)

Gordon, J. D. (1988). The Gordon rule: A state legislator fulfills his responsibility. In D. B. Wolk \& M. L Zoglin, (Eds.). New Directions for Community Colleges: External Influences in the curriculum, 64 (pp. 23-30). San Francisco: Jossey-Bass.

Gordon, M. M. (1972). Assimilation in America: Theory and reality. In N. R. Yetman \& C. H. Steele, (Eds.). Majority \& Minority: The dynamics of Racial and Ethnic Relations (pp. 283-298). Boston: Allyn \& Bacon.

Gordon, M. M. (1975). Toward a general theory of racial and ethnic group relations. In N. Glazer \& D. P. Moynihan (Eds.). Ethnicity: Theory and experience (pp. 84-110). Cambridge, MA: Harvard University Press.

Gottlieb, D. (1964). Teaching and students: The views of negro and white teachers. Sociology of Education, 37, 345353 .

Greenwood, G. E., Hazelton, A., Smith, A. B., \& Ware, W. B. (1976). A study of the validity of four types of student ratings of college teaching assessed on a criterion of student achievement gains. Research in Higher Education, 5 , 171-178. 
Griffin, W. A. (1982). How instructors demotivate the American Indian community college student. A report of a survey at Nebraska Indian Community College, Macy Campus, 1980-1981. (ERIC Document Reproduction Service No. ED 213 565)

Harlacher, E. L., \& Sims, A. (1990). Counseling the new majority student. Community, Technical, and Junior College Journal, 61(3), 14-15.

Hart, J., \& Driver, J. (1978). Teacher evaluation as a function of student and instructor personality. Teaching of Psychology, 5, 198-200.

Haslett, B. J. (1976). Student knowledgeability, student sex, class size, and class level: Their interactions and influences on student ratings of instruction. Research in Higher Education, 5, 39-65.

Haugen, R. E. (1980). The relationship between student ratings and selected characteristics of university transfer instructors in the community college. Dissertation Abstracts International, $41 \mathrm{~A}(7-8)$.

Haugen, R. E. (1984). Educationists and academics: ratings of community college instructors. Community/Junior college Quarterly, 8, 103-113.

Higgins, E. B., \& Warner, R. W. (1975). Counseling blacks. Personnel and Guidance Journal, 53, 3382-385.

Howard, G. S., \& Maxwell, S. E. (1982). Do grades contaminate student evaluation of instruction? Research in Higher Education, 16, 175-188.

Hunter, W. E. (1980). Relationships between learning styles, grades, and student ratings of instruction. Community/Junior college Research Quarterly, $5,73-84$.

Ingold, S. (1990). An analysis of the effect of a sixteenweek orientation program on student retention (Doctoral dissertation, Florida International University).

Isaacs, H. R. (1975). Basic group identity: The idols of the tribe. In N. Glazer \& D. P. Moynihan (Eds.). Ethnicity: Theory and experience (pp. 29-52). Cambridge, MA: Harvard University Press.

Jackson, G. \& Cosca, C. (1974). The inequality of educational opportunity in the southwest: An observational study of ethnically mixed classrooms. American Educational Research Journal, 11(3), 219-229. 
Johnson, M. E., \& Lashley, K. H. (1989). Influence of Native-Americans' cultural commitment on preferences for counselor ethnicity and expectations about counseling. Journal of Multicultural Counseling and Development, 17(3), $115-122$.

Kachigan, S. K. (1982). Multivariate statiscal Analysis. New York: Radius.

Kappner, A. S. (1990). Creating something to celebrate: Planning for diversity. Community, Technical, and Junior College Journal, 61(3), 16-21.

Kerlinger, F.N. (1986). Foundations of Behavioral Research (3rd ed.). New York: Holt, Rinehart and Winston.

Kierstead, D., D'Agostino, P. , \& Dill, H. (1988). Sex role stereotyping of college professors: bias in students' ratings of instructors. Journal of Educational Psychology, $\underline{80}(3), 342-344$.

Kocher, E. D. (1983). How do you rate? Paper presented at the Annual Conference of the Southeastern Association for Community college Research, "Community colleges in the Information Society". Myrtle Beach, SC (ERIC Document Reproduction Service No. ED 238 479)

Kulik, J. A., \& McKeachie, W. J. (1975). The evaluation of teachers in higher education. In F. N. Kerlinger (ed.), Review of research in education (Vol. 3, pp. 210-240). Ithaca, IL: F. E. Peacock.

Lavender, A. D. (1977). Dissonance as a factor in college student evaluation of faculty. College student Journal, $11(2), 122-127$.

Licata, C. M. (1986). Post-Tenure Faculty Evaluation: Threat or Opportunity? ASHE-ERIC Higher Education Report No. 1. Washington, D. C.: Association for the Study of Higher Education.

Licata, C. M. \& Andrews, H. A. (1990). The status of tenured faculty evaluation in the community college. Community College Review, 18(3), 42-50.

London, H., \& Devore, L. (1988). Layers of understanding: counseling ethnic minority families. Family Relations, $37(3), 310-314$. 
Marsh, H. W. (1980). The influence of student, course, and instructor characteristics in evaluations of university teaching. American Educational Research Journal, 17, 219237.

Marsh, H. W. (1982). The use of path analysis to estimate teacher and course effects in student ratings of instructional effectiveness. Applied Psychological Measurement, 6, 47-59.

Marsh, H. W. (1984). Students' evaluations of university teaching: Dimensionality, reliability, validity, potential biases, and utility. Journal of Educational Psychology, 76, 707-754.

Marsh, H. W. (1987). Dimensionality of students' evaluations. The need for a multidimensional approach. International Journal of Educational Research, 11, 263-388.

Marsh, H. W. (1991). Multidimensional students' evaluations of teaching effectiveness: A test of alternative higherorder structures. Journal of Educational Psychology, $83(2)$, 285-296.

Marsh, H. W. , Overall, J. U., \& Thomas, C. S. (1976). The relationships between student evaluations of instruction and expected grades. Paper read at the annual meeting of the American Educational Research Association. (ERIC Document Reproduction Service No. ED 126 140).

Marsh, H. W., Overall, J. U., \& Kesler, S. P. (1979). Validity of student evaluations of instructional effectiveness: A comparison of faculty self-evaluations and evaluations by their students. Journal of Educational Psychology, 71, 149-160.

McCarberry, R. J. (1970). The relationship of selected factors to ratings of community college teachers. (From Dissertation Abstracts International, 31, 1120A. UMI 70-17, 237).

MCFadden, J. (1976). Stylistic dimensions of counseling Blacks. Journal of Non-White Concerns in Personnel and Guidance, $\underline{5}(1), 23-28$.

Mckeachie, W. J. (1979). Student ratings of faculty: a reprise. Academe, 65, 384-397.

McKeachie, W. J. (1986). Teaching tips: a guidebook for the beginning college teacher ( 8 th ed.). Lexington, MA: D.C. Heath. 
Mckeachie, W. J. (1990). Comments from Dr. Wilbert J. McKeachie. Instructional Evaluation, 11(1), 7-8.

Mckeachie, W. J., \& Lin, Y. G. (1971). Sex differences in student response to college teachers: teacher warmth and teacher sex. American Educational Research Journal, $8,221-$ 226.

Menges, R. J. (1973). The new reporters: students rate instruction. In C. R. Pace (Ed.) New Directions for Higher Education: Evaluating Learning and Teaching (pp. 59-75). San Francisco: Jossey-Bass.

Miami-Dade Community College. (1988). Faculty excellence at Miami-Dade Community College. Miami: Author.

Miami-Dade Community College. (1988). The Teaching/Learning Project 1987-88 summary report (year two). Miami: Author.

Miami-Dade Community college. (1989). The Teaching/Learning Project summary report (year three) 1988-89. Miami: Author.

Miami-Dade Community College. (1990). The Teaching/Learning Project summary report (year four) 1989-90. Miami: Author.

Miami-Dade Community College. (1990). Factbook Miami-Dade Community College. Miami: Author.

Miller, R. I. (1987). Evaluating Faculty for Promotion and Tenure. San Francisco: Jossey-Bass.

Murray, H. G. (1985). Classroom teaching behaviors related to college teaching effectiveness. In $J . G$. Donald \& $A$. $M$. Sullivan (Eds.). Using research to improve teaching New Directions for Teaching and Learning, 23 (pp. 21-34). San Francisco: Jossey-Bass.

Naftulin, D. H., Ware, J. E., \& Donnelly, F. A. (1973). The Doctor Fox lecture: A paradigm of educational seduction. Journal of Medical Education, 48, 630-635.

Nimmer, J. G. \& stone, E. F. (1991). Effects of grading practices and time of rating on student ratings of faculty performance and student learning. Research in Higher Education, 32(2), 195-216.

Noel, D. L. (1971). A theory of the origin of ethnic stratification. In N. R. Yetman \& C. H. Steele, (Eds.). Majority \& Minority The dynamics of Racial and Ethnic Relations (pp. 32-50). Boston: Allyn \& Bacon. 
Norusis, M.J. (1988). SPSS/PC+ Studentware. Chicago: SPSS Inc.

Oliver, M. L., Smith, A. W., \& Wilson, K. R. (1989). Supporting successful black students: Personal, organizational, and institutional factors. National Journal of Sociology, $3(2), 199-221$.

Overall, J. U., \& Marsh, H. W. (1980). Students' evaluations of instruction: A longitudinal study of their stability. Journal of Educational Psychology, 72, 321-325.

Padron, E. J. (1991). The challenge of first-generation college students: A Miami-Dade Community College perspective. Miami: Miami-Dade Community College. Wolfson Campus.

Paiva, K. A. (1989). Faculty evaluation in community colleges. Unpublished manuscript.

Parsons, T. (1975). Some theoretical considerations on the nature of trends of change of ethnicity. In N. Glazer \& D. P. Moynihan (Eds.). Ethnicity: Theory and experience (pp. 53-83). Cambridge, MA: Harvard University Press.

Pascarella, E T. (1980). Student-faculty informal contact and college outcomes. Review of Educational Research, 50 (4), 545-595.

Pascarella, E. T., Duby, P. B., \& Iverson, B. K. (1983). A test and reconceptualization of a theoretical model of college withdrawal in a communiter institutional setting. Sociology of Education, 56, 88-100.

Pohlmann, J. T. (1975). A multivariate analysis of selected class characteristics and student ratings of instruction. Multivariate Behavioral Research, 10, 81-92.

Ponterotto, J. G., Anderson, W. H., \& Grieger, I. Z. (1986). Black students' attitudes toward counseling as a function of racial identity. Journal of Multicultural counseling and Development, 14 (2), 50-59.

Poole, L. H. \& Dellow, D. A. (1983). Evaluation of full-time faculty. In A. Smith (Ed.). New Directions for Community Colleges: Evaluating Faculty and Staff, 41 (pp. 19-31). San Francisco: Jossey-Bass.

Poussaint, A. F. (1971). A negro psychiatrist explains the negro psyche. In N. R. Yetman \& C. H. Steele, (Eds.). Majority \& Minority: The dynamics of Racial and Ethnic Relations (pp. 348-356). Boston: Allyn \& Bacon. 
Powell, R. W. (1977). Grades, learning, and student evaluation of instruction. Research in Higher Education, I, 193-205.

Ramirez, M. , \& Price-Williams, D. R. (1974). Cognitive styles of children of three ethnic groups in the United states. Journal of Cross-Cultural Psychology, 5, 212-219.

Rasor, R. A., Ludquist, K., \& Miller, D. (1981). student evaluations of their best and worst college experience.

Sacramento, CA: American River Junior College. (ERIC

Document Reproduction Service No. ED 210 073)

Reminick, R. A. (1983). Theory of ethnicity: An anthropologist's perspective. Lanham, MD: University Press of America.

Ringer, B. B. \& Lawless, E. R. (1989). Race-Ethnicity and Society. New York: Routledge.

Rodin, M., \& Rodin, B. (1972). Student evaluations of teachers. Science, 177, 1164-1166.

Roosens, E. E. (1989). Creating ethnicity: The process of ethnogenesis. Frontiers of Anthropology: Vol. 5. Newbury Park, CA: Sage.

Rosenbaum, J. E., Kulieke, M. J., \& Rubinowitz, L. S. (1987). Low-income black children in white suburban schools: A study of school and student responses. Journal of Negro Education, 56(1), 35-43.

Rosenfeld, L., \& Jarrard, M. (1985). The effects of perceived sexism in female and male college professors on students' descriptions of classroom climate. Communication Education, 34, 205-213.

Ross, J. M. (1989). Critical teaching behavior as perceived by adult undergraduates. Paper presented at the annual meeting of the American Education Research Association, San Francisco, CA. (ERIC Document Reproduction Service No. ED 311015 )

Roueche, J. E. \& Baker, G. A., III. (1987). Access and Excellence: The open-Door college. Washington, DC: The Community College Press.

Sacken, D. M. (1990). Taking teaching seriously. Journal of Higher Education, 61(5), 548-564.

Scheck, D., \& Bizio, S. (1977). Students' perceptions of the ideal professor. College Student Journal, 11, 335-343. 
Scheurich, V. (1983). Expected grades versus specific evaluations of the teacher as predictors of students' overall evaluation of the teacher. Research in Higher Education, 19, 159-173.

Schmedinghoff, G. J. (1977). Counseling the black student in higher education: Is it a racial, socioeconomic, or human question? Journal of College student Personnel, 18(6), 472477 .

Seldin, P. (1984). Changing Practices in Faculty Evaluation: A critical Assessment and Recommendations for Improvement. San Francisco: Jossey-Bass.

Shapiro, E. G. (1990). Effect of instructor and class characteristics on students' class evaluations. Research in Higher Education, 31(2), 135-148.

Sheehan, D. S. \& Marcus, M. (1977). The effects of teacher race and student race on vocabulary and matehmatics achievement. Journal of Educational Research, 70, 123-126.

Sherman, B. R., \& Blackburn, R. T. (1975). Personal characteristics and teaching effectiveness of college faculty. Journal of Educational Psychology, 67, 124-131.

Smith, J. (1987). Equity with excellence. Community, Technical and Junior College Journal, 57(4), 22-24.

SPSSX User's Guide. (1983). Chicago: McGraw-Hill.

Stevens, J. J. (1987). Using student ratings to improve instruction. In L. M. Aleamoni (Ed.). New Directions for Teaching and Learning: Techniques for Evaluating and Improving Instruction, 31 (pp. 33-38). San Francisco: Jossey-Bass.

Tetenbaum, T. J. (1975). The role of student needs and teacher orientation on student ratings of teachers. American Educational Research Journal, 12, 419-429.

Theall, M., Franklin, J., \& Ludlow, L. (1990). Attributions and retributions: student ratings and the perceived causes of performance. Instructional Evaluation, 11(1), 12-17.

Thompson, R. H. (1989). Theories of ethnicity: A critical appraisal. Contributions in Sociology, Number 82. New York: Greenwood Press.

Tomasco, A. T. (1980). Student perceptions of instructional and personality characteristics of faculty: A canonical analysis. Teaching of Psychology, $7(2), 79-86$. 
Unger, R. (1979). Sexism in teacher evaluation: The comparability of real life to laboratory analogs. Academic Psychology Bulletin, 1, 163-171.

Van Allen, G. (1981). An analysis of the relationship between student evaluation of faculty, and student-faculy educational attitude similarity and selected variables. Dissertation Abstracts International, 42, 4710. (University Microfilms No. AAC8209497).

Vierra, A. (1984). The relationship between Chicano children's achievement and their teachers' ethnicity. Hispanic Journal of Behavioral Sciences, $6(3), 285-90$.

Volkwein, J. F., King, M. C., \& Terenzini, P.T. (1986). Student-faculty relationships and intellectual growth among tranfer students. Journal of Higher Education, 57(4), 413430 .

Vorp, R. (1988). Does Miami-Dade's image differ among ethnic groups? (Res. Rep. No. 88-30). Miami, FL: Miami-Dade Community College, office of Institutional Research.

Whitman, N. \& Weiss, E. (1982). Faculty evaluation: The use of explicit criteria for promotion, retention, and tenure. (AAHE Research Report No.2). Washington. D.C.: American Association for Higher Education. (ERIC Document Reproduction Service No. ED 221 148)

Wilson, R., Wood, L. \& Gaff, J. (1974). Socialpsychological accessibility and faculty-student interaction beyond the classroom. Sociology of Education, 47, 74-92.

Wood, K., Linsky, A. S., \& Straus, M. A. (1974). Class size and student evaluations of faculty. Journal of Higher Education, 45, 524-534.

Yamamoto K., \& Dizney, H. F. (1966). Eight professors-A study on college students' preferences among their teachers. Journal of Educational Psychology, 57, 146-150. 
APPENDICES

168 


\section{APPENDIX A \\ STATEMENT OF \\ FACULTY EXCELLENCE}

The qualities and characteristics of excellent faculty at MiamiDade Community College are described in four categories: their own motivation and their ability to motivate others, their interpersonal skills, their knowledge base, and their skill at applying that knowledge.

\section{ASSUMPTIONS}

A set of assumptions undergirds and provides context for this description of faculty excellence.

1. All Miami-Dade faculty whether their primary assignments are in the classroom or in nonclassroom areas are involved in the teaching/learning process, that is, in imparting knowledge and skills to students and assuring student success.

2. The qualities identified as representative of faculty excellence apply equally to classroom and to nonclassroom faculty. These qualities are described in general terms in order to relate to all faculty; thus, to determine specific applications for individuals, further definition and elaboration will occur at the department level.

3. This description of excellence is not intended to be a job description. Excellent faculty at Miami-Dade Community College make many contributions to the College, by developing curriculum and new programs, through community involvement, by serving on committees and task forces, and by recruiting students, among other activities.

4. This definition of faculty excellence is not designed as an evaluation instrument. The qualities of faculty excellence as defined in this document have been identified by Miami-Dade faculty, administrators and students as significant in promoting student success. Therefore, any evaluation system devised should be based on this definition. 


\section{MOTIVATION}

Excellent faculty at Miami-Dade Community College are dedicated to their profession in higher education and to the community college philosophy as defined at Miami-Dade. Their greatest concern is for student learning; thus, they themselves are highly motivated to achieve excellence and strive to motivate students to reach their educational and personal goals.

Excellent faculty at Miami-Dade are enthusiastic about their work. Faculty, administrators, and students all regard enthusiasm as a primary motivational factor. Faculty manifest this enthusiasm in a variety of ways. They communicate their deep interest in their discipline fields and the satisfaction they themselves have gained through increasing their knowledge. Faculty demonstrate their enthusiasm in their professional areas by willingly working in a personal way with students or prospective students to help them achieve their goals. Faculty share with students and colleagues the rewards of their involvement in their professional organizations and associations. They build in students a sense of accomplishment when they demonstrate their learning and they instill in them both the desire and self-confidence needed to increase their learning. In short, they communicate the values and satisfactions to be gained in the teaching and learning activity.

Excellent faculty at Miami-Dade set challenging individual and collective performance goals for themselves. These goals address not only learning activities and other specific academic responsibilities, but also the many other areas of professional involvement. They continually strive to increase their own knowledge and to perfect their job-related skills, practices, and procedures. In so doing, they serve as positive role models for both students and colleagues.

Excellent faculty at Miami-Dade also set challenging performance goals for students. They communicate to students that progress is not made without a cost; it must be paid for in time and effort. Thus, they encourage students to overcome their limitations and to reach beyond their current achievements in an attempt to fulfill all of their potential.

Excellent faculty at Miami-Dade are committed to education as a profession. They value their work highly because of the intrinsic satisfaction they receive from knowing they have helped students to learn and to succeed in their lives. Regardless of circumstances, commitment to their students does not waver. 
Excellent faculty, who are committed to the mission and values of Miami-Dade, project a positive attitude about students' ability to learn. Outstanding faculty have a strong commitment to the open door policy; they believe that students with diverse needs can learn and so they challenge them accordingly. This belief is, no doubt, a motivating factor for both students and faculty.

Excellent faculty at Miami-Dade display behavior consistent with professional ethics. They are aware that a failure to commit to professional standards weakens the profession. They guard against behavior that may detract from the teaching/learning process. Thus, these faculty maintain the most professional and ethical relationships with students and colleagues.

Finally, excellent faculty are concerned with the many aspects of students as individuals, not just in their roles as learners. Accordingly, they provide counsel and assistance whenever appropriate.

\section{INTERPERSONAL SKILLS}

Excellent faculty at Miami-Dade Community College interact actively and positively with students and with their colleagues. Their interpersonal skills are evident in their interaction with students, staff, and colleagues, and with community members and business, civic and governmental representatives.

Excellent faculty at Miami-Dade treat all individuals with respect. This respect characterizes all of their dealings with students, especially when providing corrective feedback. This professional attitude is critical when they interact with students, colleagues and members of the community.

Excellent faculty at Miami-Dade respect diverse talents. They recognize that students have different strengths and weaknesses, have different learning styles, and bring different skills and backgrounds to the teaching/learning process. Consequently, they encourage students to develop their individual abilities in learning situations.

Excellent faculty at Miami-Dade work collaboratively with colleagues. They know the importance of bringing their collective strengths to deal with departmental, campus and College issues in order to achieve excellence in the teaching/learning process. Their collaborative efforts serve as a model for students both inside and outside the classroom. 
Excellent faculty at Miami-Dade are available to students. They realize that student contact with faculty is critical to the success of the majority of Miami-Dade students. Hence, they provide students ample opportunities for such contact and encourage students to meet and interact with them.

Excellent faculty at Miami-Dade listen attentively to what students say. They are sensitive to nonverbal as well as verbal cues, including careful analyses of students' written responses. They pay particular attention to student feedback in critiquing and improving their own performance.

Excellent faculty at Miami-Dade are responsive to students' needs. They realize that students, in addition to needing academic support, often need encouragement and individual attention as they try to adjust to the varied demands in their lives. Excellent faculty can also provide legitimate and appropriate responses to students' needs. They are careful to maintain a professional approach in their interactions with students.

Excellent faculty at Miami-Dade are fair in their evaluations of students. They maintain objectivity and follow carefully the evaluation criteria which they provide to all students at the beginning of each term. They do not allow subjective opinions to interfere with student evaluations.

Excellent faculty at Miami-Dade present ideas clearly. They are good transmitters as well as good receivers of messages. Faculty and students agree that communicating ideas clearly is one of the most critical interpersonal skills.

Finally, excellent faculty at Miami-Dade create a climate that is conducive to learning. They know that the atmosphere in the learning environment can have a great impact on student learning. They see things in perspective, taking themselves and their subject matter with appropriate seriousness, but respecting the fact that there are important disciplines and interests in life, other than theirs. In some cases, that sense of perspective may be manifested in a sense of humor; in other cases, tolerance, open-mindedness, acceptance, approachability, and sensitivity may be the positive characteristics that create the atmosphere conducive to learning. 


\section{KNOWLEDGE BASE}

Excellent faculty at Miami-Dade Community College have the intellectual skills and knowledge requisite for superlative performance. They have a thorough understanding not only of their own work areas and disciplines, but also of how students learn and develop. This knowledge base is essential in their work within the context of Miami-Dade's open admissions policy.

Fundamental to excellence, according to faculty, administrators, and students, is that faculty members at Miami-Dade are knowledgeable about their work areas and disciplines. This knowledge includes not only the content of the disciplines, but also their roles in their departments and their campus in support of the overall teaching and learning process. These faculty also share their knowledge with one another in a collegial effort to achieve excellence. There is no substitute for faculty members' having in-depth knowledge of their fields and disciplines in order to facilitate the transfer of knowledge to students. Without substantial knowledge in their fields, faculty are ill-prepared to foster student learning, even if their motivational techniques and interpersonal skills are sound.

Excellent faculty at Miami-Dade are knowledgeable about how students learn. They understand established principles of learning which serve as a foundation for their work with students as they advise, teach and provide learning support. This knowledge encompasses the many differences in students which, in part, stem from the great cultural diversity found on the Miami-Dade campuses.

Excellent faculty at Miami-Dade integrate current subject matter into their work. Students should have information and the results of research and study which reflect the latest work in the field. Excellent faculty consistently update their own knowledge, professional skills, and resources to make their instruction meaningful, timely, and refreshing to their students.

Excellent faculty at Miami-Dade also provide perspectives that include a respect for diverse views. They provide a variety of theories and interpretations that represent the best thinking in their fields. Moreover, they demonstrate to their students an openness and willingness to communicate and share differing views. These excellent faculty are particularly sensitive to Miami-Dade's diverse student body, which represents a wide variety of cultures and academic traditions. 
Excellent faculty at Miami-Dade do their work in a wellprepared and well-organized manner. Faculty have clear learning goals and well planned activities enabling students to master content material and to process and apply information. Faculty proceed logically and use time effectively so that students learn as much as possible. Faculty provide assistance to students in a clear manner so that they know and can use the College's educational systems effectively.

\section{APPLICATION OF KNOWLEDGE BASE}

Excellent faculty at Miami-Dade Community College not only know well their own professional fields and established principles of learning, but they also put these principles of learning into practice as they carry out their responsibilities related to the teaching and learning process. They continue to seek ways to meet individual needs of students and to help students learn as effectively and efficiently as possible.

Excellent faculty at Miami-Dade provide students with alternative ways of learning. This implies that faculty understand different learning styles and analyze the effectiveness of different instructional strategies. Faculty match students' individual learning styles by employing a variety of instructional strategies, given the limitations of the learning environment. Faculty help students discover their most effective ways of learning and plan their educational programs and individual study accordingly.

Excellent faculty at Miami-Dade stimulate intellectual curiosity. They develop challenging presentations and activities, while keeping the subject at an appropriate level of difficulty and creating an interactive learning environment, one in which students are not merely passive observers.

Excellent faculty at Miami-Dade also encourage independent thinking. As students develop independence in acquiring, analyzing, and accessing knowledge, they are able to take more responsibility for their own learning. Thus, the faculty member's role becomes less that of a communicator of information and more that of a mentor who guides students in their pursuit of learning. These outstanding faculty understand that students must develop independent thinking in order to make the most productive use of their talents and abilities. 
Excellent faculty at Miami-Dade encourage students to be analytical listeners. To develop their students' intellectual curiosity and independent thinking, they provide opportunities for students to analyze carefully what they hear. As students listen more carefully and more critically, they will be able to engage in more mature conceptual thinking.

Excellent faculty at Miami-Dade provide cooperative learning opportunities for students. In recognition of current research on learning, they plan learning strategies that promote collaborative study among students. As students understand that learning is properly a collaborative rather than a competitive activity, the entire educational process at Miami-Dade will be enhanced.

Excellent faculty at Miami-Dade give constructive feedback to students promptly. They understand that timely feedback that promotes positive action is most useful to students. Thus, they use various means to respond to students in a timely manner.

Excellent faculty at Miami-Dade give consideration to feedback from students and others. These faculty know the importance of analyzing and evaluating their own performance. Thus, feedback from students, from other faculty members, and from observers of their performance, is welcomed as a positive resource for their own improvement. Excellent faculty use this feedback to make immediate adjustments that improve student learning.

Finally, excellent faculty provide clear and substantial evidence that students have learned. This evidence allows both students and faculty to have accurate and realistic appraisals of their performance, to know the effectiveness of their work. To acquire this evidence, excellent faculty first establish clear objectives and performance standards. With this positive evidence, excellent faculty can enjoy the professional and personal satisfaction of work well done. 


\section{STATEMENT OF \\ FACULTY EXCELLENCE AT \\ MIAMI-DADE COMMUNITY COLLEGE \\ SUMMARY STATEMENTS \\ MOTIVATION}

EXCELLENT FACULTY MEMBERS AT MIAMI-DADE COMMUNITY COLLEGE, WHETHER CLASSROOM 'TEACHERS, LIBRARIANS, COUNSELORS, OR SERVING IN ANY OTHER FACULTY CAPACITY:

Are enthusiastic about their work.

Set challenging individual and collective performance goals for themselves.

Set challenging performance goals for students.

Are committed to education as a profession.

Project a positive attitude about students' ability to learn.

Display behavior consistent with professional ethics.

Are concerned with the many aspects of students as individuals not just in their roles as learners.

\section{INTERPERSONAL SKILLS}

EXCELLENT FACULTY MEMBERS AT MIAMI-DADE COMMUNITY COLLEGE, WHETHER CLASSROOM TEACHERS, LIBRARIANS, COUNSELORS, OR SERVING IN ANY OTHER FACULTY CAPACITY:

Treat all individuals with respect.

Respect diverse talents.

Work collaboratively with colleagues.

Are available to students.

Listen attentively to what students say.

Are responsive to students' needs.

Are fair in their evaluations of students.

Present ideas clearly.

Create a climate that is conducive to learning. 


\section{KNOWLEDGE BASE}

EXCELLENT FACULTY MEMBERS AT MLAMI-DADE COMMUNITY COLLEGE, WHETHER CLASSROOM TEACHERS, LIBRARLANS, COUNSELORS, OR SERVING IN ANY OTHER FACULTY CAPACITY:

Are knowledgeable about their work areas and disciplines.

Are knowledgeable about how students learn.

Integrate current subject matter into their work.

Provide perspectives that include a respect for diverse views.

Do their work in a well-prepared and well-organized manner.

\section{APPLICATION OF KNOWLEDGE BASE}

EXCELLENT FACULTY MEMBERS AT MIAMI-DADE COMMUNITY COLLEGE, WHETHER CLASSROOM TEACHERS, LIBRARIANS, COUNSELORS, OR SERVING IN ANY OTHER FACULTY CAPACITY:

Provide students with alternative ways of learning.

Stimulate intellectual curiosity.

Encournge independent thinking.

Encourage students to be analytical listeners.

Provide cooperative learning opportunities for students.

Give constructive feedback to students promptly.

Give consideration to feedback from students and others.

Provide clear and substantial evidence that students have learned. 
At its meeting of April 19, 1990 the District Board Of Trustees of Miami-Dade Community College adopted this revision to the Statement of Faculty Excellence. The revision reflects changes that were made to ensure that the Statement is relevant to nonclassroom as well as classroom faculty. The key language that framed the twenty-nine characteristics of excellence articulated in the original Statement (adopted on October 25, 1988) has not been altered; rather changes broaden the supporting narration so that it better fits the many roles of faculty as they engage in the teaching/learning process whether inside or outside the classroom.

Members of The Faculty Excellence Subcommittee of the Teaching/Learning Project

Bruce Davis, Co-chair
Vince Napoli, Co-chair
Thelma Altshuler
Ernestine Cole
Gina Cortes
Dorma Gottlieb
Ida Gropper
John Losak
Jeff Lukenbill
Bill Weaver

Members of the Non-Classroom Faculty Subcommittee of the Teaching/Learning Project
Isabel Hernandez, Co-cbair
Wallis Riley-Tinnie, Co-chair
Carmen Casal
Carol Cooper
Paula Epstein
Georgina Fernandez
Marilyn Finkelstein
Rene Garcia
Emerald Jackson
Suzanne Richter
Richard Townsend
Bob Watters

Teaching/Learning Project Director

Mardee Jenrette 


\section{Student Feedback Questionnaire}

This questionnaire gives you the opportunity to express your views on how this coune has becn taught meste read each item very carefully. This survey is ANONYMOUS and individual responses will be kept CONFIDEN.

TLAL. No results will be given to the instructor unil AFTER your final grade has becn submittcd.

\section{Instructions:}

Mark your response to each item by darkening or bubbling in the desired choice on the ANSWTR SHEET provided.

Please bubble in the 3 digit Jocation code wnder the Kentflacation Number columns $A, 13$. C, and the 5 digit course sequence number under columns D, E, F, G, H. Put a zero (0) under column 1 and a one (I) under $J$.

Please use the followiag scale to respond to items 1 to 23
$A=$ Strongly agree
You strongly agree with the
statement as it applics to this instructor.
$B=$ Agree
You agree more than you disagree with the statement as it applies to this instructor.
$c=$ Disagree
You disagree more than you agree with the stucment at it applies to this instructor.
$D=$ Strongly disagnee You strongly disagree with the statement is it applics to this instructor.

1. The instructor is prepared for class.

2. The instructor shows interest in the subject.

3. The instructor distributed the course ohjectives/ competencies.

4. There is agreement between the objectives competencies of this course and what is mught.

5. The instructor is concernce with my progress.

6. The instructor shows me how the course material can benefit me beyond the classroom.

7. The instructor makes this courc interesting.

8. The instructor is available for individual help.

9. The instructor encourages questions in class.

10. The examinations and/or other forms of evaluation are related to the course material.

11. The examinations and/or other forms of evaluation are graded farly.

12. The instructor made the grading system clear to me.
13. The instructor presents course material clearly:

14. The instructor creates a classrow atmosphere that cncoumges me to learn.

15. The instructor demonstrates knowledge of the subject.

16. The instructor uses a variety of teaching methods for exmple, lechure, discussions, demonstration. adunvisual aids andor ohers)

17. Assignments help me learn the course material

18. The instructor cncourages me to think for mystit

19. The instructor informs me regularly about my progress.

20. The instructor pays attention to my comments.

21. The instructor treats me with respect

22. The instructor discussed the grabing system at the beginning of the semester.

23. The instructor starts class on time.

Please use the following scale to respond to items 24 to 27
$A=$ Always or almost always
$\mathrm{B}=$ Often
$C=$ sometimes
$\mathrm{D}=$ Never or almost never

24. How ofen do you come to class?

25. How often are you prepared for class?

26. How often do you pay attention in class?

27. How ofen are you late for class?

Continue on the back of this page 
28. So far how would you rate your performance in this class?
A. Exicllent
B. Good
C. Fair
D. Poor
E. Don't know

29. How difficult is this course compared to orfer courses you have taken?
A. More difricult
B. About the same
C. Less difficult

30. How does the amount of work in this course con. pare to the amoun in other courses you have taken?

A. The amount of work is greater

B. The amount of work is about the same

C. The amount of work is less

31. What do you think about the number of students in this class?
A. Too many students
B. The right number of students
C. Too ferv students

32. Why are you taking this course?
A. As a requirement for a degree
B. As an elective for a degree
C. To upgrade my job skills
D. For personal interest
E. For other ressons not listed above

33. Have you registered for this course before?
A. Yes
B. No

34. $1 \mathrm{~mm}:$
A. Male
B. Fermale

35. How old are you?
A. 18 or under
B. 19 to 24
C. 25 to 31
D. 32 to 10
E. 11 or over

36. Please indicate how you identify yourself
A. American Indian or Alaskan native
B. Asian or Pacific islander
C. Black
D. White
E. Other

37. Is year cthnic heritage Hispanic?
A. Ykis
11. No

38. Do you have family commitments that inter: with how well you do in class?
A. Yes
11. No

39. How many hours per week do you usually w at rour job?
A. don't have a job
B. 1 to 20 hours per week
C. 21 to 30 hours per week
D. 31 to 40 hours per week
E. more than 10 hours per week

10. How many credits are you taking this semest
A. 11 or fewer
B. 12 or more

41. Have you taken a course with this instructor bef
A. les
13. No
C.I Ion't remember

42. This questionnaire is
A. 700 long
B. About the right length
C. Too short

43. This questionnaire was
A. Easy to understand
D. Hard to understand

47. On the lines below, please make any SUGGESTIONS you have on the QUESTIONNAIRE itself SUch as ag you would like to see in the future or changes in wording that may make it easief to understand. 


\section{This page will be returned to the instructor only after final grades are reported.}

45. On the lines below, please write any COMMENTS you have about the INSTRUCTOR in this course.

46. On the lines below, please write any COMMENTS you have about this COURSE.

Thank you for your cooperation. 


\section{FACULTY DIRECIIONS FOR ADMINISTLIRING THE STUDENT FELDIBACK QULSTIONNAIRE}

Distribute the questionnatres and the answer sheets. Write the following fufornution on the hourd: the campus code (a 3 digit number foumd on the envelope labsl); the 5 dight sequence number for this course; wnd the dights ot to represent the full 90.1 term. Then rend alwud the following instructlons.

This class has been selected to complete a Collegewide student feedback questionmaire. This questionnaire gives you the opportunity to express your views on the instructor and how the course is being taught. I will not see your individual responses. Only a summary total for the entire class will be given back to me uffer grades have been assigned. The last page of the questionnaire, on which you may write comments, will be returned to me nfer the semester is wer. Notice that the questionnaite is printed front and back. You also have an answer shect on "hich to respond. You may use pencil or pen (except red ink) to mak your responses.

Since this questionnaire is nnonymous, you need not identify yourself on either form. This means that you should not complete any identifying information except for the number I have written on the board. This number should be cntered in the section marked IDENTIFICAIION NUMBER in the lower left hand corner of the answer sheet. Please find this section now, and bubble in the number.

Have students enter this Information on the answer shece now. Ask the students ir they huve any questions about marhing the allswer sheet.

On the front of the questionnaire are complete instructions. Please rend them before marking your answer sheet. Make only one mark for each item, and be sure the number on the answer sheet matches the number of the item you are answering.

I will now ask a student to be responsible for collecting all materials, scaling them in the envelope provided, and returning them to the designated ofice on this campus. Before you begin answering the questionnaire I will step outside and only this student will see or handle the forms until they are processed.

While I am out, please do not discuss the questions among yourselves. It is important that the answers you give be your own. Thank you.

Select the sfudent now, nud make sure thut the student knows where to return the completed questionuires. The information is found at the bottom of this shect and atso on the label that will be used to seal the cuvelope.

TO TIE SELECTED STUDENT: Please use the Inbel provided to seal the envelope for PROTECTION. Return the sealed package to 